Florida International University FIU Digital Commons

FIU Electronic Theses and Dissertations

University Graduate School

2011

\title{
Hybrid Motor Drives: Characterization and Control
}

Brian M. Hadley Mr.

Florida International University, bhadl001@fiu.edu

DOI: $10.25148 /$ etd.FI1 1080809

Follow this and additional works at: https://digitalcommons.fiu.edu/etd

\section{Recommended Citation}

Hadley, Brian M. Mr., "Hybrid Motor Drives: Characterization and Control" (2011). FIU Electronic Theses and Dissertations. 458. https://digitalcommons.fiu.edu/etd/458

This work is brought to you for free and open access by the University Graduate School at FIU Digital Commons. It has been accepted for inclusion in FIU Electronic Theses and Dissertations by an authorized administrator of FIU Digital Commons. For more information, please contact dcc@fiu.edu. 


\title{
FLORIDA INTERNATIONAL UNIVERSITY
}

\author{
Miami, Florida
}

HYBRID MOTOR DRIVES: CHARACTERIZATION AND CONTROL

\author{
A thesis submitted in partial fulfillment of the \\ requirements for the degree of \\ MASTER OF SCIENCE \\ In \\ ELECTRICAL ENGINEERING \\ By \\ Brian M. Hadley
}




\section{To: Dean Amir Mirmiran}

College of Engineering and Computing

This thesis, written by Brian M. Hadley, and entitled Hybrid Motor Drives:

Characterization and Control, having been approved in respect to style and intellectual content, is referred to you for judgment.

We have read this thesis and recommend that it be approved.

Jean Andrian

Chen Liu

Behrooz Mirafzal, Major Professor

Date of Defense: July 15, 2011

The thesis of Brian M. Hadley is approved.

Dean Amir Mirmiran

College of Engineering and Computing

Dean Lakshmi N. Reddi

University Graduate School

Florida International University, 2011 


\section{DEDICATION}

To my wife Kate, thank you for your love, support, and patience. It has been a long road, but you've been with me the whole time. I love you.

To my parents Curt and Fran, my sister Chris, and my brother Curtis, everything that I am, and ever will be is because of you. I love you.

To my family, thank you for everything you have done for me, and for those who have passed, I know you're watching over us. I love you. 


\section{ACKNOWLEDGMENTS}

It is with great pleasure and appreciation that I take this opportunity to thank my advisor and mentor Dr. Behrooz Mirafzal. With his encouragement, dedication, and expert tutelage he has pushed me to expect more of myself, and opened my eyes to new possibilities. Throughout my two years as his research assistant, and through my thesis writing process, he has provided expert tutelage, good advice, and great company.

I am deeply indebted to my thesis committee members Dr. Jean Andrian, and Dr. Chen Liu. Dr. Andrian, I have been your student for many years, and it is an honor to have you on my committee. Dr. Chen, I have greatly appreciated your expert advice, and feel privileged to have such a distinguished committee member.

I wish to thank Mr. Ali Kashefi Kaviani, and Mr. Ramachandran Krishnan Menon for their friendship and support during my thesis writing process. I would also like to thank Mr. Mahdi Saghaleini, and all of the other graduate students in the electrical engineering department for the friendship, camaraderie, entertainment, and caring they provided.

Finally, I would like to thank Mr. Ron Bartos of A.O. Smith, and Dr. Dan Ionel of Vestas R\&D Technology, Americas. Were it not for their generous donation of the variable speed pump, and for their keen advice, this project would not have been possible. 


\section{ABSTRACT OF THE THESIS}

by

Brian M. Hadley

Florida International University, 2011

Miami, FL

\section{Dr. Behrooz Mirafzal, Major Professor}

The purpose of this thesis was to explore the behavior in power sharing and control of Hybrid Motor Drives. In this research, a solar-based hybrid adjustable-speed pump, which has been developed in the laboratory, was used to investigate the power-sharing in hybrid (dual-input) motor-drive systems. The laboratory test setup contained a DC-DC module connected to the DC-bus capacitors of a 2.5hp 230V PWM-based adjustablespeed motor-drive. The experimental results demonstrate that the power-sharing of a Photovoltaic (PV) array/DC-DC converter is not a function of motor speed in hybrid solar-based motor-drives, as long as the power contribution of the AC-grid stays above zero. In these conditions, the PV-DC-DC module behaves like a current source, and the dynamic behavior of the motor is decoupled from the dynamic behavior of the AC-grid, given that the PV-DC-DC module can provide the motor load. 


\section{TABLE OF CONTENTS}

CHAPTER

PAGE

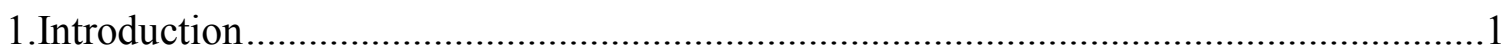

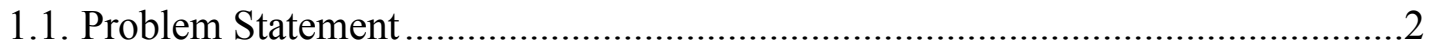

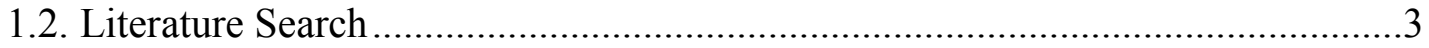

1.3. Objectives and Contributions of the Thesis ………….......................................

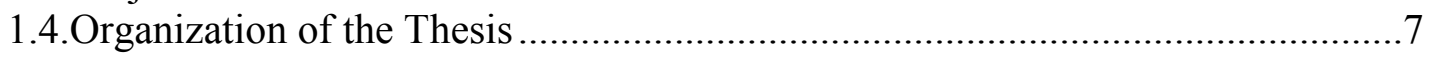

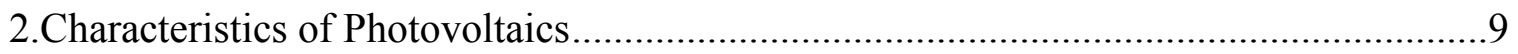

2.1. Principles of PV Energy Conversion and Materials .........................................10

2.2. Equivalent Circuit Models and Behavior........................................................... 12

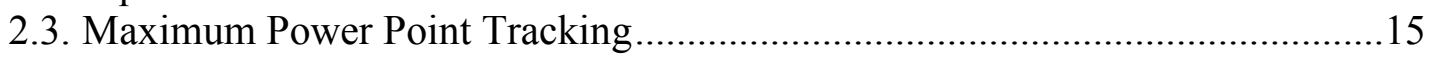

2.4. Applications in Hybrid Drive Systems .........................................................2

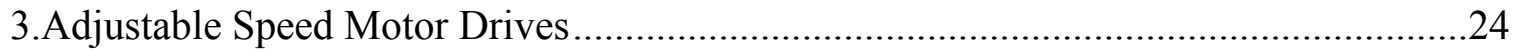

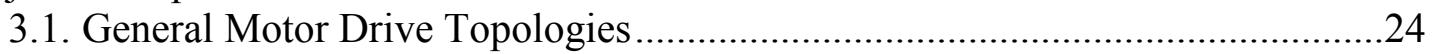

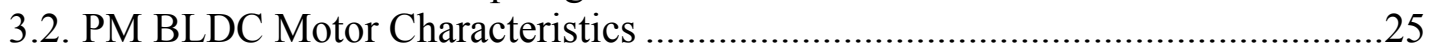

3.3. Switching Schemes and Control Methods …………......................................29

3.4. Applications In Hybrid Drive Systems ...............................................................35

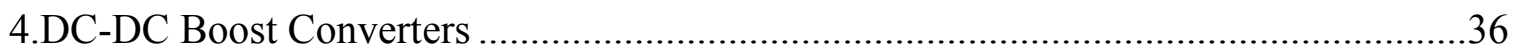

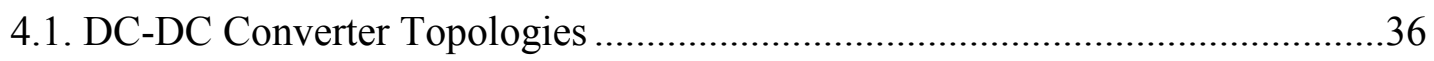

4.2. DC-DC Boost Converter Characteristics and Control ..........................................38

4.2.1 DC-DC Boost Converter Modes of Operation ......................................39

4.2.2 DC-DC Boost Converter Dynamic Analysis.........................................45

4.3. Applications in Hybrid Drive Systems ...........................................................4

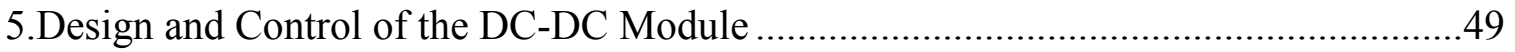

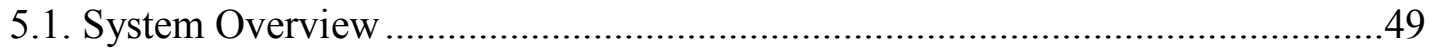

5.2. The PV-DC-DC Module Developed Power ……………...................................51

5.3. Hybrid Drive DC-DC Module Dynamics ...........................................................54

5.4. Technical Challenges During The Design Stage .................................................60

5.4.1 Hardware Challenges ......................................................................60

5.4.2 Software Challenges ....................................................................63

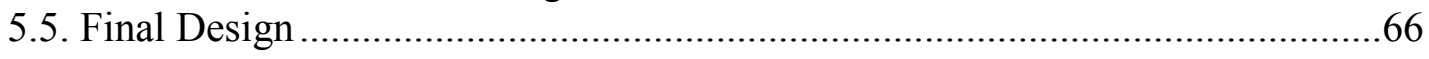

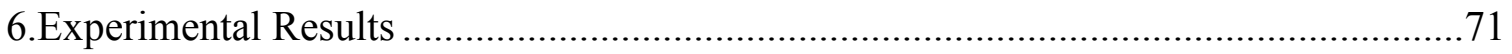

6.1. Hybrid-Drive Steady State Operation ...............................................................

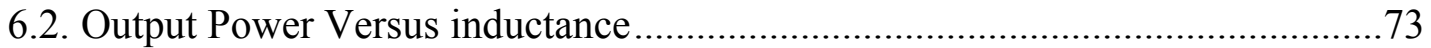

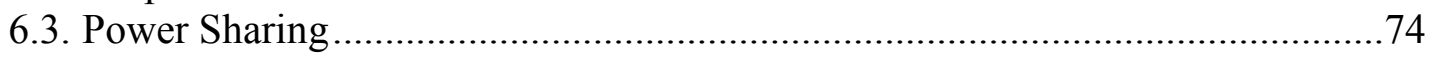

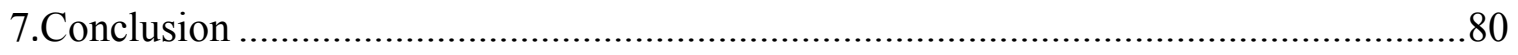




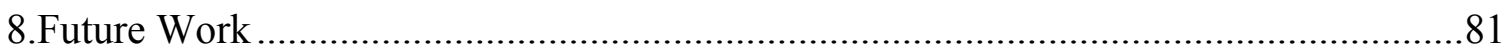

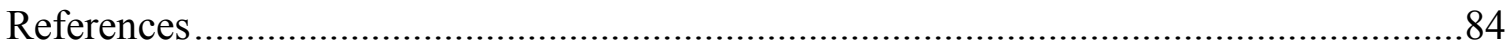

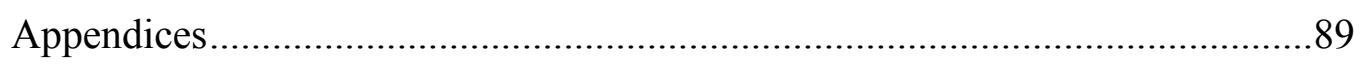




\section{List of Figures}

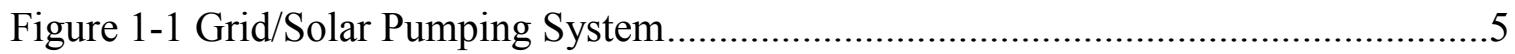

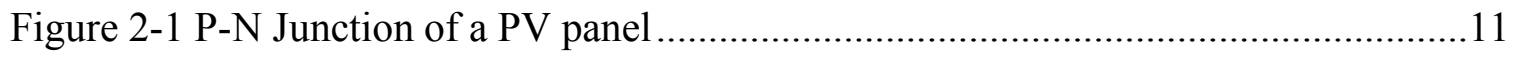

Figure 2-2 (a). I-V Curve, and (b). P-V Curve plotted for different levels of insolation. .13

Figure 2-3 Equivalent Circuit Model for a Photovoltaic Cell [35] .................................14

Figure 2-4 Perturb and Observe Method Flow Diagram ...........................................16

Figure 2-5 Incremental Conductance Flow Diagram [34] ........................................ 17

Figure 2-6 FOCV/FSCC Flow Diagram ................................................................ 18

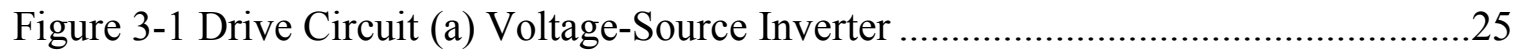

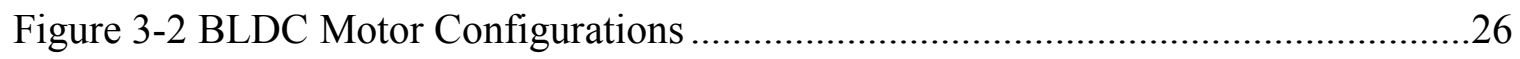

Figure 3-3 Steady-State BLDC Motor Equivalent Circuit .........................................27

Figure 3-4 Torque-Speed characteristic of BLDC motor .........................................29

Figure 3-5 Switch and Phase Voltages for $120^{\circ}$ Square Wave Pattern without PWM......34

Figure 3-6 Motor current and AC input current while the motor was at 1500rpm, with the module at $33.5 \mathrm{~V}$ PV input voltage, $30 \%$ duty cycle, and $\mathrm{fs}=5 \mathrm{kHz}$.............34

Figure 4-1 DC-DC Converter Topologies (a) Boost Converter (b) Buck Converter (c) Inverting Buck-Boost Converter (d) Non-inverting Buck-Boost Converter ...37

Figure 4-2 Switch states for a DC-DC Boost converter ..............................................39

Figure 4-3 Current and voltage waveforms of the DC inductor in Continuous Conduction Mode (CCM).

Figure 4-4 Inductor Voltages and Currents in Boundary Operation..............................41

Figure 4-5 Switching States in Discontinuous Conduction Mode...................................43

Figure 4-6 Current and voltage waveforms of the DC inductor in ...............................44

Figure 5-1 Solar-based Hybrid Motor Drive Test Setup. ...........................................49 
Figure 5-2 Hybrid Solar Motor Drive Block Diagram ......

Figure 5-3 Original prototype of the DC-DC module (size:8 L-6W-2.1H inches). .51

Figure 5-4 PV Characteristic and Eq. (5-4) intersection indicates the operating point of the hybrid motor-drive system .53

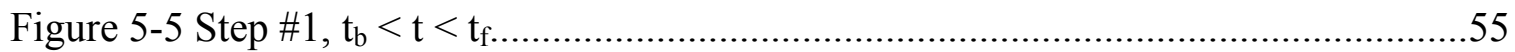

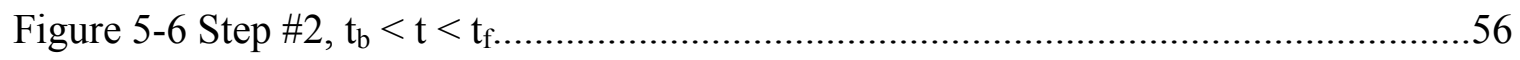

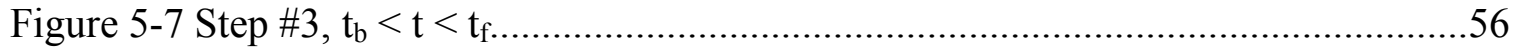

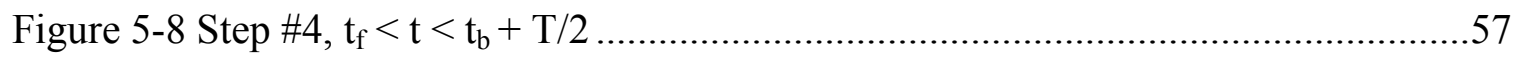

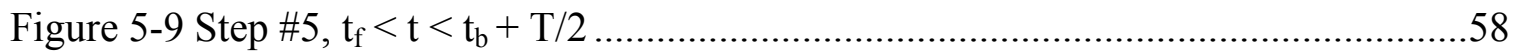

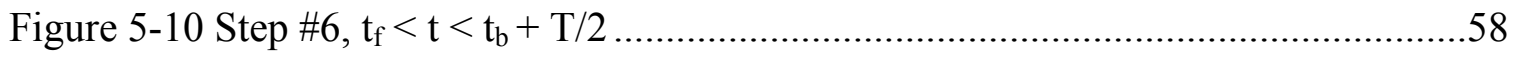

Figure 5-11 DC-DC Module Replacement Parts ......................................................63

Figure 5-12 DC-DC Module Block Diagram .............................................................65

Figure 5-13 DC-DC Module Post Failure Analysis - Top Side ....................................66

Figure 5-14 Final Circuit Board - Top Side ….........................................................66

Figure 5-15 Final Prototype - Enclosure …....................................................67

Figure 5-16 Final Prototype Circuit Board Close-up.................................................68

Figure 5-17 Simulink Microchip Blockset Model .....................................................69

Figure 5-18 Simulink Model Subsystem .......................................................... 70

Figure 6-1 DC-DC input current and output current while the motor was at 1500rpm, with the module at $33.5 \mathrm{~V}$ input, $30 \%$ duty cycle, and $\mathrm{fs}=5 \mathrm{kHz} \ldots \ldots \ldots \ldots \ldots . . .72$

Figure 6-2 Line loss (AC-grid voltage loss) test, while motor was at $1500 \mathrm{rpm} . . . \ldots \ldots \ldots . . . .73$

Figure 6-3 Experimentally obtained output power of the DC-DC module vs. input inductance, while the motor was running at $1500 \mathrm{rpm}$..............................74 
Figure 6-4 Experimentally obtained instantaneous powers of PV (top) and single-phase $230 \mathrm{~V}$ AC-grid (bottom) vs. time over $10 \mathrm{msec}$

Figure 6-5 Experimentally obtained average power of the grid, PV (horizontal lines), and motor in watts vs. motor speed in rpm for the duty cycles of $\mathrm{D}=20 \%, \mathrm{D}=$ $30 \%$, and $\mathrm{D}=40 \%$ at the switching frequency of $5 \mathrm{kHz}$ for the DC-DC module.

Figure 6-6 Experimentally obtained average power of the grid, PV (horizontal lines), and motor in watts vs. motor speed in rpm for the duty cycles of $\mathrm{D}=20 \%, \mathrm{D}=$ $30 \%$, and $\mathrm{D}=40 \%$ at the switching frequency of $10 \mathrm{kHz}$ for the DC-DC

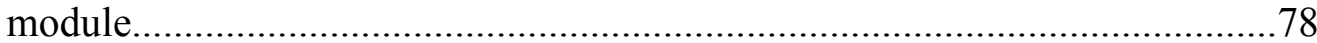

Figure 6-7 Experimentally obtained average power-sharing in watts vs. PV (DC power supply) voltage in volts, while the pump is running at a constant speed (1500 $\mathrm{rpm}$ ), the duty cycle of $\mathrm{D}=30 \%$ with the switching frequencies $10 \mathrm{kHz}$ (gray) and $5 \mathrm{kHz}$ (black).

Figure 6-8 Experimentally obtained average power-sharing in watts vs. PV (DC power supply) voltage in volts, while the pump is running at a constant speed (1500 $\mathrm{rpm})$, the switching frequency of $5 \mathrm{kHz}$ and the duty cycle of $\mathrm{D}=20 \%$ (black), $\mathrm{D}=30 \%$ (dark-gray), and $\mathrm{D}=40 \%$ (light-gray) .79 


\section{List of Tables}

Table B - 1 DC-DC Module Prototype 4.1 (Final Prototype) Bill of Material.............. 102

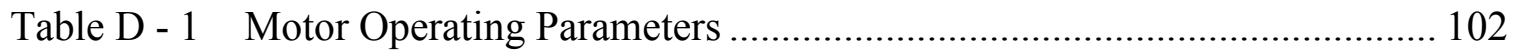

Table D - 2 DC-DC Module Prototype v1.0 first test............................................... 103

Table D - 3 DC-DC module prototype v1.0 - Electrical performance test data for $f_{s}=10$ $\mathrm{kHz}$, constant $20 \%$ duty ratio, and constant $78.7 \mathrm{~V}$ input voltage vs. motor speed 104

Table D - 4 DC-DC module prototype v1.0 - Electrical performance test data for $f_{s}=10$ $\mathrm{kHz}$, constant $30 \%$ duty ratio, and constant $79.1 \mathrm{~V}$ input voltage vs. motor speed. 105

Table D - 5 DC-DC module prototype v1.0 - Electrical performance test data for $f_{s}=10$ $\mathrm{kHz}$, constant $20 \%$ duty ratio, and constant $79.6 \mathrm{~V}$ input voltage vs. motor speed 105

Table D - 6 DC-DC module prototype v1.0 - Electrical performance test data for $f_{s}=10$ $\mathrm{kHz}$, constant $30 \%$ duty ratio, and various input voltage levels vs. motor speeds

Table D - 7 DC-DC module prototype v1.0 - Electrical performance test data for $f_{s}=10$ $\mathrm{kHz}$, constant $30 \%$ duty ratio, and constant $60 \mathrm{~V}$ input voltage vs. motor speed 107

Table D - 8 DC-DC module prototype v1.0 - Electrical performance test data for $f_{s}=10$ $\mathrm{kHz}$, constant $20 \%$ duty ratio, and constant $75 \mathrm{~V}$ input voltage vs. motor speed 108

Table D - 9 DC-DC module prototype v1.0 - Electrical performance test data for $f_{s}=10$ $\mathrm{kHz}$, constant $20 \%$ duty ratio, and constant $90 \mathrm{~V}$ input voltage vs. motor speed...... 108

Table D - 10 DC-DC module prototype v1.0 - Electrical performance test data for $f_{s}=5$ $\mathrm{kHz}$, constant $20 \%$ duty ratio, and constant motor speed vs. input voltage

Table D - 11 DC-DC module prototype v1.0 - Electrical performance test data for $f_{s}=5$ $\mathrm{kHz}$, constant $30 \%$ duty ratio, and constant motor speed vs. input voltage 
Table D - 12 DC-DC module prototype v1.0 - Electrical performance test data for $f_{s}=5$ $\mathrm{kHz}$, constant $40 \%$ duty ratio, and constant motor speed vs. input voltage 110

Table D - 13 DC-DC module prototype v1.0 - Electrical performance test data for $f_{s}=5$ $\mathrm{kHz}$, constant $20 \%$ duty ratio, and constant $95 \mathrm{~V}$ input voltage vs. motor speed..... 110

Table D - 14 DC-DC module prototype v1.0 - Electrical performance test data for $f_{s}=5$ $\mathrm{kHz}$, constant $20 \%$ duty ratio, and constant $52.4 \mathrm{~V}$ input voltage vs. motor speed 112

Table D - 15 DC-DC module prototype v1.0 - Electrical performance test data for $f_{s}=5$ $\mathrm{kHz}$, constant $30 \%$ duty ratio, and constant $52.4 \mathrm{~V}$ input voltage vs. motor speed 112

Table D - 16 DC-DC module prototype v1.0 - Electrical performance test data for $f_{s}=5$ $\mathrm{kHz}$, constant $40 \%$ duty ratio, and constant $52.4 \mathrm{~V}$ input voltage vs. motor speed 113

Table D - 17 Electrical performance test data for DC-DC module prototype v2.0 with PI Controller, $f_{s}=4.649 \mathrm{kHz}$, and $1500 \mathrm{RPM}$ constant motor speed 113

Table D - 18 Thermal performance test data for DC-DC module prototype v2.0 with PI Controller, $f_{s}=4.649 \mathrm{kHz}$, and $1500 \mathrm{RPM}$ constant motor speed 113

Table D - 19 Electrical performance test data for DC-DC module prototype v4.0 with PI controller, $f_{s}=4.649 \mathrm{kHz}$, and $1750 \mathrm{RPM}$ constant motor speed 114

Table D - 20 Thermal performance test data for DC-DC module prototype v4.0 with PI Controller, $f_{s}=4.649 \mathrm{kHz}$, and $1750 \mathrm{RPM}$ constant motor speed 114

Table D - 21 Electrical performance test data for DC-DC module prototype v4.1 with PI Controller, $f_{s}=4.649 \mathrm{kHz}$, and $1750 \mathrm{RPM}$ constant motor speed 115

Table D - 22 Thermal performance test data for DC-DC module prototype v4.1 with PI controller, $f_{s}=4.649 \mathrm{kHz}$, and $1750 \mathrm{RPM}$ constant motor speed 115

Table D - 23 Electrical performance test Data for DC-DC module prototype v4.2 with PI Controller, $f_{s}=5.029 \mathrm{kHz}$, and $2250 \mathrm{RPM}$ constant motor speed 115

Table D - 24 Thermal performance test data for DC-DC module prototype v4.2 with PI Controller, $f_{S}=5.029 \mathrm{kHz}$, and $2250 \mathrm{RPM}$ constant motor speed. 116 


\section{CHAPTER 1}

\section{INTRODUCTION}

According to a survey of county property appraisers, in 2006, there were approximately 1,095,347 residential swimming pools in the state of Florida [1]. Each of these swimming pools is operated for 8 to 10 hours per day, usually when there is sunshine and solar energy is available. If operated for 8 to 10 hours per day, a pool pump will consume over $3000 \mathrm{kWh}$ per year [2]. This adds up to at least $3.286 \mathrm{GWh}$ of electrical power consumed annually.

As the price of oil continues to be unpredictable, and as the cost of energy continues to increase, people around the world are looking for efficiency, and an alternative means to reduce their cost of living. Solar energy is a safe alternative to fossil fuels, and provides electrical power free of cost, aside from maintenance, and the initial capital costs. However, this initial capital investment is a major disadvantage to the utilization of solar energy and although new technologies are beginning to make Photovoltaic (PV) arrays competitive, there is still a strong need to optimize the size of PV arrays according to their intended usage.

The i-v characteristic of solar modules makes them suitable voltage sources. However, a major technical challenge of PV modules comes when the current, supplied by the PV module, passes the knee point of the i-v curve. Often, PV arrays are oversized to supply stand-alone motor drives. This is due to several factors. One of the primary reasons is that if there is a rapid power reduction due to a change in incident solar radiation, then there is a possibility for voltage collapse at the input terminals of the load [3]. Once the voltage collapses, the DC-bus voltage of the drive will collapse resulting in 
motor shutdown. This lack of reliability can be overcome by using an energy storage device [4] or by using the AC-grid as a supplementary source. By utilizing contributions from both the PV source, and the grid, the benefits of both sources can be used to balance their deficits (i.e. instability for the PV source, and cost for the grid).

In the following sections, a brief background of the problem will be explained, followed by additional background material on typical pump motors, variable speed motor drives, and photovoltaic energy and its application in variable speed drive systems. This will not only shed light on the justification for exploring this system, but also on some of the system characteristics, and behavior.

\subsection{Problem Statement}

The National Resources Defense Council (NRDC) estimates that there are as many as 4.5 million residential swimming pools in the United States, which roughly spend between $\$ 1.1$ and $\$ 1.6$ billion dollars annually [5]. With the application of modern power electronics, this amount can be reduced significantly. The NRDC, and the Department of Energy (DOE) have released recommendations regarding common practices involving the energy consumption of electric water pumps, and ways to increase the efficiency of energy usage when one owns a pool. Among the recommendations delineated by the NRDC is to replace existing single speed pool pumps with higher efficiency two-speed pumps, or variable speed pumps [6]. Since variable speed pumps utilize inverters to drive their motors, they present the opportunity to power the AC motor-pumps from renewable energies. In this research effort, the efficiency of the variable speed pump has been taken a step further through the development of the hybrid-solar adjustable-speed water pump. 
As mentioned previously, the hybridization of this variable speed drive will permit the pumping of water with less, or no electricity drawn from the grid. Since pool pumps are typically operated during peak daylight hours, the usage of hybrid-solar pumping systems will shave kilowatt-hours off the peak daytime demand on the $\mathrm{AC}$ grid, thereby alleviating some of the stress on the aging U.S. energy infrastructure. In hybrid motordrive systems, the contribution made by the AC-grid serves to stabilize the DC-bus voltage of the variable speed drive. Fluctuations in incident solar radiation make solar power unpredictable. Thus, by utilizing power grid to stabilize the DC-bus voltage, solarbased hybrid systems can use solar energy as it becomes available. By using solar energy in a supplementary configuration, the benefits of renewable energy are combined with the reliability and stability of the power grid and thereby increase the reliability of the system while decreasing the cost. Through proper switching of the DC-DC module, power can be injected into the pump from the solar array instead of the grid, even though they are connected simultaneously. This allows the AC power to operate as a supplementary source, and vice versa, as the availability changes. In steady-state conditions, the pump can run solely on the available solar power unless there are very rapid changes in the load (i.e. stating transient), or in the incident solar radiation. When these changes occur, the pump will seamlessly draw the lacking portion of power from the grid to compensate.

\subsection{Literature Search}

Although it is well understood that power sharing is possible in systems with a common DC-link, and the control and characterization is simple due to the passive nature of these circuits, the initiative has not been put forth to understand the characterization 
and control of active power sharing in systems with a common DC-link. The literature review presented here will cover some of the available literature leading up to this research effort, however, it should be noted, that there exists a lack of any relevant research regarding active power sharing in these systems.

The study of the use of photovoltaic energy to operate motors and motor drives has been a topic of research for well over 30 years. At that time, the gap in knowledge was still the performance analysis of photovoltaic coupled DC motors, and motors that were directly coupled to photovoltaic conversion systems [7-9]. In addition, efforts to include the use power electronics to reconfigure the arrays according to motor performance were studied [10]. Since that time, improvements in power electronic technology have improved reliability and robustness of control of motors in adjustable-speed drives(ASDs), and these improvements and the higher penetration of ASDs have inspired research into the coupling of PV arrays, and motor drives, and since the late 1980's there has been plenty of research into photovoltaic pumping systems. This research has included everything from surveys of PV pumping applications for rural communities [1113], to the application of MPPT algorithms for maximum power extraction [14], optimization [15], performance analysis[16], and modeling and simulation of solar pumping systems[17].

In 1991, a research effort was performed on a grid-connected/solar pumping system [18] in rural South Africa. In this system, an inverter was connected to an AC motor through a three-phase transformer, which was connected to the AC-grid through an inductor, see Figure 1-1. Since this is an AC system, power can be injected back into the 
grid by using standard AC power flow theory to change the power angle of the inverter. A major disadvantage to this system, is that it utilizes a connection known as a singlewire Earth return, which is only utilized in rural areas due to concerns over voltage drops and instability. In addition, the inefficiencies of this system are high due to the configuration.

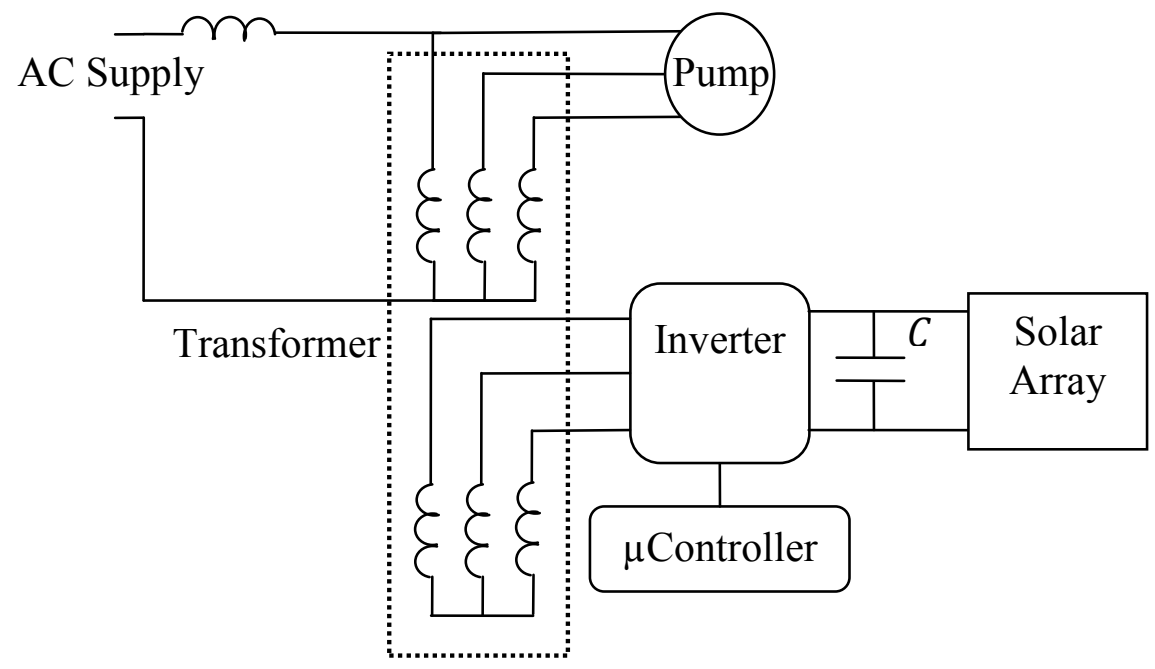

Figure 1-1 Grid/Solar Pumping System

Although the system in the following research is not technically "grid-connected", because it is a rural oil well field, the infrastructure exists in that area such that a microgrid has been established that provides reliable, and stable electric power. In this research, a so-called "Wind (Solar)/Grid Complement Power Supply" [19] has been established to reduce the power consumption of the DC loads (motor drives) on the micro-grid, and a case study has been performed. In the case study, the investigators provided a measurement calculus for the power saving in their system where the output power is a function of the rated power, and wind speed. However, little explanation of the system was performed. Another hybrid AC/DC source system in depicted in [20], where 
a common DC bus is used to connect battery, PV, and AC grid sources. The DC bus is then connected to $\mathrm{AC}$ adapters that power their individual loads. In this system, a proposed PV-battery step up DC-DC converter is presented, where the PV and the battery is connected in series, and on the buck-boost converter side of a so-called high step up hybrid boost-flyback converter. The researcher in this effort claims that the proposed topology offers an equivalent conversion ratio to the typical boost converter, without the additional switch stresses. However, the efficiency of this system varies widely with the output power and the voltage, and the claims that the system has lower stresses than conventional boost converters are exaggerated, since the peak currents are over $2.5 \mathrm{~A}$ for minimal power ranges (less than $20 \mathrm{~W}$ ). Additionally, the calculated conversion ratio for this converter is claimed to be higher than that of a conventional boost converter, which is true if one compares a boost converter in continuous conduction mode with this system. However, when the boost is operating in discontinuous conduction mode (which is also the mode of operation for this system), the gain ratio is equivalent, or less. In the research presented in [21], a hybrid battery/ultra-capacitor system is investigated. In this system, various configurations of ultra-capacitors, batteries, and bi-directional converters are analyzed according to specific criteria. A most ideal candidate is chosen, and compared against the typical B/UC configuration (parallel connection). Accordingly, the ideal case is specified is such that $75 \%$ of the UC voltage will be available, therefore $50 \%$ of the UC voltage must be drained in order to draw that equivalent amount of power. Again, although the power sharing in this system is essential, analysis of the active power sharing between the UC and the battery is not performed, since the main objective of this design is to maximize the system's ability to drain the UC voltage. 


\subsection{Objectives and Contributions of the Thesis}

The objective of this Thesis is to characterize active power sharing, control of the power sharing in a hybrid motor drive between a PV source, and the DC bus, and the design, implementation, testing, and analysis of a hybrid-solar motor drive prototype. The contribution from this Thesis is an equation, which describes the behavior of power sharing in these systems, which can potentially be extended to other, similar systems. In addition, there is expected to be a system of equations that describe the control system of the hybrid motor drive, as well as a working prototype, which can be evaluated for market potential by A.O Smith Corporation, who is the sponsor of this research.

The contributions of this Thesis are listed as follows:

a. An investigation of power sharing in a hybrid motor drive, using the hybrid-solar pump as a test case.

b. Identification of the control parameters (switching frequency, PV voltage, duty cycle ratio, and inductance) for power sharing in the test case hybrid-solar system.

\subsection{Organization of the Thesis}

Aside from this introductory chapter, there are six other chapters. Chapter 2 covers

the characteristics of PV cell energy generation systems, and some of the advantages of integrating PV sources with the AC grid that have been discovered during this research effort. Chapter 3 is a review of variable speed motor drives, including Brushless DC Motor Drives (BLDC), which is used in the case study. Chapter 4 is an analysis of the 
DC-DC boost converter, including its topology, operating modes, and control. Chapter 5 covers the design of the DC-DC module, including the test bed setup, and the original proof of concept prototype, as well as the final version of the DC-DC module. This section also covers presents and develops the state-spate equations that describe the control of power sharing in hybrid solar drives. Chapter 6 is a presentation of the experimental results that were acquired from the original prototype, and a brief comparison with the results of the final version of the DC-DC module. Finally, Chapter 7 concludes this Thesis, and offers future work for consideration. In addition to the seven chapters, there are four appendices, which cover the PCB design data, the design and system data, the Microchip code, Simulink models, and programming procedures, and finally all of the data acquired through testing of the hybrid-solar pump. 


\section{CHAPTER 2}

\section{CHARACTERISTICS OF PHOTOVOLTAics}

In this chapter, the characteristics of photovoltaic (PV) energy generation, and panels will be discussed. This discussion includes the basic principles of photovoltaic energy conversion, and types of materials used for PV junctions, followed by equivalent circuit models, operational behavior, and some technical challenges associated with the technology.

The history of photovoltaic energy research dates back almost three centuries, with contributions from some of the most well known people in Science and Engineering. In 1839, Alexandre-Edmonde Becquerel [22] first discovered the photovoltaic effect, while he was studying electrolytes and metal electrodes. Learning from Becquerel's discovery, William G. Adams, who was a professor of natural history at the King's College, London ,along with his student R.E. Day, created the first solar panel from a Selenium-Platinum junction in 1887 [23]. However, even though the phenomenon was known, it was not understood until 1905, when Albert Einstein delivered a full analysis and explanation of the photovoltaic effect in his paper titled "On a Heuristic Viewpoint Concerning the Production and Transformation of Light" [24], for which he was awarded the Nobel Prize in 1921. Since that publication, understanding and development of PV technology has evolved according to the concepts upon which Einstein shed illumination. The study and development of Selenium based photovoltaics continued until 1953, when the first monocrystalline Silicon PV cell was engineered by G.L. Pearson and C.S. Fuller[25], and the first Germanium PV cell was discovered by Dr. Dan Trivich[26]. The significance of their discoveries was a large increase in efficiency of conversion from light to electricity, 
and in the case of Dr. Trivich, the characterization of conversion efficiency according to the spectrum of the radiant light. A focus on the efficiency of the photovoltaic conversion process was the most prevalent topic in research for the next two decades, until C. Feldman et al. published research regarding the deposition of Silicon films in 1976 [27]. This publication lead to the invention of Thin-film PV panels, which are thin, flexible solar panels that can be molded to various surfaces. Another innovation was achieved in 1977, with the development of Amorphous Silicon PV cells [28]. This significance of these two discoveries was that these developments produced a less efficient, but much less expensive PV panel, allowing for increased economic development in the PV sector, and a focus on affordability. The efficiency and affordability of PV panels has continued to improve since these discoveries, and in 2008, First Solar, which is one of the preeminent solar module manufacturers in the world, broke a major milestone in solar technology by reducing the manufacturing cost of their solar modules to under $\$ 1$ per watt [29].

\subsection{Principles of PV Energy Conversion and Materials}

PV cells operate by the photovoltaic effect, whereby electrons are released from the surface of a material upon exposure to light. The release of the electrons is caused by the excitation that is generated by the additional photons being radiated upon the material surface. In PV cells, a voltage is induced across a semiconductor junction, when that junction is exposed to light. The semiconductor junction is a p-n junction, which is essentially a diode. Since the electrons can only pass through the junction in one direction, current flow occurs. An example of a PV cell is visible in Figure 2-1. 


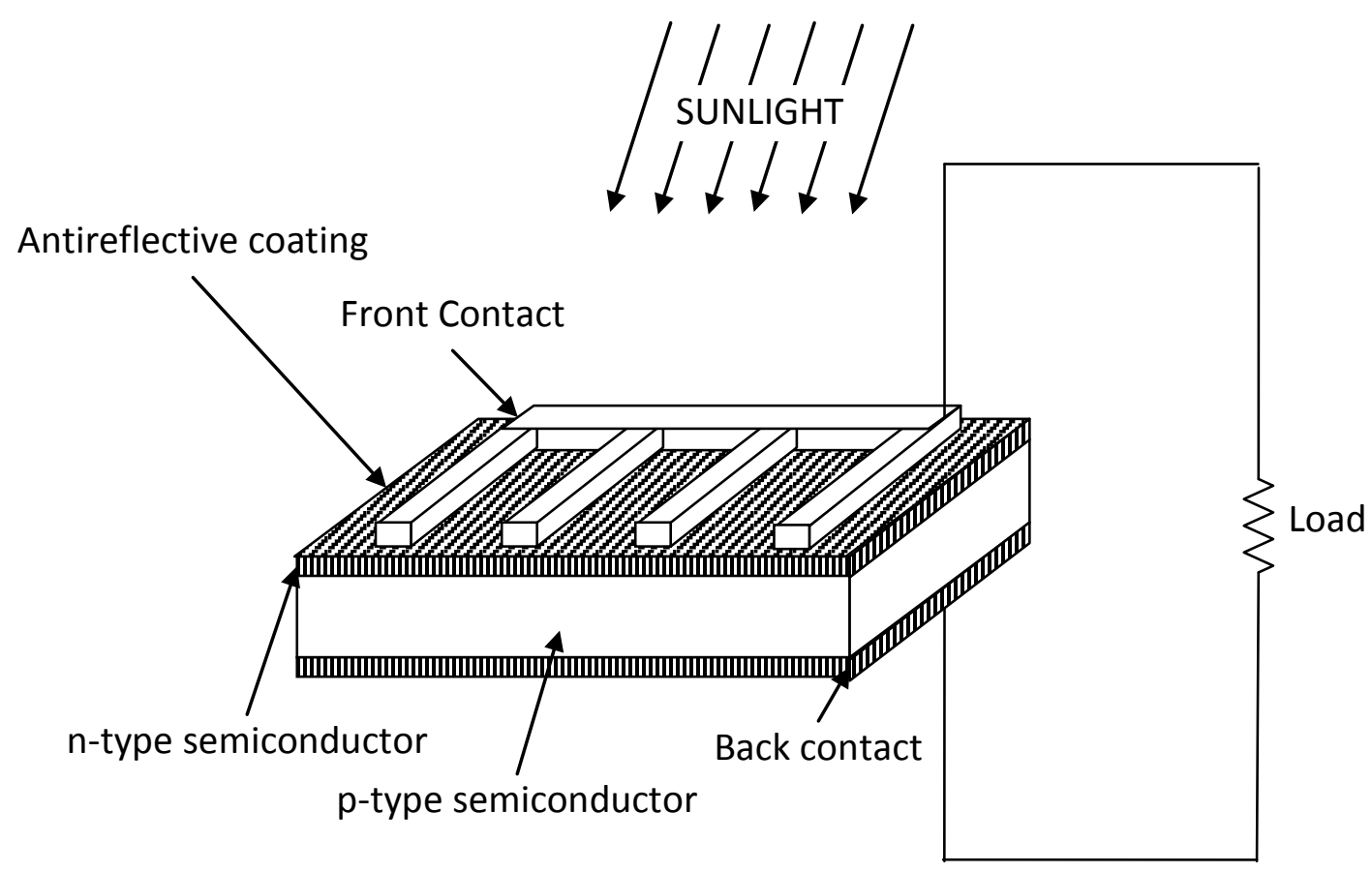

Figure 2-1 P-N Junction of a PV panel

Two layers of semiconductor material create the p-n junction. The difference in the type of material is caused by a technique known as doping, whereby impurities are added to the semiconductor material in order to produce desirable electrical characteristics. There are many different techniques for doping semiconductors, but those are out of the scope of this research. The " $p$ " in the $p$-type material denotes that it is a positive material, where a dopant that has one less electron has been introduced into the semiconductor to create an abundance of positive charge carriers know as "electron holes". Consequently, the " $n$ " in $n$-type material means that the material has been doped with elements that have an extra electron.

The materials used for PV cells first began with pure Selenium and Platinum[23]. Since the discovery that Silicon and Germanium work well for photovoltaic cells [23]- 
[24], there has been a wide range of different semiconductor-dopant combinations. Discoveries have even been made of semiconductor materials which do not need to be doped in order to produce the junction. Some of the typical combinations are listed in [30]:

- Monocrystalline Silicon

- Polycrystalline Silicon

- Amorphous Silicon

- Gallium-Arsenide

- Cadmium-Telluride

- Copper-Indium-DiSellenide

New materials, and junctions are being discovered every year, such the Tin-Zinc Oxide junction, and Tin-Zinc Oxide-Indium junction that are being researched for many nano-PV cells [31]. Therefore, this should be considered to be a summarization of common junction materials, and not a comprehensive collection.

\subsection{Equivalent Circuit Models and Behavior}

A brief description of how PV cells generate electrical was delivered in the previous subsection. In this subsection, an explanation of how that energy can be harvested and utilized is covered, beginning with the equivalent circuit for a PC cell.

The electric behavior of a PV cell is described by the equation [32]: 


$$
I=I_{p h}-I_{o}\left(e^{\frac{q V}{a k T}}-1\right)=I_{p h}-I_{d}
$$

where, $I_{p h}$ is the photo-current that is generated by the light exposure, $I_{d}$ is the Shockley diode equation, $I_{o}$ is the reverse saturation current, $q$ is the charge of an electron $\left(1.60217646 \times 10^{-19} \mathrm{C}\right), a$ is the diode ideality constant, $k$ is Boltzman's constant $\left(1.3806503 \times 10^{-23} \mathrm{~J} / \mathrm{K}\right)$, and $T$ is the junction temperature in Kelvin. The magnitude of $I_{p h}$ changes according to the level of incident solar radiation, also known as insolation. Insolation is measured, not only in the magnitude of intensity, but also in the angle at which the light strikes the face of the PV panel. In Figure 2-2, the I-V, and P-V curve of a solar panel are plotted for several levels of insolation.
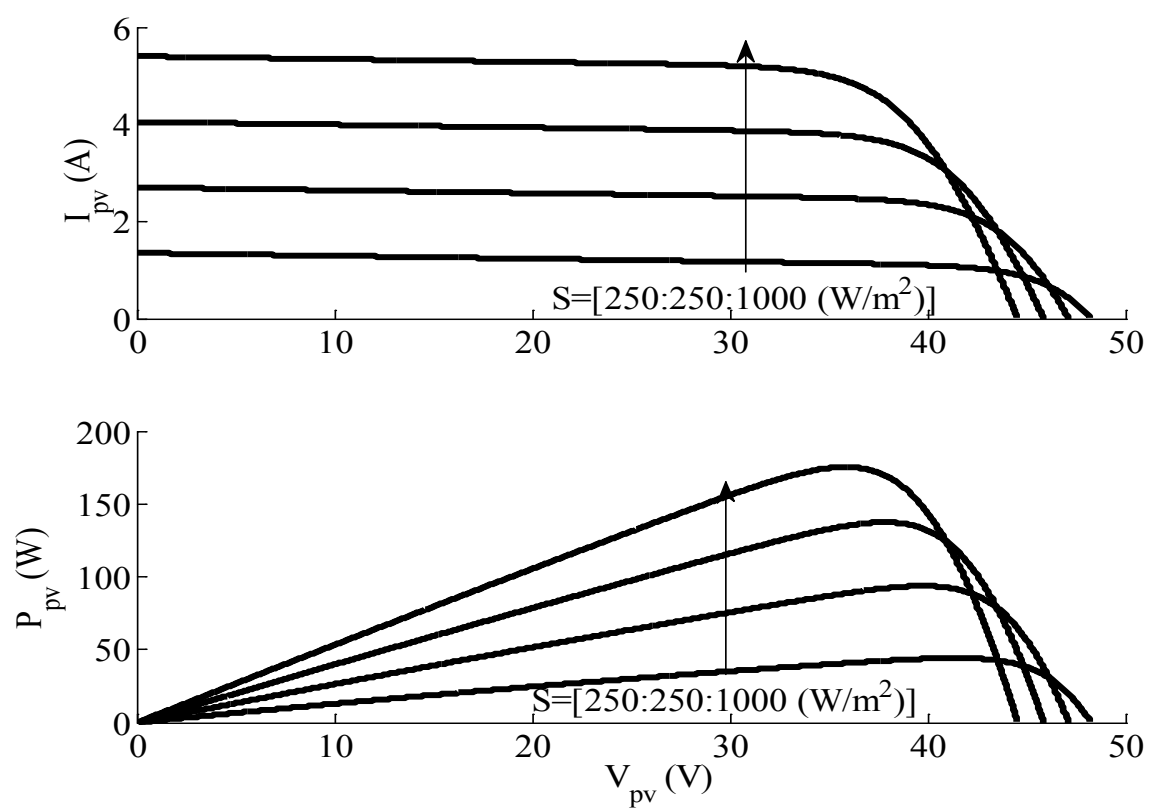

Figure 2-2 (a). I-V Curve, and (b). P-V Curve plotted for different levels of insolation.

The easiest way to understand the electrical characteristics of a PV-cell is to examine the simplified circuit diagram. The ideal circuit consists of a current source in 
parallel with a diode. However, in practice, the actual behavior of the cell is similar to that of a current source connected in parallel to both a diode, and a resistor, with a series connected resistance connected between the cell and the terminals [33]. A diagram of the ideal versus the practical equivalent circuit for the PV-cell is visible in Figure 2-3.

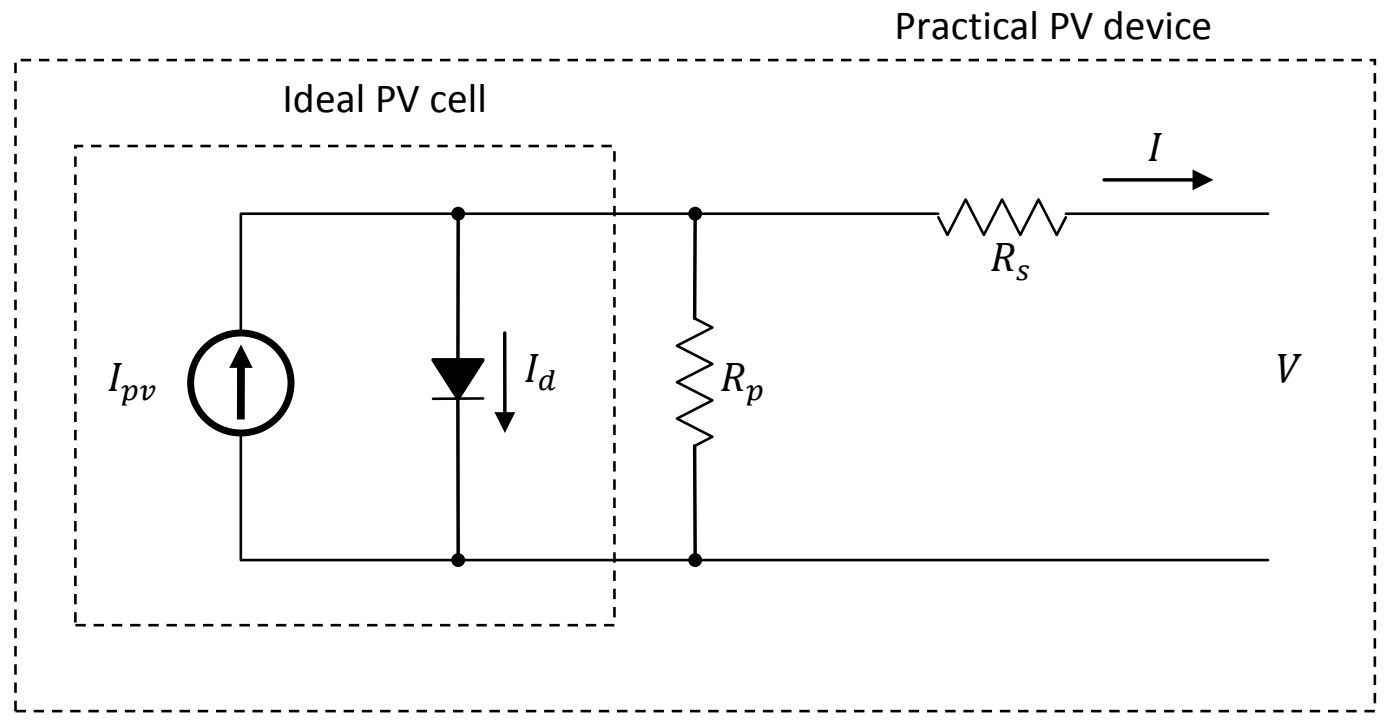

Figure 2-3 Equivalent Circuit Model for a Photovoltaic Cell [35]

In the equivalent circuit, $R_{p}$ is typically a very large resistance that is used to model the leakage current of the diode, and $R_{s}$ is a very small resistance that is used to model the connection resistances. In some models these resistances may be neglected, however, they accurately model the behavior of the cell in both modes of operation. In current source mode, the parallel resistance $R_{p}$ has more of an effect on the operation of the circuit, because of the increased effect of the leakage current. However, while in voltage source mode, the series resistance $R_{s}$ is more influential because the increased power dissipation reduces the maximum power of the panel. 


\subsection{Maximum Power Point Tracking}

Due to the unique behavior of PV cells, and the nature of the I-V, and P-V curves, there are certain technical challenges that must be overcome. From examination of the P$\mathrm{V}$ curves, it can be observed that there is a point along each one of the curves where the maximum power of the panel can be harvested. This is known as the Maximum Power Point (MPP), and there are many studies related to tracking changes in this point, so that the maximum amount of energy can be harvested from PV panels at all times. The MPP is often referred to as the "knee-point", and a lack of consideration for this point can result in a system operating at a lower power level than what is possible, or potentially at a point that is way beyond the available power level. In this case, the characteristic of the PV-cell will cause an array to go into current-source mode, and the voltage at the input terminals of the system will collapse, likely resulting in system shutdown. The practice of tracking the MPP is appropriately titled Maximum Power Point Tracking (MPPT).

There are many MPPT techniques, which have different advantages and disadvantages. Some are inexpensive to implement, yet they have slow convergence on the maximum power point. Others may require expensive, hand-bandwidth sensors, and require complex programming and but may offer extremely accurate control, and fastresponse. According to [34], there are at least nineteen different MPPT techniques, with varying degrees of cost and ability. The following will only cover seven of the most commonly used techniques. 
The first two techniques are known as the "Perturb and Observe Method"(POM), and the "Hill Climb Method"(HCM). These two methods use similar techniques to track the MPP. In the POM approach, the output voltage of the system (typically some sort of DCDC converter), is incremented, or decremented by a small amount, hence, the term "Perturb". Next, the input power to the system is monitored for fluctuations. If the output voltage is incremented, and the input power increases, then the next perturbation will again be an increment. However, if the input power decreases, then the operating point of the system is past the knee-point in the I-V curve, and the next perturbation will decrement the output voltage, see Figure 2-4. The HCM operates in a similar manner, but the duty cycle ratio is incremented, or decremented, instead of the output voltage, and the power is measured. This method is widely used, but has some drawbacks. The first drawback is that the system will continuously oscillate about the maximum power point.

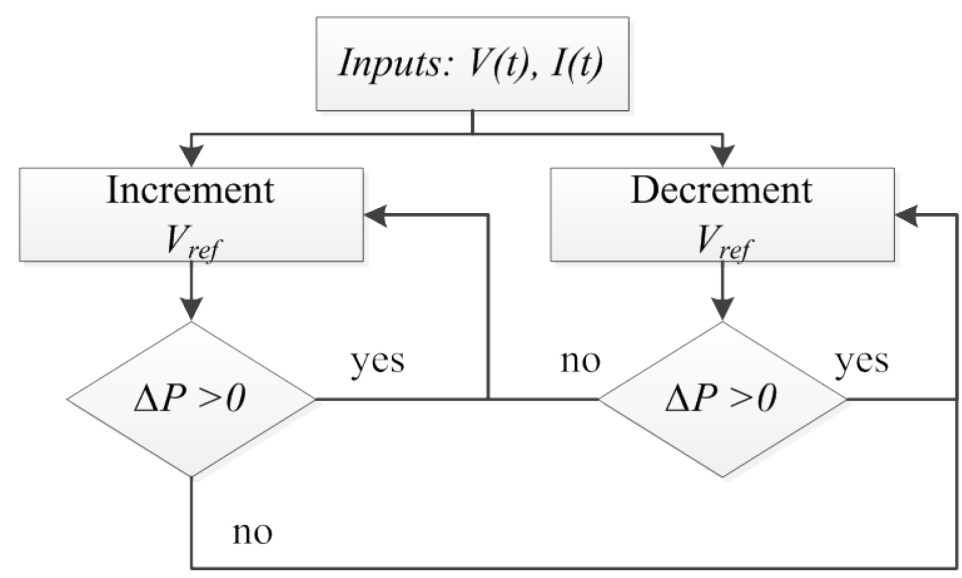

Figure 2-4 Perturb and Observe Method Flow Diagram

Therefore, a variable perturbation step-size must be used once the system is operating at a level close to the MPP in order to reduce the oscillation size. The second 
drawback is that rapidly changing atmospheric conditions render this technique useless. Since the MPP is rapidly changing, the control scheme will continuously hunt in different directions [34].

The next method is known as incremental conductance. In this technique, an input voltage sensor, and an input current sensor are used to measure the conductance of the connected source. The logic behind this method is that if the connected PV source is at its MPP, then changes in conductance of the source will be zero, see Figure 2-5 for reference.

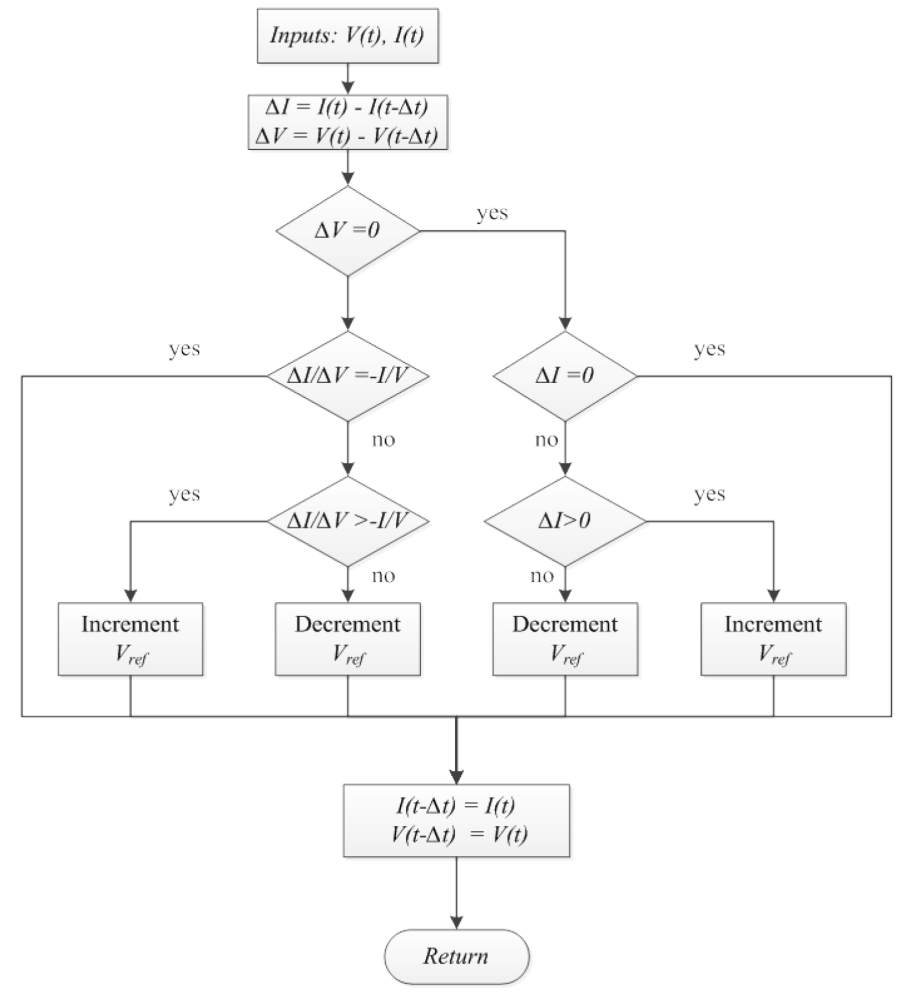

Figure 2-5 Incremental Conductance Flow Diagram [34] 
The technique is performed by measuring the conductance of the source, and then comparing that measuring against the previous measurement. If the incremental conductance is used to generate an error signal, then a PI controller can be used to track the MPP [34].

Another two similar methods that operate according to similar principles are titled, Fractional Open-Circuit Voltage, and Fractional Short-Circuit Current. It can be seen that the MPP voltage is linearly related to the open circuit voltage. This relationship is figured in the equation $V_{M P P}=k_{1} V_{O C}$, where $k_{1}$ is a constant that is dependent on the particular PV panel. If $k_{1}$ has been calculated, then the MPP can be tracked by briefly shutting down the converter, and measuring the terminal voltage of the PV panel. The disadvantage of this method is that the system must be open circuited in order to know the operating point. Fractional Short-Circuit Current operates in a similar manner. Again, it can be seen that the short-circuit current of the panel is linearly related to the MPP current by the equation $I_{M P P}=k_{2} I_{S C}$, see Figure 2-6.

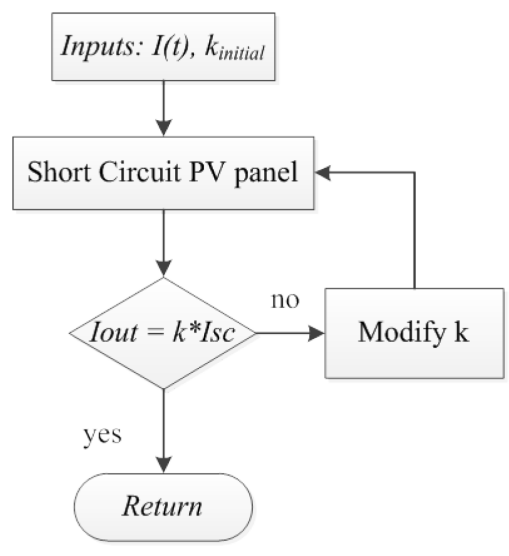

Figure 2-6 FOCV/FSCC Flow Diagram 
However, this method does not have any drawbacks if used in a DC-DC Boost converter, or a CSI-based Boost Inverter, because these systems rely on short-circuiting an inductance for proper operating. If the system is not one of those previously mentioned, then this method can increase the cost and complexity of the circuit [34].

There are several intelligent methods of MPPT, such as utilizing Neural Networks $(\mathrm{NN})$, or Fuzzy Logic (FL). In an NN MPPT control scheme, the input voltage and current, along with the temperature, and irradiance make up the input variables, and then network is trained to maintain the output variable at the MPP according to the input variables. Since the environmental conditions, and the behavior of the PV array may change over time, it is important that the $\mathrm{NN}$ be programmed as an Adaptive Neural Network(ANN). In an ANN, the weight coefficients that determine the output of the network are continuously changing according to recent operating data. As a result, the control system does not have to be retrained in order to ensure that it is actually tracking the MPP. In FL control systems, membership functions are formed to control the output of the system according to linguistic variables. These control systems are useful because they do not require linear inputs to operate with high precision, as long as the rule base and the membership functions are set up correctly. FL systems are often used to replace PI controllers, when the inputs are non-linear. This is because the coefficients of the PI controller are correct for a portion of the total operational range. Unless the coefficients are updated according to the operating point, the PI will deliver stable control for a particular operating range, and will be unstable elsewhere. In the typical FL MPPT control scheme, an error signal is generated according to the PV outputs, such as the 
incremental conductance, or FOC voltage. The FL control method is then used to regulate the power electronic apparatus such that the error between the reference operating point, and the actual operating point is zero.

The final MPPT algorithm that is discussed in this section is known as Ripple Correlation Control (RCC). The two steps in this method are to calculate the derivative of the power with respect to time, and the derivative with respect to time of either the voltage, or the current. The next step is to multiply the two derivatives. Since an increase in the voltage or the current above the MPP will result in a negative value for the product of the two derivatives, the output (i.e. duty cycle ration) will reduce until the MPP is reached. Accordingly, if the value is positive, the output will be increase [34]. In many ways, this method works like a combination of the methods mentioned previously.

\subsection{Applications in Hybrid Drive Systems}

Photovoltaic cells convert radiant light energy to electrical energy. Accordingly, after losses through the atmosphere, and depending on location, the sun delivers an approximate peak value of $1.0 \mathrm{~kW} / \mathrm{m}^{2}$ to the surface of the Earth [35]. Since this is essentially free energy (minus initial installation, and maintenance costs), PV arrays present an opportunity to alleviate the demand that is present on the already over-stressed electrical grid, and save money. However, PV panels are not a perfect solution, and there are certain concerns in PV systems that must be answered. A short list of the drawbacks are: voltage collapse due to shading, or large loads, inefficiency in converting solar 
energy to electrical energy, and limited use due to the fact that they only produce energy in the presence of sunlight. Motor drive systems offer an opportunity to combine the reliability, and stability of the AC grid with the cost efficiency of solar energy. Since motor drives have a DC bus, and the energy generated by PV systems is DC, the two can be merged through the use of modern power electronics. In this section, some of the benefits of combining PV energy and motor drive systems are covered.

The DC bus voltage of low horsepower motor drive systems is typically between 100VDC and 700VDC. The average voltage output of a PV panel typically ranges from 15VDC to 50VDC. Through the use of the DC-DC module studied in this research effort, the low voltage of the PV panels can be converted to the DC bus voltage, and used to power the load instead of the AC grid, or in combination with the grid if the load demand is too large for the available PV energy. From the start, this offers a significant benefit that is not found in standalone PV systems. Standalone solar pumps offer a good example. One way to power the DC bus of a standalone variable speed water pump directly from a PV array is to connect a number of PV panels in series, and then to connect them to the input terminals of the drive. However, this has some disadvantages that make it a non-ideal solution. Firstly, PV panels that are connected in series have reduced reliability because of issues such as partial shading. When partial shading occurs, the total available power of the array is reduced dramatically because the weakest panel limits the overall current. A similar issue increases the cost of the system because in the case that partial shading occurs, if the shadow reaches completely across any of the panels, the entire array becomes open circuited. A way to prevent this from being a 
possibility is to include bypass diodes in the panels so that a partial obstruction, or shadow will render a particular panel useless, yet still allow current from the other panels to flow. However, this significantly increases the cost per panel. Depending on the current requirement of the load, there potentially exists another drawback of this configuration. If the required current is higher than that which can be supplied from the series connected panels, another set of series connected panels must be connected in parallel to the existing array. By doing so, the available current to the load will increase. However, the cost will increase as well.

A more practical solution would be to connect the panels in parallel, and then convert the voltage to the required voltage level. However, this may cause an issue during motor start up due to the high currents required. The hybrid-solar pump does not have this problem. Since both the AC grid, and the PV array can power the DC bus simultaneously, a lack of sunlight cannot cause the shutdown of the pump. Following that which was explained in the previous section, since variable speed drives offer higher efficiency and system control, another opportunity is available for hybrid-solar drives. A majority of the electrical load of a residence comes from only a few appliances. The largest of these is typically the HVAC system, followed by the pool pump (if one is present), and then the water heater, and range. Power electronic options already exist for each of these devices, hence the opportunity to create a hybrid-solar subsystem, that has a common connection to the DC bus of each of these devices would permit one to power these loads from the energy provided by the sun. Additionally, since the DC bus would be common to all of the appliances, the size of the PV array, and the available PV energy could be increased over time to account for the entire load, instead of being forced to 
install a large PV array from the start. In conclusion, a major benefit of this technology is that it allows opportunities to increase the penetration of PV energy usage, without incurring major costs. 


\section{CHAPTER 3}

\section{Adjustable Speed Motor Drives}

There are many types of variable speed drive systems that can be discussed, however, aside from the general topologies of motor drives, only the characterisitics of PM BLDC drives will be considered in this chapter, since that is the system with which this research is concerned. This section will cover the behavior, and equivalent circuit for a PM BLDC motor, followed by the associated switching patterns and control schemes, and then some of the advantages of the BLDC pumping system in comparison with the typical induction motor driven pumping system, and the applications in hybrid-motor drive systems. Firstly, this section will begin with the general topologies of motor drives

\subsection{General Motor Drive Topologies}

In order to understand how the variable speed pump operates, it is important to understand the topology of the BLDC drive converter. The physical topology of the motor drive is that of a standard three-phase voltage source inverter, a common DC bus, with an input energy source [36-37]. In the case of this research, that input power source is a single-phase rectifier input stage, and a single-phase $\mathrm{AC}$ voltage source, connected through a transformer. The topology is depicted in Figure 3-1(a). 


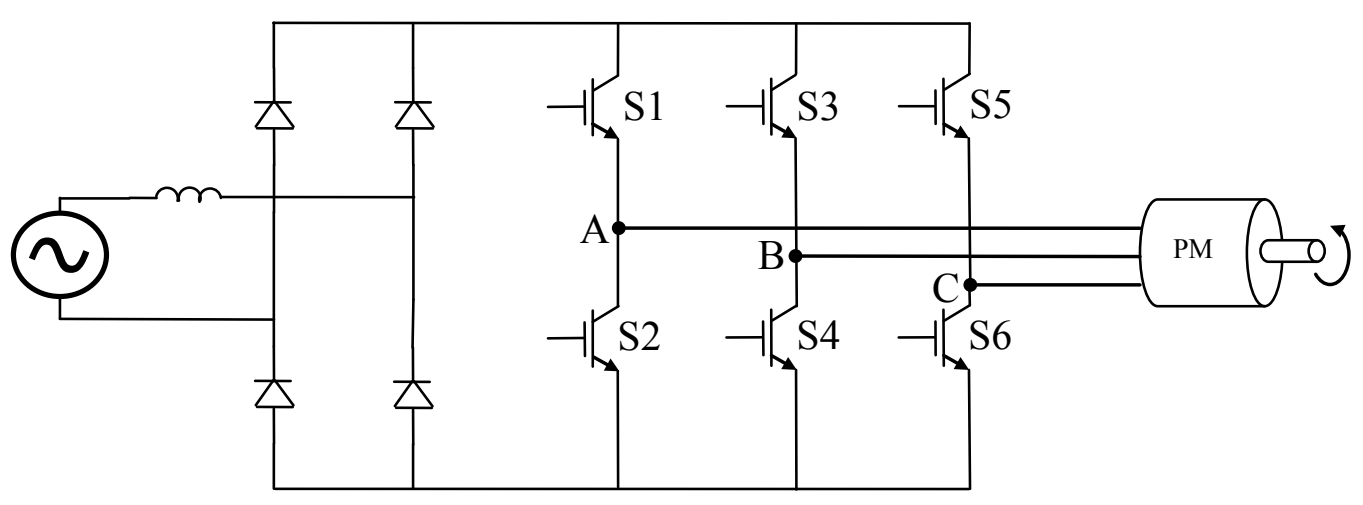

\section{Figure 3-1 Drive Circuit (a) Voltage-Source Inverter}

\subsection{PM BLDC Motor Characteristics}

In order to understand the test case hybrid-motor drive, it is important to understand the PM BLDC motor. These motors consist of two parts: a rotor, and a stator. However, there are several different configurations for BLDC machines. The first is often referred to as an inside-out machine, where the rotor rotates around a central stator. In this configuration, the windings are on the non-rotating stator, and the magnets, which are attached to the rotor, rotate around the windings, see Figure 3-2(a). The second configuration, is known as an axial-flux, axial air-gap, or pancake rotor machine. In this motor configuration, the magnets are attached to a disk-shaped rotor which rotates parallel to a disk-shaped stator, see Figure 3-3(b). This actually permits both the rotor and stator to counter-rotate about the same axis. The third configuration is known as a slotless motor. In this configuration, the cylindrical rotor has magnets attached to it, and rotates inside of the non-rotating stator. The stator consists of a cylindrical tube of 
stainless steel, which is wrapped with copper windings see Figure 3-4(c). This configuration permits different winding techniques, such as toroidal or helical winding. The final configuration is the motor type which is used in this research, and it is sometimes referred to as a radial flux machine. The stator is the non-rotating portion of the machine, and it consists of a cylindrical tube of laminations of magnetic iron that are stacked together. These laminations have slots cut into them for the windings. The rotor has magnets attached to it, and fits inside of the stator with an air-gap between it and the stator [38], see Figure 3-5(d).

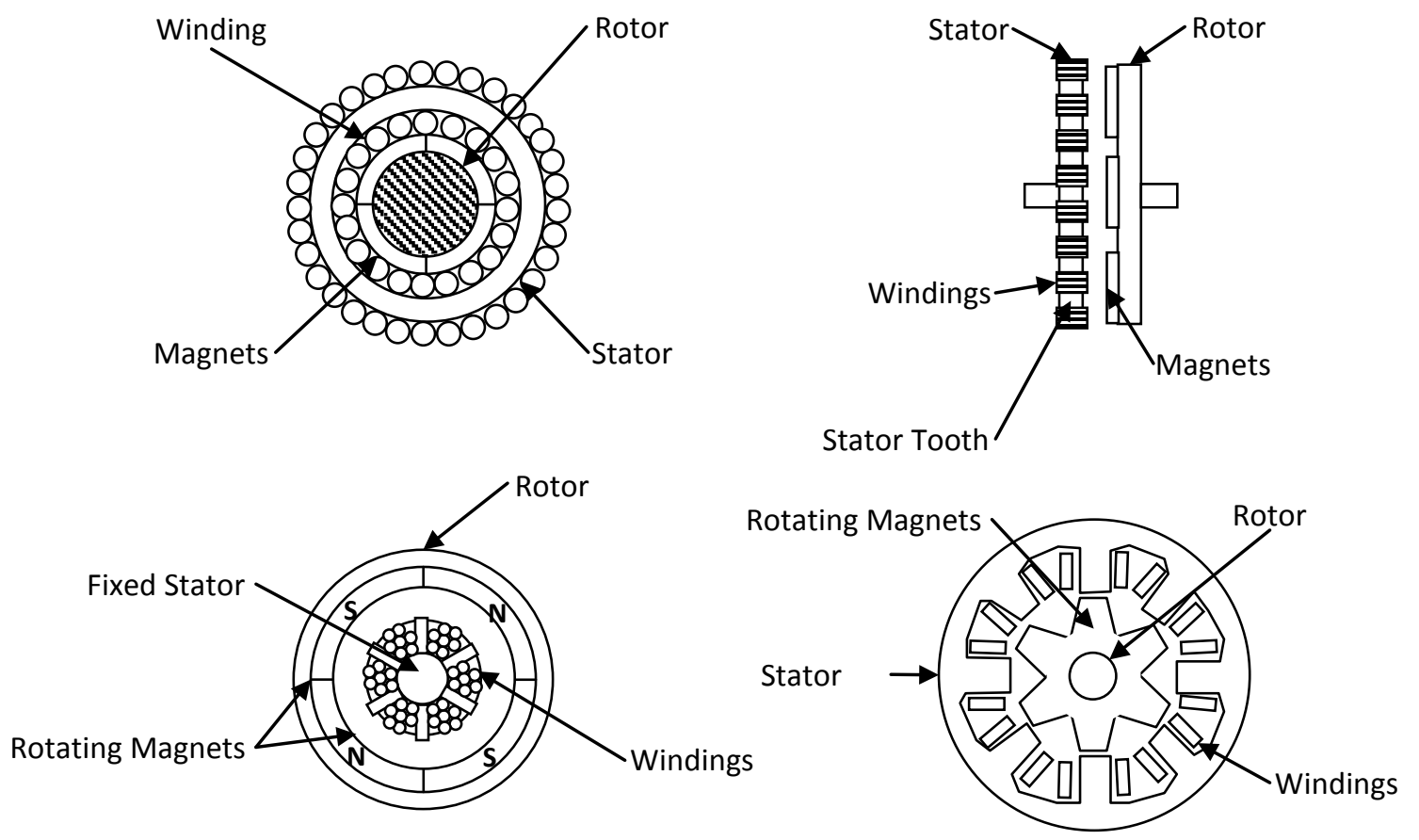

Figure 3-2 BLDC Motor Configurations

Following the brief review of some of the different BLDC motor types in the previous subsection, the behavior of the radial-flux machine will now be addressed. Prior to the advent of power electronics, motors in were typically $\mathrm{DC}$, single phase $\mathrm{AC}$, or 
three phase AC because of the available power system. Hence, since BLDC motors require some sort of power electronic interface to operate, they have not been limited according to available single phase, and three phase, or DC power supplies like conventional motors. Therefore, not only does there exist a single, and three phase configuration, but also 5, 6, 12, and a 4-phase configuration, which was popular for lowpower applications in the late 1960's [38]. However, since this research effort deals with a three-phase BLDC motor, this explanation will only cover the three-phase configuration.

The operating characteristics of a three-phase BLDC motor are the same as that of a synchronous machine. A simplified, single-phase representation of a BLDC pump is visible in Figure 3-3. If a voltage $V_{s}$ is applied across the windings of the BLDC motor, the equivalent relationship can be expressed as: $V_{s}=E+I R_{c u}+V_{s w}$, where $E$ is the back-EMF, $I R_{c u}$ is the voltage drop across the motor windings, and $V_{s w}$ is the drop across the semiconductor switches.

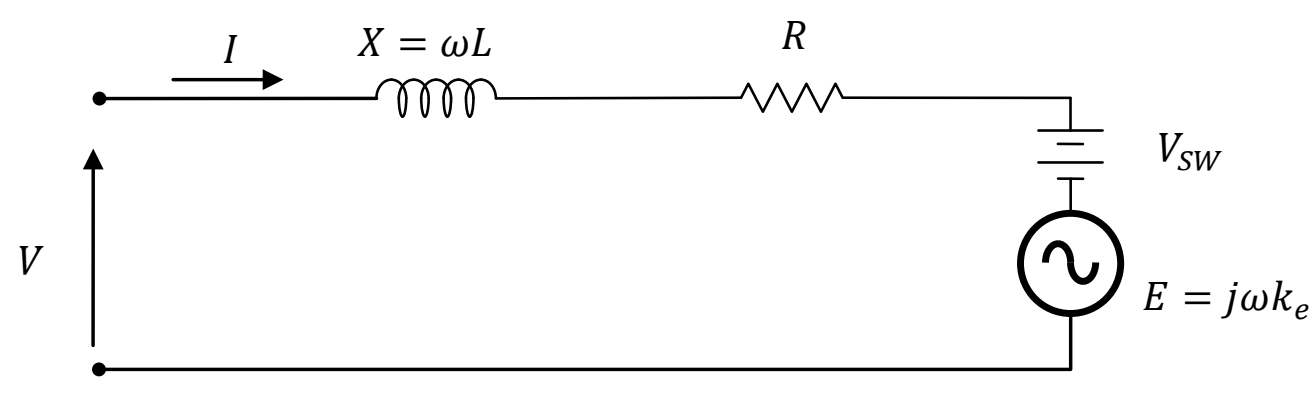

Figure 3-3 Steady-State BLDC Motor Equivalent Circuit 
According to Faraday's law, the back-EMF is equal to the rate of change of the flux-linkage. Therefore, the instantaneous back-EMF can be shown to be $e=\omega_{m} \frac{\partial \psi}{\partial \theta}$, where e is equal to the slope of the flux-linkage waveform, $\omega_{m}$ is equal to the rotational velocity, $\psi$ is equal to the magnetic flux, and $\theta$ is equal to the angular position of the motor. Accordingly, when the motor is operating at a constant speed, the relationship between the electrical and mechanical energy of the motor, as $E I=T_{m} \omega_{m}$, where $E$ equals the back-EMF across two connected windings, and $I$ is equal to the DC current [38]. Due to the fact that the rate of flux-linkage change is constant for every $120^{\circ}$ of rotation, the back-EMF can be represented as: $E=k_{e} \omega_{m}$, where $k_{e}$ is a constant coefficient for any design. From the preceding equations, the following can be derived: $T_{m}=k_{e} I$. Next, the no-load speed-torque relationship can be shown to be: $\frac{\omega_{m}}{\omega_{n l}}=1-\frac{I}{I_{L R}}$, where $\omega_{n l}$ is the no load rotational velocity equal to $\frac{V_{s}}{k_{e}}$, and $I_{L R}$ is the locked-rotor current [38]. Consequently, it can be seen that when starting from zero rotational velocity, the back-EMF will be very small. Within the motor it will only be limited by the small resistance in the windings, since the source voltage is significantly larger that the drop across the switches. Therefore, the starting current must be limited externally.

Although they are idealized, these equations show a very important characteristic of BLDC motors; that the torque of the machine is constant for constant voltages. Therefore, a linear reduction in the voltage across the terminals will result in a linear lowering of the torque, and a reduction in the torque demand on the motor will reduce in 
a linear voltage increase across the terminals (if the voltage is unregulated). Figure 3-4 displays the torque-speed characteristic of BLDC motors.

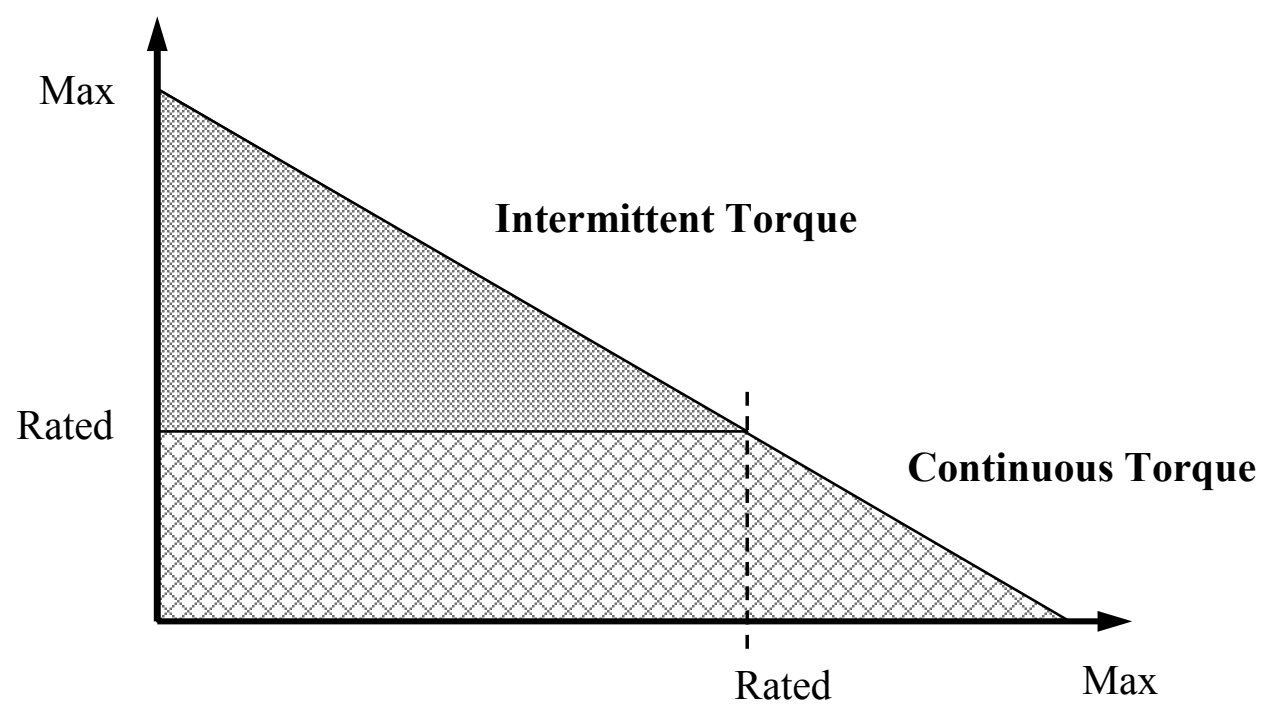

Figure 3-4 Torque-Speed characteristic of BLDC motor

\subsection{Switching Schemes and Control Methods}

The next issue of interest in BLDC drive systems is the switching, and control scheme. Control for BLDC drive systems is oriented according to the shape of the backEMF waveform of the motor, and the presence of position sensors, or lack thereof (i.e. sensorless control). There are two back-EMF profiles for BLDC machines, sinusoidal, and trapezoidal. It should be stated that machines with a sinusoidal back-EMF profile are sometimes referred to as Brushless AC (BLAC) machines. However, in the context of this section, they will both be referred to as BLDC machines.

If the back-EMF waveform is sinusoidal, then the presence of an absolute position encoder is often used to monitor the angular position of the rotor (see Figure 3-5(a) for an example of an absolute position, and an incremental position encoder). 

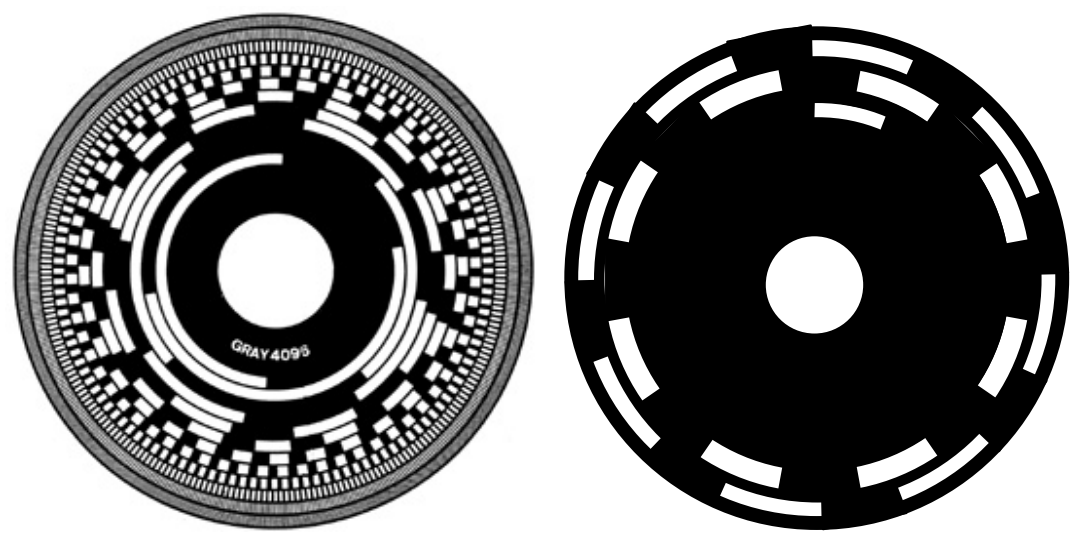

\section{Figure 3-5. Position Encoders: (a) Absolute Position[39] ; (b)Incremental Position[40]}

The need for an absolute position indicator, stems from the fact that with a sinusoidal back-EMF profile, a sinusoidal pulse width modulation (SPWM) switching pattern can be used to control the speed and position of the motor. SPWM works by comparing a sinusoidal signal of frequency $f_{f}$ with a triangular waveform of time period $f_{s}$. The frequency $f_{f}$ is known as the fundamental frequency, and the frequency $f_{s}$ is the switching frequency. If the magnetic position of the motor is known with respect to the windings, then the SPWM signal can be adjusted to generate the current needed to rotate the motor at a desired velocity, or to a particular angular position.

As mentioned previously, the rotor can be moved to any position if the controller knows what the exact position of the rotor is with respect to the stationary reference point because the controller can calculate the motor currents that will move the rotor in a particular direction at a particular speed. Since the absolute position encoder is used in this method, the controller has knowledge of the current angular position of the rotor, which in turn means that it has knowledge of the position of the rotor magnets with 
respect to the windings. For example, if the angular position of the motor is at the reference position $\theta=0$ while it is in rotation. The controller knows that the current in the windings at that angular position should be $i(t)=I_{s} \cos (\theta(t))$ in order to maintain rotation of the motor, where $I_{s}$ is the peak current. By increasing or decreasing $I_{S}$, the motor torque can be increased or decreased, and by increasing or decreasing $\theta(t)$ the rotational velocity and direction of the motor can be modulated. Another benefit of this method is that the currents in the windings are equal in magnitude, but offset by $\pm 120^{\circ}$. Therefore, only the current for one phase needs to be calculated. [41]. No additional calculation is necessary, which makes this a simple and effective control scheme.

When the back-EMF of the BLDC motor is trapezoidal, several options in the control and switching scheme are available. Firstly, if the BLDC motor is used in a servodrive, then either an incremental, or an absolute position sensor can be utilized, and a similar control scheme can be implemented as with the sinusoidal profile. However, since the back-EMF is trapezoidal, the profile of the phase currents must be rectangular, in order to develop torque that has a small magnitude of torque ripple [41]. Another option for trapezoidal profile motors, which is implemented in the drive being utilized in this study, is to use Hall Effect sensors instead of position encoders to determine the angular position of the rotor. Hall Effect sensors operate by generating a digital signal that corresponds to the magnetic poles (i.e. 1 for $\mathrm{N}$ or $\mathrm{S}$, and 0 otherwise). With Hall effect sensors, a control scheme called "Square-Wave", or trapezoidal control can be implemented, as well as a slightly modified version of a six-step inverter control scheme for torque control, and another method known as hysteresis band control (HBBC). In 
HBBC, high-bandwidth current sensors are used in conjunction with the Hall effect sensors to control the current passing through the windings of the motor. By setting upper and lower current bands for particular windings in the motor, the motor will be forced to rotate in the direction that the current flowing through the windings dictates. Once the rotor reaches a particular position, the Hall effect sensors will cause the controller to shift the bands to different windings in accordance with the desired direction of rotation [37]. This is a robust, and simple method of control, however, it has several drawbacks. First, the switching frequency in this control system is undefined, therefore the switching losses can vary widely, according to the current hysteresis band setting, the phase inductance, the back-EMF, and the bus voltage. The six-step inverter control scheme is a well-known method of control that was commonly used in induction motor drive systems. However, the distinction between the method used for induction machines, and the method used for BLDC machines is that for BLDC motors, two switches are energized at any given time, while as with induction motor drives there are three switches operating at any given time. Six-step operates in BLDC systems by closing the switches across two windings, thereby shorting them across the DC bus. As current begins to flow through the windings, the rotor begins to turn, a Hall effect sensor triggers the next switches in the rotation to close, and the currently closed switches to open. Since the instantaneous torque of the motor has previously been shown to be directly related to the current through the winding, and the torque of the motor has been shown to be directly proportional to the motor speed, increasing the speed of rotation of the six-step scheme increases the speed of rotation of the motor. The drawbacks of this control scheme in BLDC motor systems stem from the brief explanation at the beginning of this section 
regarding starting currents. Since the starting currents for BLDC motors are very high, and the starting speed does not increase instantaneously, this method can cause high current levels in the windings, potentially resulting in motor failure, and reduced operational life. In addition, this method cannot be used for servo-drive systems because it is unidirectional.

Square-wave is a scheme that combines the two previous methods to create a more robust control scheme. In particular, square-wave is the control scheme and switching pattern that is implemented in drive in this research effort, therefore, the majority of explanation will focus on this method. Square-wave is a combination of two distinct control schemes. The first is an outer torque control loop, which is established by using the six-step inverter algorithm, and the second is an inner current control loop that limits the phase currents according to the desired torque reference. Square-wave is essentially a six-step inverter, implemented by pulse width modulation. The six-step inverter waveform is the one which controls the rotational speed of the motor, while the PWM controls the currents flowing through the windings. There is an additional mode of operation for square-wave control which has an effect on the switching losses, and the electromagnetic interference (EMI) generated by the inverter. The two states of this mode of operation are referred to as uni-polar and bi-polar operation. The benefit of bipolar operation is that the conducted EMI is reduced; however, uni-polar mode is more efficient because the switching losses are reduced. The switch states of the square-wave control scheme are depicted below in Figure 3-6. 


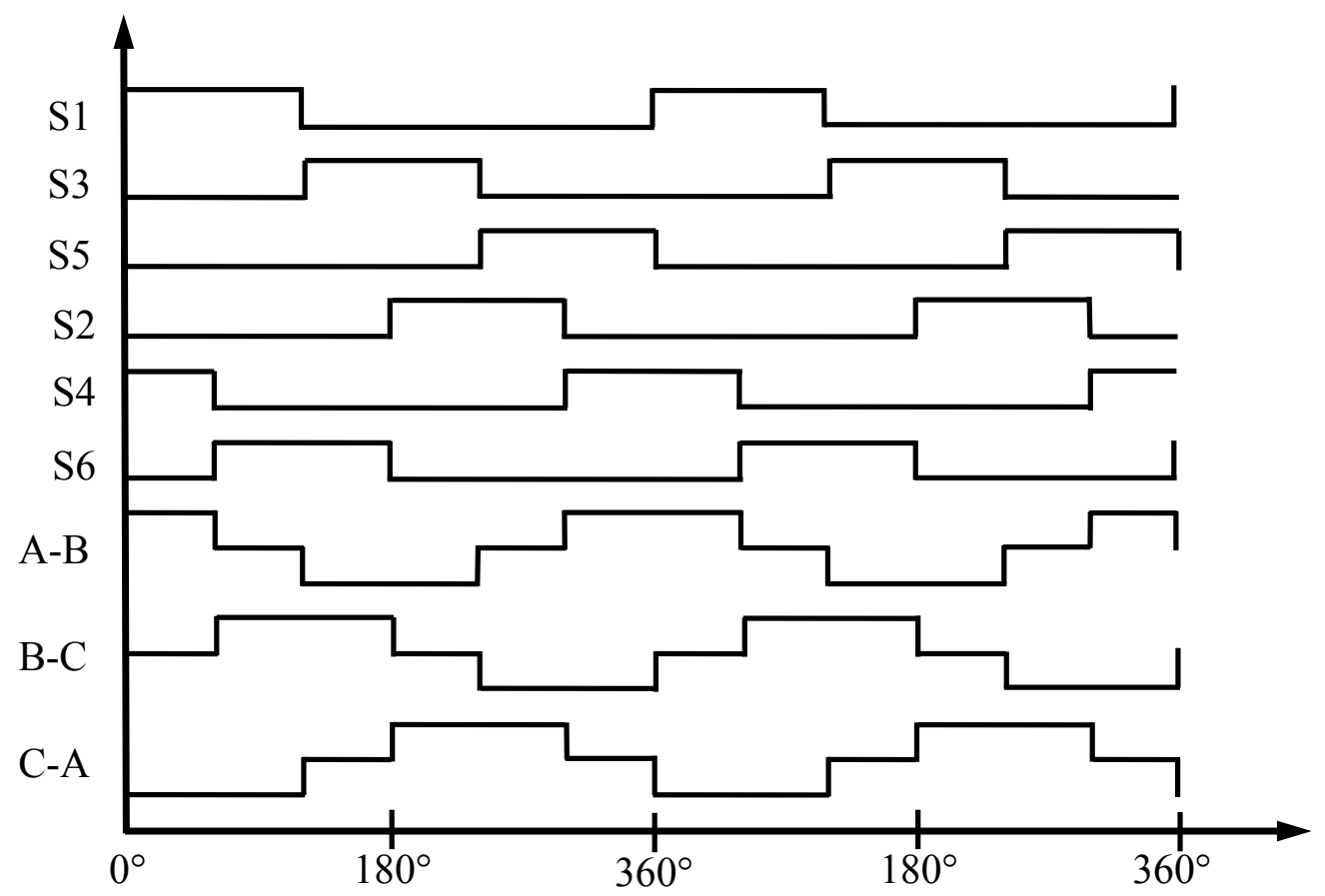

Figure 3-5 Switch and Phase Voltages for $120^{\circ}$ Square Wave Pattern without PWM
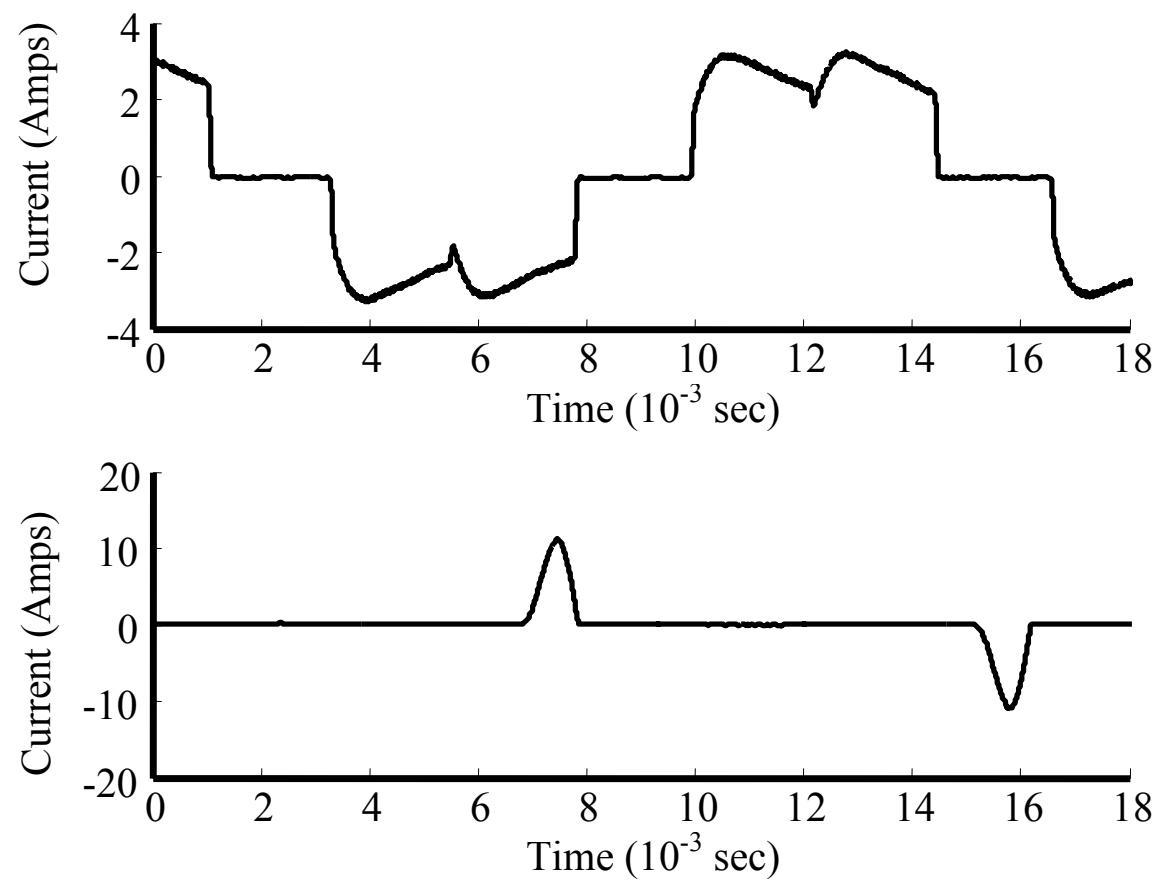

Figure 3-6 Motor current and AC input current while the motor was running at $1500 \mathrm{rpm}$, with the module at $33.5 \mathrm{~V}$ PV input voltage, $30 \%$ duty cycle, and $\mathrm{fs}=5$ 


\subsection{Applications In Hybrid Drive Systems}

Only minor modifications need to be made to a motor drive in order to allow access to the DC bus. In actuality, many drives have terminals, which connect to the DC bus, that are readily available for the connection of a braking system. This is means that most motor drive systems are easily convertible to hybrid motor drives. Since BLDC drives offer the highest efficiency amongst motor drives [42], it is naturally an ideal system to hybridize. In addition, BLDC drives are commonly used in hybrid vehicles, at high DC voltages [43]-[44]; therefore, a small amount of work is necessary to hybridize the drives so that PV arays can be used as an additional source for the vehicle. Since bi-directional converters are already used in many PHEV power systems [45], power can be funneled directly to the bus of the motor drive, and the PHEV control system can manage the charging or discharging of the battery bank. In addition, hybrid charging stations are possible, where the both the AC grid, and $\mathrm{PV}$ arrays are used in conjunction to recharge stationary electric vehicles. 


\section{CHAPTER 4}

\section{DC-DC BOOST CONVERTERS}

An integral component of the Hybrid-Drive is the DC-DC converter, specifically the DC-DC Boost converter, without this, power sharing in this system is impossible. The boost converter is one of the three archetypes of DC-DC converters, the other two are the buck converter, and the buck-boost converter. The converter types are named, appropriately, by the way that they function, that is, the boost converter boosts the output voltage to a higher magnitude than then input voltage, the buck converter reduces the output voltage to a magnitude that is lower than the input voltage, and the buck-boost can both increase, or decrease the magnitude of the output voltage. In addition to their function, DC-DC converters are again divided into sub-groups with respect to their galvanic isolation, that is, isolated, and non-isolated converters. Since the converter used in the Hybrid-Drive is non-isolated, only that type will be considered in this text. The remainder of this chapter is broken into three sections. Applications for DC-DC converters in Hybrid-Drive systems will be covered, as well as control techniques for boost converters. Firstly, the remainder of this chapter will begin with the DC-DC boost converter topology.

\subsection{DC-DC Converter Topologies}

The DC-DC boost converter is often referred to as a step-up converter. The topology of the boost converter is depicted in Figure 4-1(a). As can be seen in the figure, the system contains an inductor, a capacitor, and two semiconductor switches. The two 
passive elements are the reason that this converter is often referred to as a second-order system. A fuller explanation of what this means will be discussed in the next section. The buck converter is also a second-order system, however, the topology is slightly different. This can be seen in Figure 4-1(b). The last of the DC-DC converter topologies that are being discussed is the Buck-Boost converter. This converter is also a secondorder system in its inverting form, Figure 4-1(c).

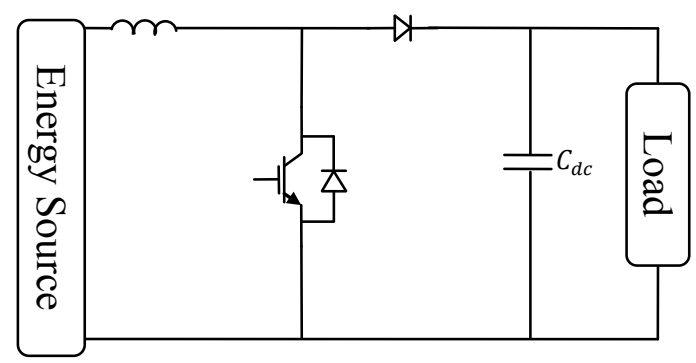

(a)

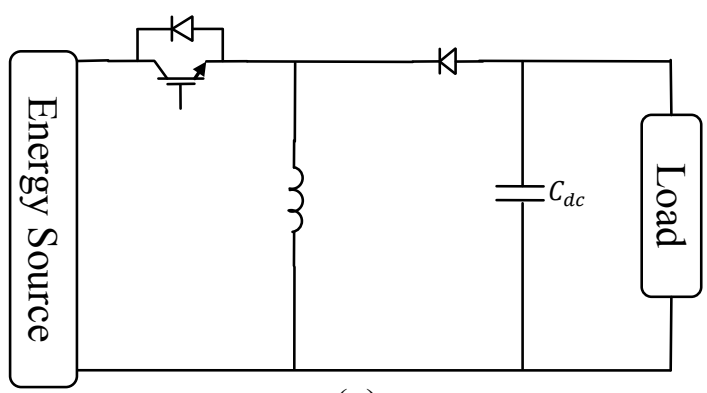

(c)

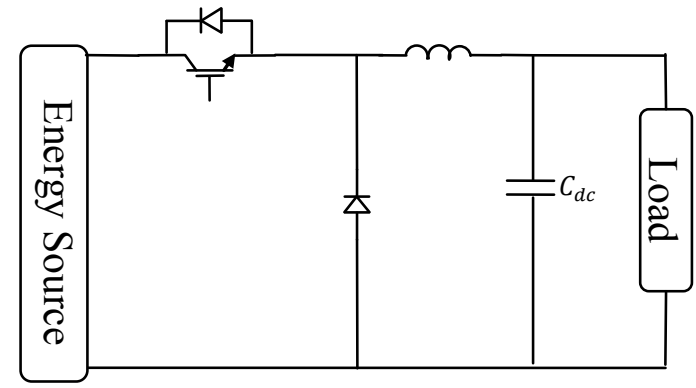

(b)

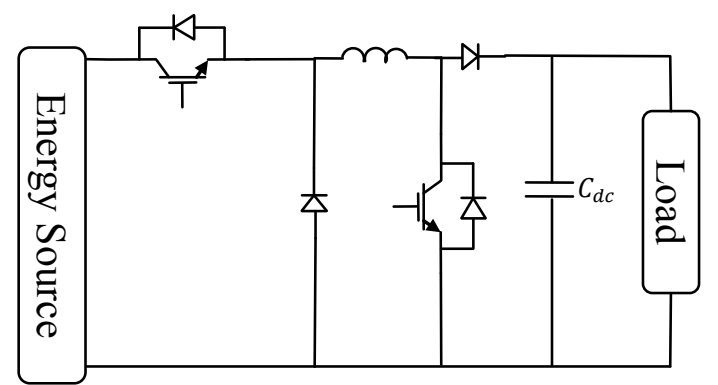

(d)

Figure 4-1 DC-DC Converter Topologies (a) Boost Converter (b) Buck Converter (c) Inverting Buck-Boost Converter (d) Noninverting Buck-Boost Converter

However, there is another non-inverting topology, which is essentially a buck converter that is cascaded with a boost converter, Figure 4-1(d). This circuit may be a second-order, or third order system depending on its mode of operation. 


\subsection{DC-DC Boost Converter Characteristics and Control}

This section will deliver a brief explanation of the control theory regarding DC-DC boost converters, as well as an explanation of the modes of operation, and characteristic operation. Firstly, there are two principles that are intrinsic to the analysis of the DC-DC boost converter. These principles are, the inductor Volt-Second Balance, and the Capacitor-Charge balance. Simplified, the inductor volt-second balance explains that in a steady state, the net change of current passing through an inductor over a single switching cycle, is zero. Hence, the total area of the voltage waveform of an inductor for one cycle (Volt-Seconds) is zero. In mathematical form, that is, since:

$$
\frac{d i_{L}(t)}{d t}=\int_{0}^{T_{S}} v_{L}(t) d t=0, \text { then } 0=\frac{1}{T_{S}} \int_{0}^{T_{S}} v_{L}(t) d t=\left\langle v_{L}\right\rangle
$$

The Capacitor-Charge Balance is similar to the Volt-Second Balance, except that it is in reference to the voltage across a capacitor. In mathematical form, that is, since:

$$
\frac{d v_{c}(t)}{d t}=\int_{0}^{T_{s}} i_{c}(t) d t=0, \text { then } 0=\frac{1}{T_{s}} \int_{0}^{T_{s}} i_{c}(t) d t
$$

Now that these principles are understood, the operation of the circuit can be considered. The operational characteristics of the boost converter can best be explained according to its three modes of operation. These three modes are named according to the current that is passing through the DC inductor. When the magnitude of current passing through the inductor is always positive (i.e. it never falls to zero), the converter is said to be operating in continuous current conduction mode or continuous conduction mode $(\mathrm{CCM})$ as it is more commonly known. If the magnitude of the current falls to zero for 
some period of time during a switching cycle, then the converter is operating in Discontinuous Conduction Mode (DCM). Although there is a situation where the current falls to zero exactly at the end of the switching cycle, this is not considered to be an operational mode, but rather a boundary condition. The control scheme of the boost converter is linked directly to its mode of operation; therefore, the control will be explained for the two modes of operation in the following subsection. However, since the DC-DC module used in this research is based on a DC-DC boost converter that is operating in DCM, this mode of operation, and its control will be considered more thoroughly.

\subsubsection{DC-DC Boost Converter Modes of Operation}

The DC-DC boost converter is a non-linear circuit. Therefore, analysis this circuit is not simple. However there are some techniques, such as "State-Space Averaging" [4648], and "Average Switch Modeling”[49-54], which makes the task less difficult. If the semiconductor devices can be considered to be ideal switches, then the circuit can be analyzed by separating the non-linear switching circuit into individual linear circuits, according to the state of the switches (see Figure 4-2).

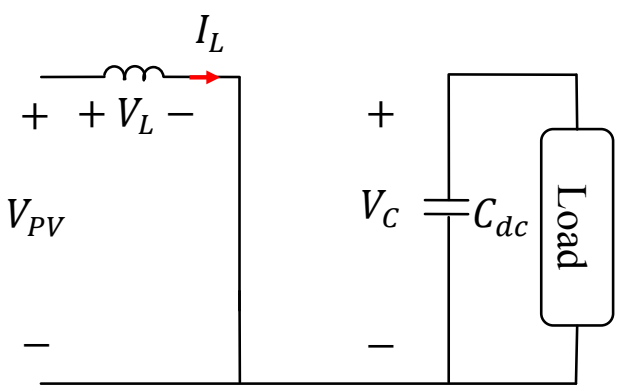

(a)

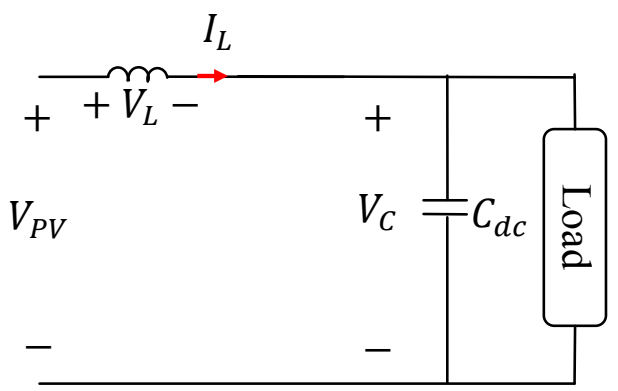

(b)

Figure 4-2 Switch states for a DC-DC Boost converter 
When the switch is closed, the DC power source is shorted across the inductor. Therefore, if the inductor is assumed to be ideal, the current flow increases at a linear rate. Once the switch opens, the current in the inductor cannot instantaneously change to zero. Thus, it continues to flow out of the inductor, and into the output stage of the converter. When the average of the current flowing through the inductor is greater than one half of the peak current flowing through the inductor, the converter can be said to be operating in CCM.

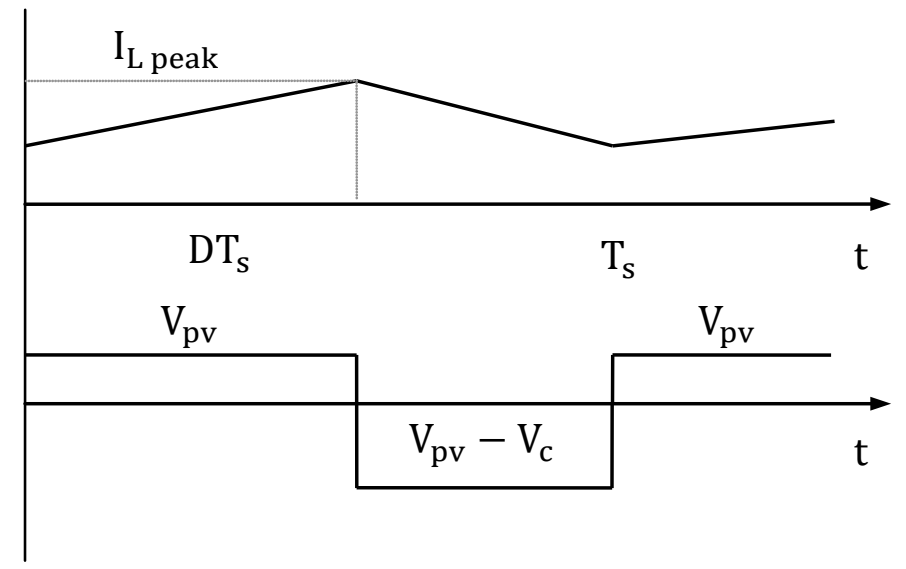

\section{Figure 4-3 Current and voltage waveforms of the DC inductor in Continuous Conduction Mode (CCM)}

Explained mathematically, if: $I_{L}>\frac{1}{2} i_{L, p e a k}$, where $i_{L, p e a k}=\frac{V_{d} D T_{S}}{L}, T_{S}$ is the switching period, $V_{d}$ is the source voltage, and $D$ is the duty cycle ratio, then the currents and voltages of the inductor are similar to those depicted in Figure 4-3.

In this mode of operation, the voltage gain of the circuit can be expressed as:

$$
\frac{V_{C}}{V_{p v}}=\frac{1}{1-D}
$$


When the average of the current flowing through the inductor is equal to one-half of the peak current flowing through the inductor, the converter can be said to be in its boundary operation. The inductor currents and voltages during this mode are visible in Figure 4-4.

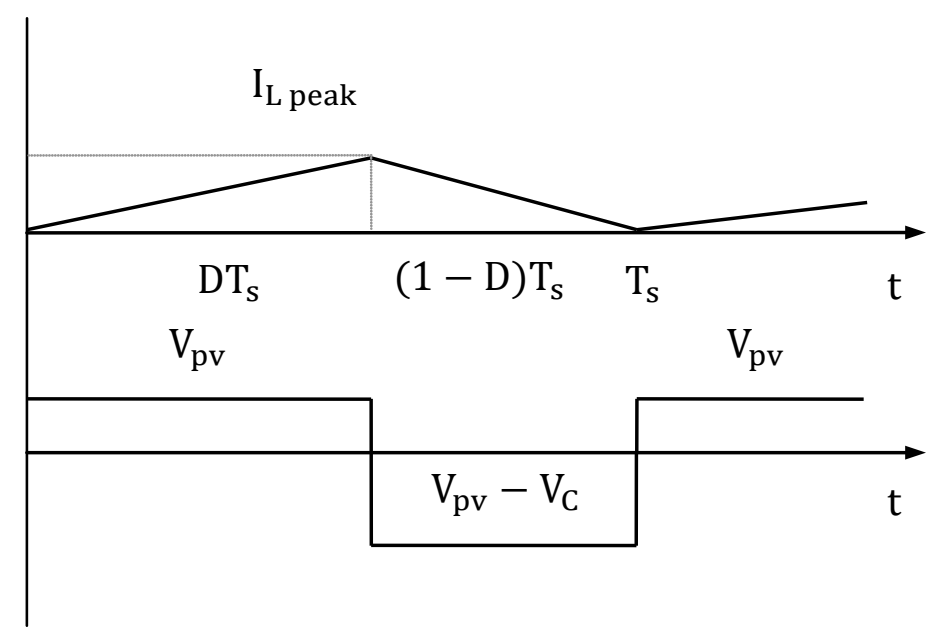

Figure 4-4 Inductor Voltages and Currents in Boundary Operation

During boundary operation,

$$
I_{L}=\frac{1}{2} i_{L, \text { peak }}=\frac{1}{2}\left(\frac{I_{D}}{L}\right) D T_{S}
$$

therefore the voltage gain is still equal to:

$$
\frac{V_{C}}{V_{p v}}=\frac{1}{1-D}
$$

From the previous equations, the boundary inductor current can be evaluated to be:

$$
I_{L B}=\frac{V_{O} T_{S}}{2 L} D(1-D)
$$

The output current is not equal to the inductor current; however, the boundary output current can be calculated from the current gain, and the previous equation to be: 


$$
I_{O B}=\frac{V_{O} T_{S}}{2 L} D(1-D)^{2}
$$

If the partial derivative of the output current is taken with respect to the duty cycle ratio, and equated to zero, the duty cycle at which $\left(I_{O B}\right)_{\max }$ will occur can be determined. Explained mathematically, if

$$
\frac{\partial I_{O B}}{\partial D}=\frac{V_{O} T_{S}}{2 L}\left[(1-D)^{2}-2 D(1-D)\right]=0, \text { then }\left(I_{O B}\right)_{\max } \text { occurs at } D=\frac{1}{3}
$$

$$
\text { Since }\left(I_{O B}\right)_{\max } \text { occurs at } D=\frac{1}{3},\left(I_{O B}\right)_{\max }=\left(\frac{2}{27}\right) \frac{V_{O} T_{S}}{L}
$$

The previous equation defines the maximum output current that the converter can drive before moving into continuous conduction mode. In addition, it defines the minimum average level of current that the converter can drive before moving into discontinuous conduction mode.

The final mode of operation, and the most important to this research effort, is the discontinuous conduction mode. The switching states when in DCM are visible in Figure 4-5. When a DC-DC converter is operating with a very small load, or if the output voltage is very high, such as in the studied system, the converter will go into DCM. During this mode of operation, there are actually three distinct switching states, when the switch is closed, when the switch is open, and when the inductor current falls to zero and the diode becomes reverse-biased. In this mode, the current falls to zero for a period in the switching cycle. The inductor voltage and current is shown in Figure 4-6. 


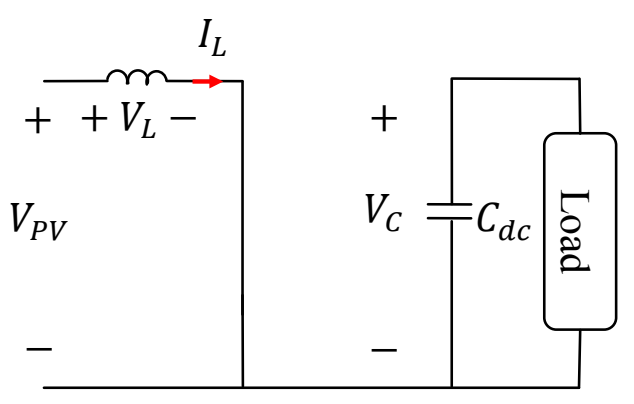

(a)

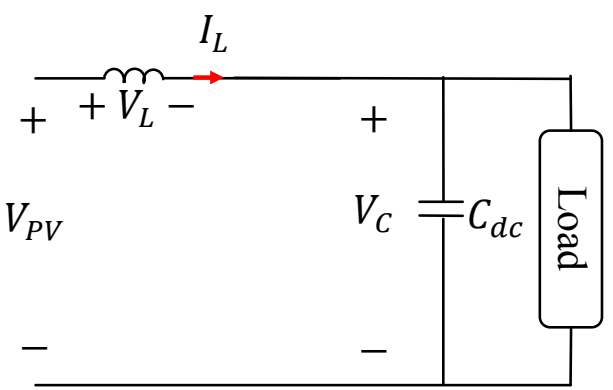

(b)

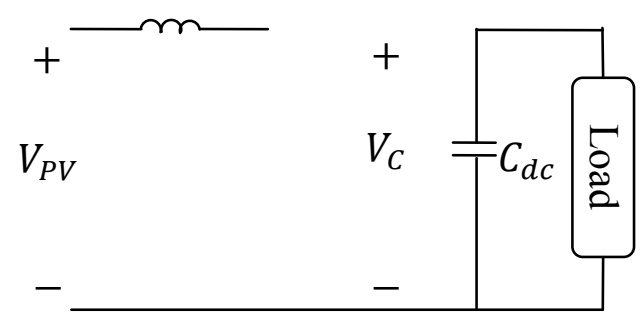

(c)

Figure 4-5 Switching States in Discontinuous Conduction Mode

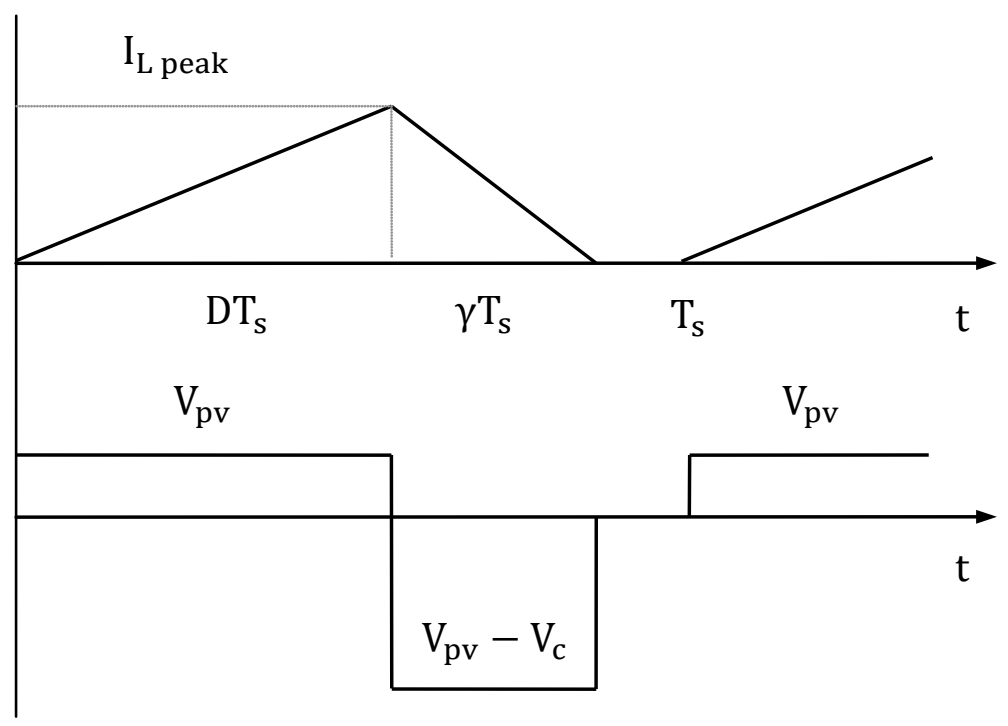




\section{Figure 4-6 Current and voltage waveforms of the DC inductor in Discontinuous Conduction Mode (DCM)}

If the voltage across the inductor is integrated for one time period, and equated to zero, the following equation results:

$$
\mathrm{V}_{\mathrm{pv}} \mathrm{DT}_{\mathrm{S}}+\left(\mathrm{V}_{\mathrm{pv}}-\mathrm{V}_{\mathrm{c}}\right) \gamma \mathrm{T}_{\mathrm{s}}=0
$$

where the value $\gamma$ is a fraction of the switching cycle. From this equation, the voltage gain can be expressed as:

$$
\frac{\mathrm{V}_{\mathrm{c}}}{\mathrm{V}_{\mathrm{pv}}}=\frac{\gamma+\mathrm{D}}{\gamma}
$$

and, assuming ideal components, the current gain can be expressed as:

$$
\frac{\mathrm{I}_{0}}{\mathrm{I}_{\mathrm{L}}}=\frac{\gamma}{\gamma+\mathrm{D}}
$$

where $\mathrm{I}_{0}$ is equal to the load current. The average input current is equal to the inductor current, which is:

$$
I_{L}=\frac{V_{p v}}{2 L} D T_{s}(D+\gamma)
$$

From the previous two equations, the average output current can be calculated to be:

$$
I_{O}=\frac{T_{S} V_{p v}}{2 L} D \gamma
$$

The output voltage of a DC-DC converter is usually desired to be constant. Therefore, it is typically more practical to determine the duty cycle ratio as a function of the voltage gain, therefore: 


$$
D=\left[\frac{4}{27} \frac{V_{c}}{V_{p v}}\left(\frac{V_{C}}{V_{p v}}-1\right) \frac{I_{O}}{\left(I_{O B}\right)_{\max }}\right]^{\frac{1}{2}}
$$

However, for the purposes of this effort, it is more important to solve for the fractional period $\gamma$, where:

$$
\gamma=\frac{2 L I_{O}}{D T_{S} V_{p v}}
$$

\subsubsection{DC-DC Boost Converter Dynamic Analysis (State-Space Averaging)}

In the following chapter, a comprehensive analysis of the discontinuous conduction mode of the DC-DC module in the hybrid motor drive prototype will be performed, ergo, only the dynamical analysis of the continuous conduction mode is performed here. Looking back to Figure 4-2, it can be seen that if KCL is applied for each of the individual switch states during $\mathrm{CCM}$, then for $0<t<\mathrm{DT}_{\mathrm{S}}$ :

$$
\left\{\begin{array}{l}
\frac{d i_{L}}{d t}=\frac{1}{L} v_{p v} \\
\frac{d v_{c}}{d t}=-\frac{1}{C} i_{O}
\end{array}\right.
$$

and for $\mathrm{DT}_{\mathrm{S}}<t<\mathrm{T}_{\mathrm{S}}$ :

$$
\left\{\begin{array}{l}
\frac{d i_{L}}{d t}=-\frac{1}{L} v_{C}+\frac{1}{L} v_{p v} \\
\frac{d v_{C}}{d t}=-\frac{1}{C} i_{O}+\frac{1}{C} i_{L}
\end{array}\right.
$$

Using State-Space Averaging, the two sets of differential equations can be combined as: 


$$
\left\{\begin{array}{l}
\frac{d i_{L}}{d t}=-\frac{1}{L}(1-u) v_{c}+\frac{1}{L} v_{p v} \\
\frac{d v_{c}}{d t}=-\frac{1}{C} i_{O}+\frac{1}{C} i_{L}(1-u)
\end{array}\right.
$$

Where $\mathrm{u}$ is 0 , or 1 depending on the switch state. If new variables are defined as $\mathrm{x}_{1}=\mathrm{i}_{\mathrm{L}} \sqrt{\mathrm{L}}$, and $\mathrm{x}_{2}=\mathrm{v}_{\mathrm{c}} \sqrt{\mathrm{C}}$. The previous pair of differential equations can be rewritten,

$$
\left\{\begin{array}{l}
\frac{d x_{1}}{d t}=-\omega_{0}(1-u) x_{2}+\beta_{1} v_{p v} \\
\frac{d x_{2}}{d t}=-\omega_{0}(1-u) x_{1}+\beta_{2} i_{p v}
\end{array}\right.
$$

where $\omega_{0}=\frac{1}{\sqrt{L C}}, \beta_{1}=\frac{1}{\sqrt{L}}$, and $\beta_{2}=\frac{1}{\sqrt{C}}$.

If the load is represented a resistance $\mathrm{R}$, then the previous equations can be rewritten as:

$$
\left\{\begin{array}{l}
\frac{d x_{1}}{d t}=-\omega_{0}(1-u) x_{2}+\beta_{1} v_{p v} \\
\frac{d x_{2}}{d t}=-\omega_{0}(1-u) x_{1}+\left(\frac{1}{R C}\right) x_{2}
\end{array}\right.
$$

The next step is to average the equations over one cycle $\mathrm{T}_{\mathrm{S}}$. This results in the following:

$$
\begin{aligned}
& \frac{d}{d t}\left\{\frac{1}{T_{S}} \int_{0}^{T_{S}} x_{1} d t\right\}=-\omega_{0}\left\{\frac{1}{T_{S}} \int_{0}^{T_{S}}(1-u) x_{2} d t\right\}+\beta_{1}\left\{\frac{1}{T_{S}} \int_{0}^{T_{S}} v_{p v} d t\right\} \\
& \frac{d}{d t}\left\{\frac{1}{T_{S}} \int_{0}^{T_{S}} x_{2} d t\right\}=-\omega_{0}\left\{\frac{1}{T_{S}} \int_{0}^{T_{S}}(1-u) x_{1} d t\right\}+\left(\frac{1}{R C}\right)\left\{\frac{1}{T_{S}} \int_{0}^{T_{S}} x_{2} d t\right\}
\end{aligned}
$$

If $x_{1}$ and $x_{2}$ can be said to relatively constant for over a single cycle, then they can be said to be averaged. That is, $x_{1} \approx\left\langle x_{k}\right\rangle$, then the following can be said:

$$
\left\{\frac{1}{T_{S}} \int_{0}^{T_{S}}(1-u) x_{k} d t\right\} \approx(1-D)\left\langle x_{k}\right\rangle
$$

where $\mathrm{k}=1,2,3 \ldots$ 
Utilizing the derivations above, the final State-Space equations for a DC-DC boost converter in $\mathrm{CCM}$ can be expressed as:

$$
\frac{d}{d t}\left[\begin{array}{l}
\left\langle x_{1}\right\rangle \\
\left\langle x_{2}\right\rangle
\end{array}\right]=\left[\begin{array}{cc}
0 & -\omega_{0}(1-D) \\
-\omega_{0}(1-D) & \left(\frac{1}{R C}\right)
\end{array}\right]\left[\begin{array}{l}
\left\langle x_{1}\right\rangle \\
\left\langle x_{2}\right\rangle
\end{array}\right]+\left[\begin{array}{c}
\frac{1}{\sqrt{L}} \\
0
\end{array}\right] v_{D}
$$

From the State-Space model, the characteristic equation of the circuit can be determined to be:

$$
s^{2}-\left(\frac{1}{R C}\right) s+\omega_{0}^{2}(1-D)^{2}=0
$$

where the system natural frequency is $\omega_{n}=\frac{(1-D)}{\sqrt{L C}}$, and $\xi=\left(\frac{\sqrt{L / C}}{2 R(1-D)}\right)$.

\subsection{Applications in Hybrid Drive Systems}

The DC-DC module in the Hybrid Motor Drive system is essentially a modified version of a DC-DC boost converter. Although standard boost converters are typically stand-alone units that serve to power resistive loads, the DC-DC module is not capable of being used as a stand-alone device because it does not have any integrated capacitors. By using the design guidelines laid out in the following chapter, along with the essential system concepts outlined in this chapter, one can easily convert almost any motor drive into a hybrid motor drive. The relatively simple design is an asset of this system, because as long as access to the DC bus is available in a motor drive, that motor drive can be converted to a Hybrid Motor Drive without the need of a complete redesign. One of the drawbacks of the DC-DC module that is typical of converters that are operating in DCM, 
is that the voltage and current stresses experienced by the semiconductor switches are much higher than those experienced in systems that are operating in CCM. However, the voltage gain in CCM is not sufficient to reach the levels of the DC bus voltage, unless the input voltage of the DC-DC module is much higher than that of the typical PV panel. Although the option to connect a number of PV panels in series to boost the input voltage is available, there will be a tradeoff between the DC-DC module cost and the higher cost of the PV array. In addition, depending on the current level required, it may be necessary to double, or even triple the number of panels in order to provide a sufficient current. 


\section{CHAPTER 5}

\section{Design AND CONTROL OF THE DC-DC MOdULE}

\subsection{System Overview}

The functional block diagram of the case study hybrid solar-based adjustable-speed pump is depicted in Figure 5-1. The system consists of a $4 \mathrm{~kW}$ DC power supply, a DC-DC module, a $2.5 \mathrm{hp} 3150 \mathrm{rpm}$ brushless permanent magnet motor, an adjustable speed drive and a water pump, see Figure 5-1 and Figure 5-2. Moreover, a dSPACE CLP 1104 controller board and Simulink is used to control the DC-DC module duty cycle ratio. The DC power supply is a high-power switching power supply rated for $125 \mathrm{VDC}$ and $32 \mathrm{~A}$. For this particular application, the supply is programmed to be between 0 and 100VDC with a maximum average of $21 \mathrm{~A}$. The power supply is also programmed to behave like a solar array by adjusting the output to match an $\mathrm{i}-\mathrm{v}$ curve that is typical to solar modules.

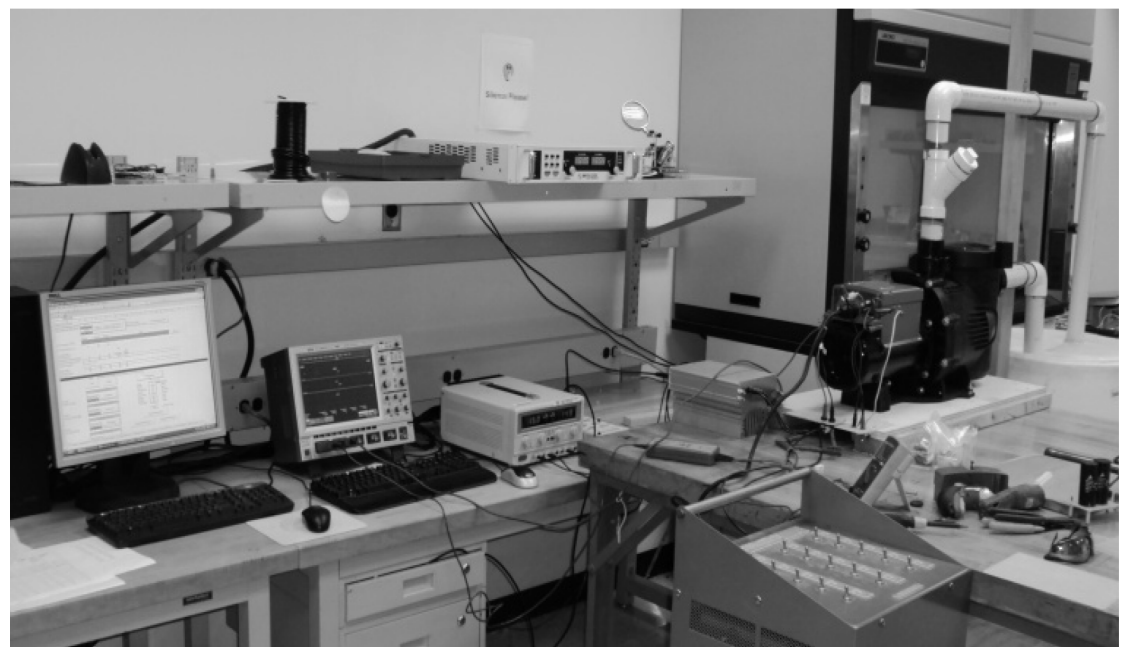

Figure 5-1 Solar-based Hybrid Motor Drive Test Setup. 
The relationship between motor output and motor speed is given by $P_{\text {out }}=$ $\left(n / n_{\text {rated }}\right) P_{\text {rated }}$ excluding the motor losses, i.e. the motor draws between $200 \mathrm{~W}$ and $250 \mathrm{~W}$ at $1500 \mathrm{rpm}$. The drive input terminals are rated for a single-phase $230 \mathrm{Vac}$ and the DCbus typically operates in the range of $290-340 \mathrm{~V}$, which also varies with motor speed (load). However, the DC-bus voltage can be stabilized using the DC-DC module where it becomes independent of the motor speed.

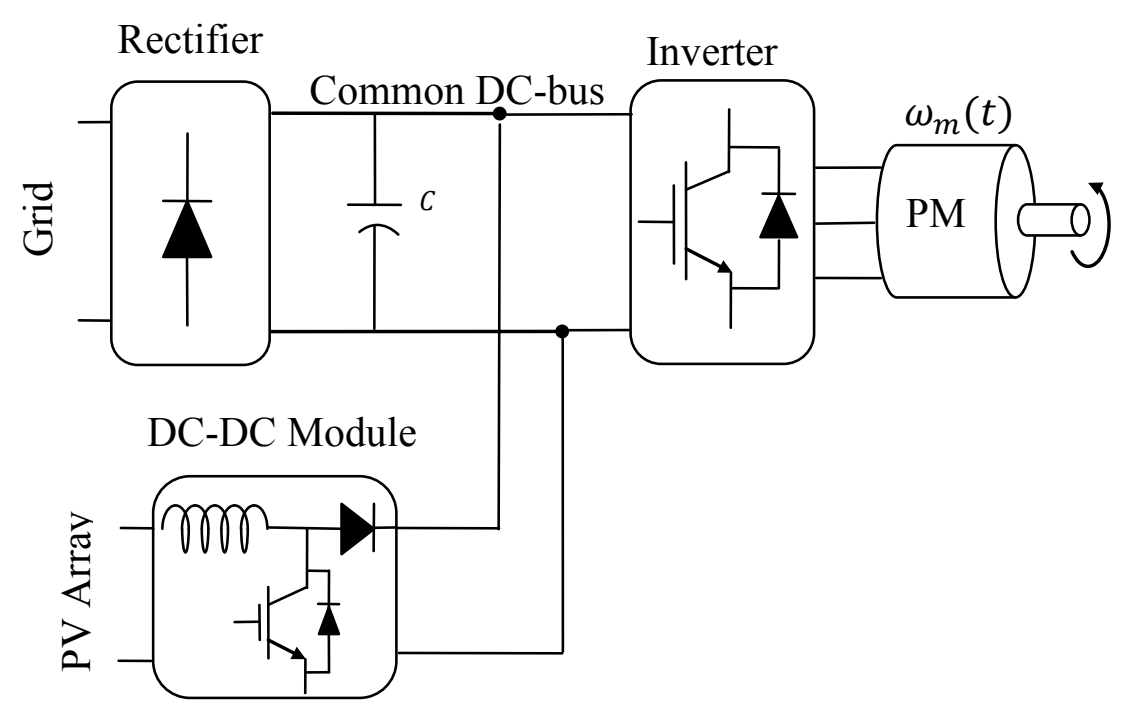

Figure 5-2 Hybrid Solar Motor Drive Block Diagram

The PV array emulator is connected to the input terminals of the DC-DC module, and the output terminals of the module are connected directly to the DC-bus of the variable frequency drive, see Figure 5-1 and Figure 5-2. Notice that the combination of the module and DC-bus capacitors constitutes a DC-DC boost converter. The converter utilizes the voltage sensor that is present at the output of the module as a feedback reference to regulate the duty cycle ratio of the boost converter. Accurate control of 
IGBT's duty cycle ratio becomes an important issue in this system, because there can be a tendency for the DC-bus voltage of the drive to increase to destructive levels if the duty cycle ratio exceeds the level that is necessary for the proper operation of the pump. This is most obvious during deceleration of the pump motor, and the consequences of a slow, inaccurate control method will be discussed in the next section.

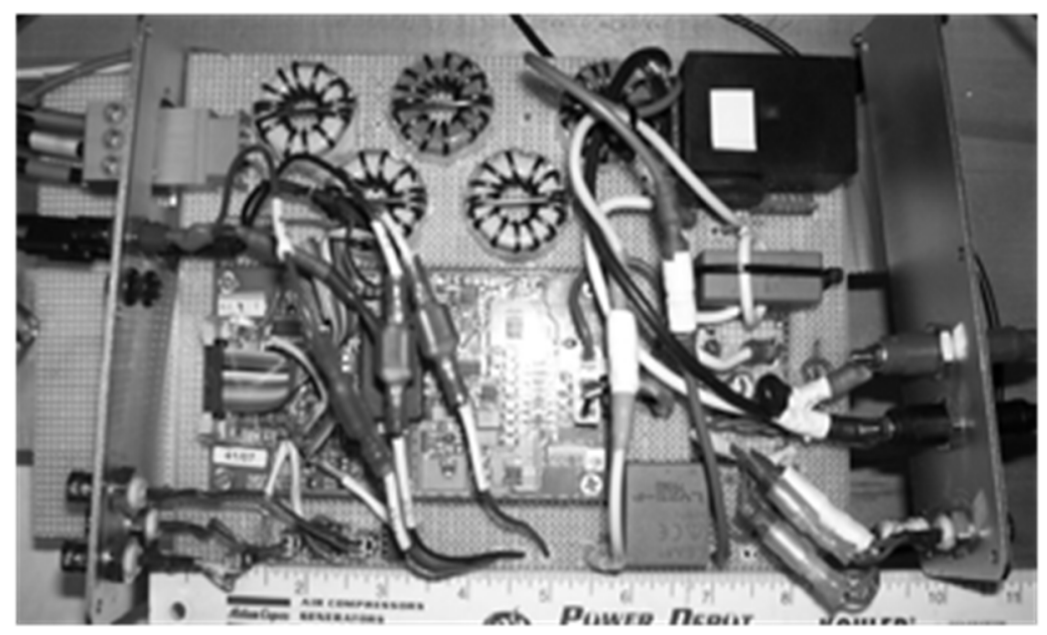

Figure 5-3 Original prototype of the DC-DC module (the physical size of the module; 8 L-6W-2.1H inches).

\subsection{The PV-DC-DC Module Developed Power}

In the hybrid motor-drives, the main objective is to minimize the number of PV panels in order to maintain the capital cost of installations as low as possible. Thus, the DC-DC boost converter is required to operate in discontinuous conduction mode. This is due to the fact that a high output-input voltage ratio can be achieved at lower duty cycle ratios in discontinuous conduction mode than in a continuous mode. Meanwhile, this discontinuous conduction mode of operation has a better stability feature than the 
continuous conduction mode of operation. and the fact that $L\left(d i_{L} / d t\right)=v_{L}$ for an inductor, the following equations can be written:

$$
\begin{gathered}
\left(L I_{\text {Lpeak }}\right) /\left(D T_{S}\right)=V_{p v} \\
\left(L I_{\text {Lpeak }}\right) /\left(\gamma T_{S}\right)=V_{c}-V_{p v} \\
I_{\text {Lmean }}=\frac{1}{2} I_{\text {Lpeak }}(D+\gamma)
\end{gathered}
$$

where, $I_{\text {Lmean }}$ and $I_{\text {Lpeak }}$ are respectively the average and the peak current of the DC-DC module inductor. Using (1) through (3) and neglecting the system losses, the average output power of the PV-DC-DC module can be obtained as follows:

$$
P_{\text {out }}=\left(\frac{T_{s} D^{2}}{2 L}\right)\left(V_{p v}^{2}\right) /\left(1-\left(V_{p v} / V_{c}\right)\right)
$$

where, $T_{s}=1 / f_{s}$ is the DC-DC module switching period, $D=t_{o n} / T_{s}$ is the switching duty cycle ratio, $V_{p v}$ is the $\mathrm{PV}$ array voltage, and $V_{c}$ is the DC-bus voltage. Notice that capacitance is not present in this equation, which is different from the equations that describe the behavior of typical boost converters. In this hybrid system, the minimum level of output voltage, $V_{c}$, is inherently regulated by the grid voltage; given that the grid contributes to the potential energy at the DC-bus. Thus, $V_{c}$ is obtained from $V_{c} \cong(k / \pi) V_{g}$ 
in which $V_{g}$ is the grid rms phase-voltage, and $k$ is respectively equal to $2 \sqrt{2}$ and $3 \sqrt{6}$ for a single-phase (grid) input and three-phase bridge rectifier, operating under steady-state conditions.

The capability of PV array and the peak current of the DC-DC module inductor are the major restriction factors in order to achieve the output power, which is indicated in (5-4). Furthermore, the intersection point of PV characteristic and PV-DC-DC module output power, see Figure (5-4), indicates the system operating point. In other words, the initial value of the switching duty cycle, D, for any maximum power point tracking (MPPT) algorithm can be obtained from (5-4), for solar-based hybrid motor-drives, see Figure 5-4.

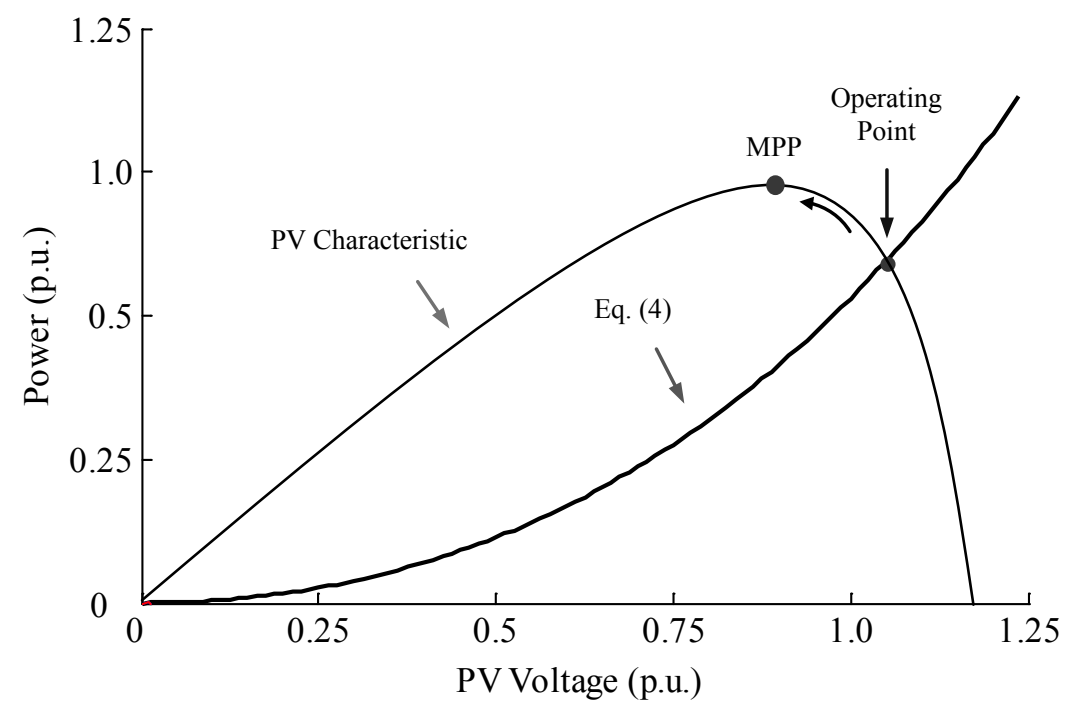

Figure 5-4 PV Characteristic and Eq. (5-4) intersection indicates the operating point of the hybrid motor-drive system

At this point, it should be specified that although it is well understood that it is possible to share power between converters with a common DC-link, this power sharing 
has not been characterized. Also, the equation (5-4) does not exist in any available literature, aside from a paper previously published by these authors. It should also be specified that although the DC-DC module is a modified DC-DC boost converter there are differences in the behavior of the circuit that distinguish the operation of this circuit from that of the standard DC-DC boost converter. For example, in a typical DC-DC converter, the discontinuous mode of operation is a function of the load, although it should be noted that there are some converters design to operate specifically in discontinuous mode. In this circuit, the load is only irrelevant to the mode operation and is only relevant in regard to the amplitude of the DC bus voltage. The DC-DC module will operate in discontinuous mode regardless of the load, and if the switching pattern of the module, or the module inductance is changed in such a fashion as to move the module into a continuous mode of operation, the module will no longer contribute power to the DC bus. This is demonstrated in (5-4), where an increase in the input inductance will result in a decrease in the output power if the other parameters remain constant. This characteristic is also shown later in Figure 6-3, where the output power is shown for various levels of inductance. In addition, it can be seen in (5-4) that a reduction in the switching frequency will result in a proportional reduction in the output power of the module.

\subsection{Hybrid Drive DC-DC Module Dynamics}

By integrating the line voltage over a half cycle, the state-space representation of the single-phase bridge rectifier can be analyzed for highly discontinuous currents. In 
addition, the state-space representation of the DC-DC boost converter can be represented through state-space averaging. If the duty ratio of the DC-DC boost converter is assumed to be constant for a half-cycle, then the two state-space representations can be combined through the procedure below. By averaging the circuit over a half cycle of the fundamental frequency, and the separating the individual switching states of the converter, as well as the states of the rectifier, the two state-space representations can be combined into a single set of state-space equations. For simplicity, a resistance has replaced the pump load.

Step $\# 1, t_{b}<t<t_{f}$, the bridge rectifier is conducting, and the switch in the converter is closed, and the converter diode is not conducting.

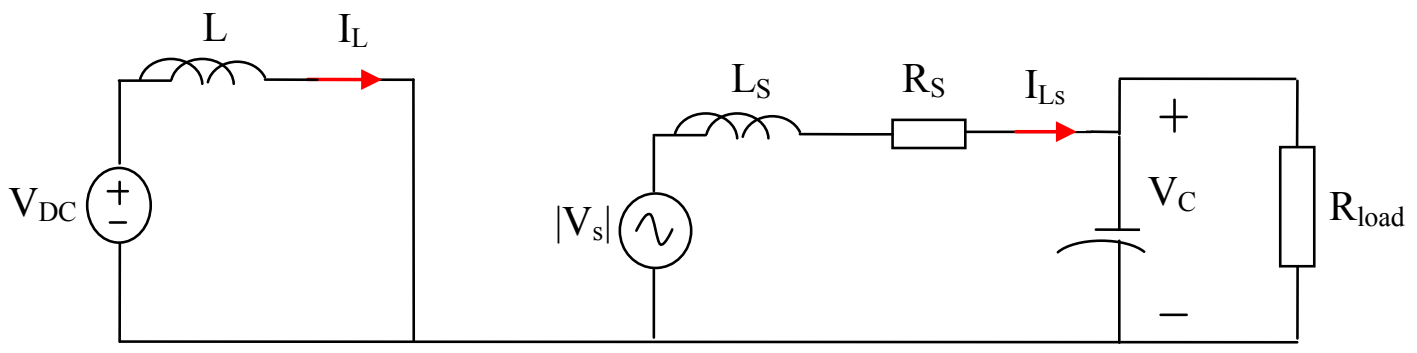

Figure 5-5 Step \#1, $t_{b}<t<t_{f}$

$$
\begin{aligned}
& {\left[\begin{array}{c}
\frac{d i_{L}}{d t} \\
\frac{d i_{L_{S}}}{d t} \\
\frac{d v_{C}}{d t}
\end{array}\right]=\left[\begin{array}{ccc}
0 & 0 & 0 \\
0 & \frac{-R_{S}}{L_{S}} & \frac{-1}{L_{S}} \\
0 & \frac{1}{C} & \frac{-1}{C R_{\text {load }}}
\end{array}\right]\left[\begin{array}{c}
i_{L} \\
i_{L_{S}} \\
v_{C}
\end{array}\right]+\left[\begin{array}{cc}
\frac{1}{L} & 0 \\
0 & \frac{1}{L_{S}} \\
0 & 0
\end{array}\right]\left[\begin{array}{l}
v_{d c} \\
\left|v_{S}\right|
\end{array}\right]} \\
& y_{1}(t)=\left[\begin{array}{lll}
0 & 0 & 1
\end{array}\right]\left[\begin{array}{c}
i_{L} \\
i_{L_{S}} \\
v_{C}
\end{array}\right]
\end{aligned}
$$


Step $\# 2, t_{b}<t<t_{f}$, the bridge rectifier is conducting, and the switch in the converter is open, and the converter diode is conducting.

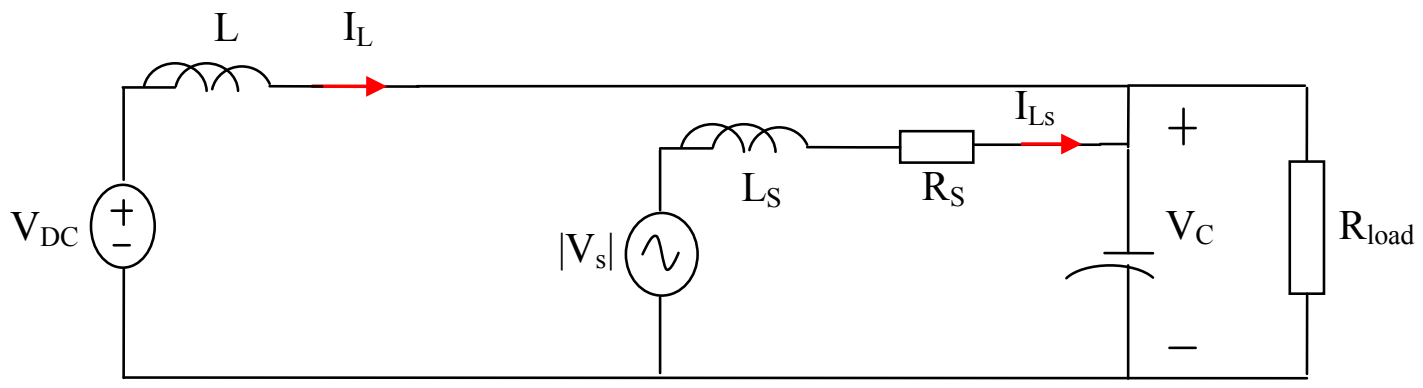

Figure 5-6 Step \#2, $t_{b}<t<t_{f}$

$$
\begin{aligned}
& {\left[\begin{array}{c}
\frac{d i_{L}}{d t} \\
\frac{d i_{L_{S}}}{d t} \\
\frac{d v_{C}}{d t}
\end{array}\right]=\left[\begin{array}{ccc}
0 & 0 & \frac{-1}{L} \\
0 & \frac{-R_{S}}{L_{S}} & \frac{-1}{L_{S}} \\
-\frac{1}{C} & \frac{1}{C} & \frac{-1}{C R_{\text {load }}}
\end{array}\right]\left[\begin{array}{c}
i_{L} \\
i_{L_{S}} \\
v_{C}
\end{array}\right]+\left[\begin{array}{cc}
\frac{1}{L} & 0 \\
0 & \frac{1}{L_{S}} \\
\frac{-1}{L} & 0
\end{array}\right]\left[\begin{array}{l}
v_{d c} \\
\left|v_{S}\right|
\end{array}\right]} \\
& y_{2}(t)=\left[\begin{array}{lll}
0 & 0 & 1
\end{array}\right]\left[\begin{array}{l}
i_{L} \\
i_{L_{S}} \\
v_{C}
\end{array}\right]
\end{aligned}
$$

Step \#3, $\mathrm{t}_{\mathrm{b}}<\mathrm{t}<\mathrm{t}_{\mathrm{f}}$, the bridge rectifier is conducting, and the switch in the converter is closed, and the converter diode has stopped conducting.

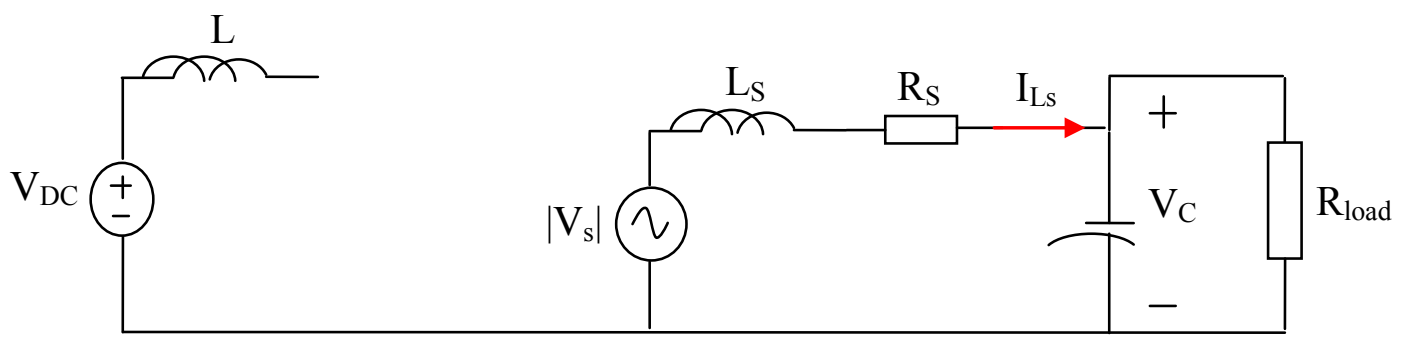

Figure 5-7 Step \#3, $t_{b}<t<t_{f}$ 


$$
\begin{aligned}
& {\left[\begin{array}{c}
\frac{d i_{L}}{d t} \\
\frac{d i_{L_{S}}}{d t} \\
\frac{d v_{C}}{d t}
\end{array}\right]=\left[\begin{array}{ccc}
0 & 0 & 0 \\
0 & \frac{-R_{S}}{L_{S}} & \frac{-1}{L_{S}} \\
0 & \frac{1}{C} & \frac{-1}{C R_{\text {load }}}
\end{array}\right]\left[\begin{array}{c}
i_{L} \\
i_{L_{S}} \\
v_{C}
\end{array}\right]+\left[\begin{array}{cc}
0 & 0 \\
0 & \frac{1}{L_{S}} \\
0 & 0
\end{array}\right]\left[\begin{array}{l}
v_{d c} \\
\left|v_{S}\right|
\end{array}\right]} \\
& y_{3}(t)=\left[\begin{array}{lll}
0 & 0 & 1
\end{array}\right]\left[\begin{array}{c}
i_{L} \\
i_{L_{S}} \\
v_{C}
\end{array}\right]
\end{aligned}
$$

Step $\# 4, \mathrm{t}_{\mathrm{f}}<\mathrm{t}<\mathrm{t}_{\mathrm{b}}+\mathrm{T} / 2$, the bridge rectifier is not conducting, and the switch in the converter is closed, and the converter diode is not conducting.

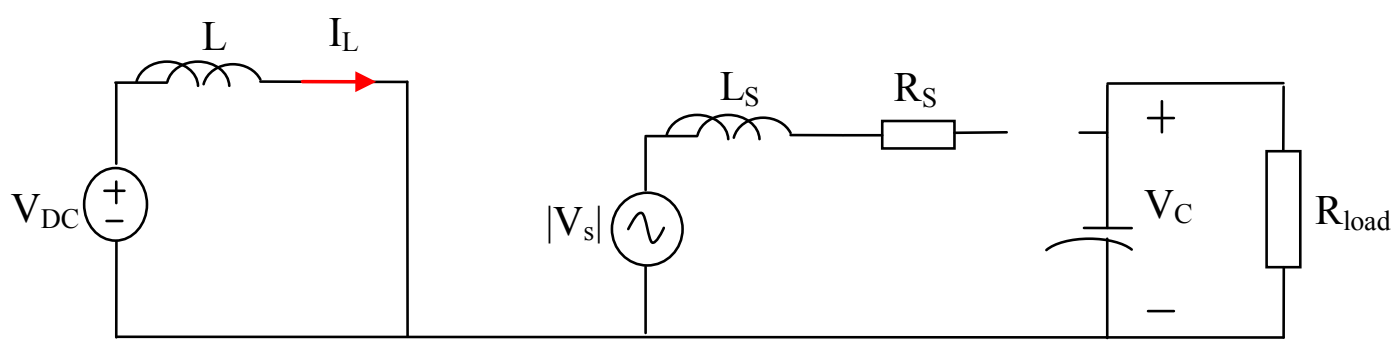

Figure 5-8 Step \#4, $t_{\mathrm{f}}<\mathrm{t}<\mathrm{t}_{\mathrm{b}}+\mathrm{T} / 2$

$$
\begin{aligned}
& {\left[\begin{array}{c}
\frac{d i_{L}}{d t} \\
\frac{d i_{L_{S}}}{d t} \\
\frac{d v_{C}}{d t}
\end{array}\right]=\left[\begin{array}{lll}
0 & 0 & 0 \\
0 & 0 & 0 \\
0 & 0 & \frac{-1}{C R_{\text {load }}}
\end{array}\right]\left[\begin{array}{c}
i_{L} \\
i_{L_{S}} \\
v_{C}
\end{array}\right]+\left[\begin{array}{cc}
\frac{1}{L} & 0 \\
0 & 0 \\
0 & 0
\end{array}\right]\left[\begin{array}{l}
v_{d c} \\
\left|v_{S}\right|
\end{array}\right]} \\
& y_{3}(t)=\left[\begin{array}{lll}
0 & 0 & 1
\end{array}\right]\left[\begin{array}{c}
i_{L} \\
i_{L_{S}} \\
v_{C}
\end{array}\right]
\end{aligned}
$$

Step $\# 5, \mathrm{t}_{\mathrm{f}}<\mathrm{t}<\mathrm{t}_{\mathrm{b}}+\mathrm{T} / 2$, the bridge rectifier is not conducting, and the switch in the converter is open, and the converter diode is conducting. 


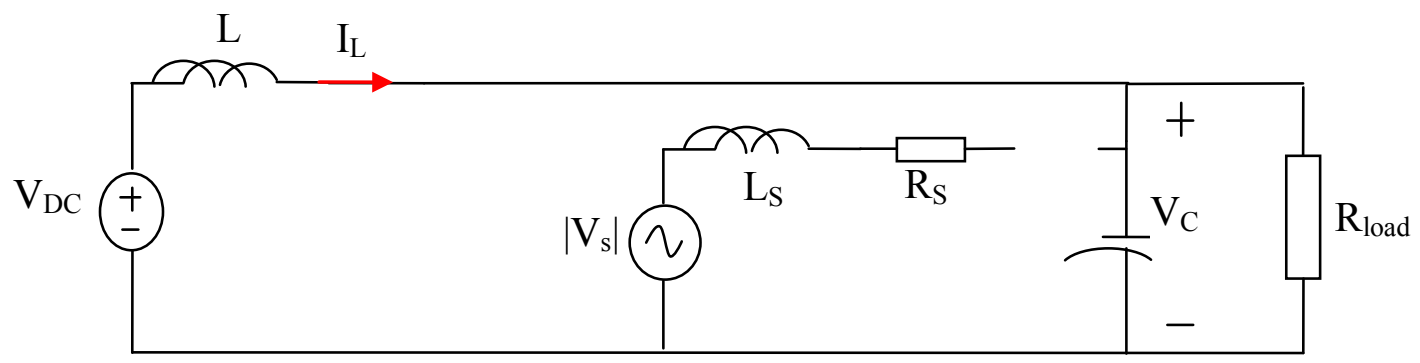

Figure 5-9 Step \#5, $\mathbf{t}_{\mathrm{f}}<\mathbf{t}<\mathbf{t}_{\mathrm{b}}+\mathbf{T} / \mathbf{2}$

$$
\begin{gathered}
{\left[\begin{array}{c}
\frac{d i_{L}}{d t} \\
\frac{d i_{L_{S}}}{d t} \\
\frac{d v_{C}}{d t}
\end{array}\right]=\left[\begin{array}{ccc}
0 & 0 & \frac{-1}{L} \\
0 & 0 & 0 \\
0 & 0 & \frac{-1}{C R_{\text {load }}}
\end{array}\right]\left[\begin{array}{c}
i_{L} \\
i_{L_{S}} \\
v_{C}
\end{array}\right]+\left[\begin{array}{cc}
\frac{1}{L} & 0 \\
0 & 0 \\
0 & 0
\end{array}\right]\left[\begin{array}{c}
v_{d c} \\
\left|v_{S}\right|
\end{array}\right]} \\
y_{3}(t)=\left[\begin{array}{lll}
0 & 0 & 1
\end{array}\right]\left[\begin{array}{c}
i_{L} \\
i_{L_{S}} \\
v_{C}
\end{array}\right]
\end{gathered}
$$

Step $\# 6, \mathrm{t}_{\mathrm{f}}<\mathrm{t}<\mathrm{t}_{\mathrm{b}}+\mathrm{T} / 2$, the bridge rectifier is not conducting, and the switch in the converter is open, and the converter diode is not conducting.
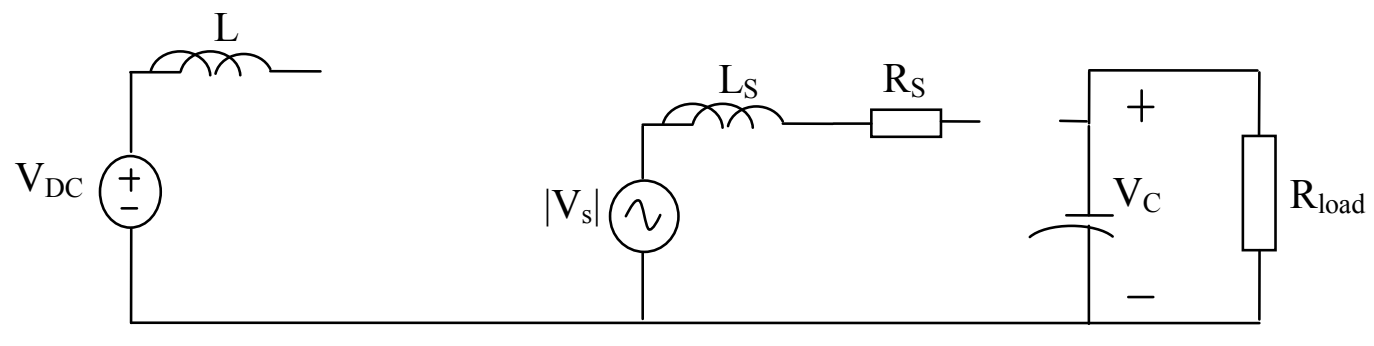

Figure 5-10 Step \#6, $\mathbf{t}_{\mathbf{f}}<\mathbf{t}<\mathbf{t}_{\mathbf{b}}+\mathbf{T} / 2$

$$
\begin{aligned}
& {\left[\begin{array}{c}
\frac{d i_{L}}{d t} \\
\frac{d i_{L_{S}}}{d t} \\
\frac{d v_{C}}{d t}
\end{array}\right]=\left[\begin{array}{llc}
0 & 0 & 0 \\
0 & 0 & 0 \\
0 & 0 & \frac{-1}{C R_{\text {load }}}
\end{array}\right]\left[\begin{array}{l}
i_{L} \\
i_{L_{S}} \\
v_{C}
\end{array}\right]+\left[\begin{array}{ll}
0 & 0 \\
0 & 0 \\
0 & 0
\end{array}\right]\left[\begin{array}{c}
v_{d c} \\
\left|v_{S}\right|
\end{array}\right]} \\
& y_{3}(t)=\left[\begin{array}{lll}
0 & 0 & 1
\end{array}\right]\left[\begin{array}{c}
i_{L} \\
i_{L_{S}} \\
v_{C}
\end{array}\right]
\end{aligned}
$$


The averaging technique for this system consists of two different averages. The first is an average over the switching cycle, and the second is an average over the period of the fundamental frequency. Since the period of the fundamental frequency is much greater than the period of the switching cycle, the error in the averaging of the switching cycle can be neglected if the duty ratio is considered to be constant over a half-cycle. From the previous work, the six state-space equations can now be be averaged.

If $d x_{n}(\mathrm{t})$ can be considered to be equal to for $n$ equal to one through six, then:

$$
\begin{aligned}
& \frac{d x(t)}{d t}=A_{1} x(t)+B_{1} u(t) \\
& \frac{d x(t)}{d t}=A_{2} x(t)+B_{2} u(t) \\
& \frac{d x(t)}{d t}=A_{3} x(t)+B_{3} u(t) \\
& \frac{d x(t)}{d t}=A_{4} x(t)+B_{4} u(t) \\
& \frac{d x(t)}{d t}=A_{5} x(t)+B_{5} u(t) \\
& \frac{d x(t)}{d t}=A_{6} x(t)+B_{6} u(t)
\end{aligned}
$$

Thus, one can write the following expressions which have been averaged:

$$
\begin{gathered}
A=\left(d_{1} A_{1}+d_{2} A_{2}+\left(1-\left(d_{1}+d_{2}\right)\right) A_{3}\right) \frac{T_{c}}{T_{f}}+ \\
\left(d_{1} A_{4}+d_{2} A_{5}+\left(1-\left(d_{1}+d_{2}\right)\right) A_{6}\right)\left(1-\frac{T_{c}}{T_{f}}\right) \\
B=\left(d_{1} B_{1}+d_{2} B_{2}+\left(1-\left(d_{1}+d_{2}\right)\right) B_{3}\right) \frac{T_{c}}{T_{f}}+ \\
\left(d_{1} B_{4}+d_{2} B_{5}+\left(1-\left(d_{1}+d_{2}\right)\right) B_{6}\right)\left(1-\frac{T_{c}}{T_{f}}\right) \\
C=\left(d_{1} C_{1}+d_{2} C_{2}+\left(1-\left(d_{1}+d_{2}\right)\right) C_{3}\right) \frac{T_{c}}{T_{f}}+
\end{gathered}
$$




$$
\left(d_{1} C_{4}+d_{2} C_{5}+\left(1-\left(d_{1}+d_{2}\right)\right) C_{6}\right)\left(1-\frac{T_{c}}{T_{f}}\right)
$$

where $\mathrm{T}_{\mathrm{c}}$ is the period of time where the rectifier diode is conducting, and $T_{f}$ is equal to the time period of the fundamental.

\subsection{Technical Challenges During The Design Stage}

During the development of the Hybrid Drive system, some technical challenges, and system failures had to be overcome. These challenges came in both the hardware, and the software development, are a few that were encountered are observed in the following subsections.

\subsubsection{Hardware Challenges}

During implementation of the second DC-DC module prototype, which was the first printed circuit board design, underestimation of the necessary range of clearance between the switching power supply transformer and the side of the enclosure caused a direct short between the positive and negative rails of the converter, and a subsequent arc flash. Below is a picture which shows the aftermath. This explosion occurred due to a lack of clearance, and insufficient insulation between one of the pins of the transformer, and the positive leg of the DC bus. The damage to the enclosure is visible in Figure 5-11. Subsequently, the VIPER SMPS, the transformer, and several components related to the SMPS, had to be replaced, as well as the switching transformer. In addition, the copper traces on the board had to be checked for any short circuits, or other damage. 


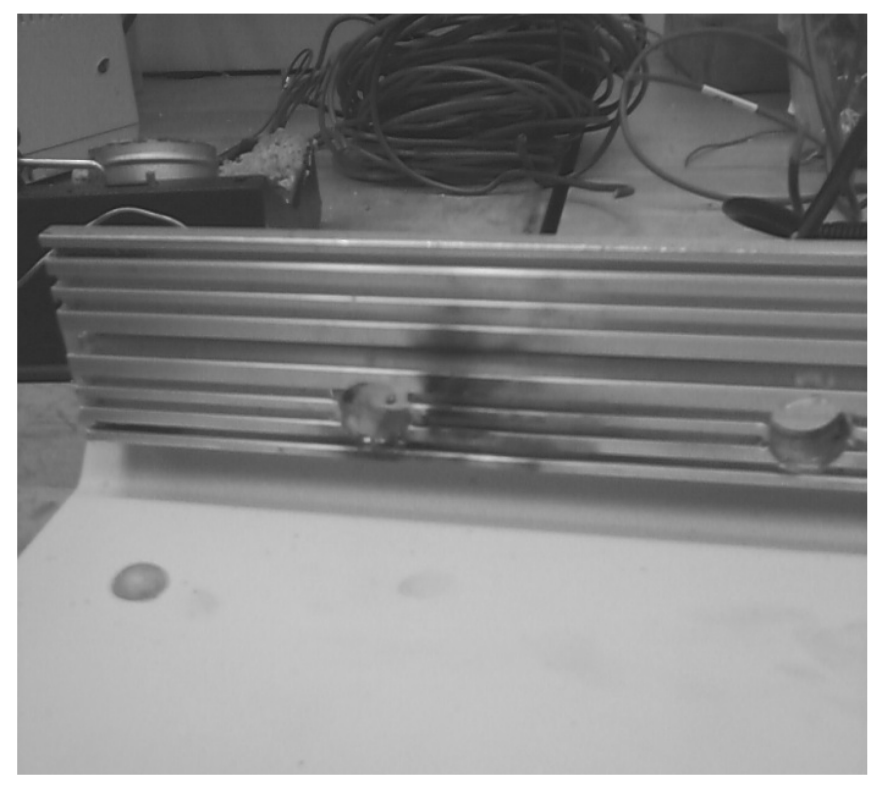

\section{Figure 5-11 Post Short-Circuit Enclosure Damage}

Once the survey of the damage was completed, the circuit was again energized, and the VIPER SMPS again exploded.

After a further analysis, it was determined that the original fault created a high impedance short circuit between the two rails of the DC bus. This caused the short to go unnoticed when continuity checks were performed. However, upon energization, the VIPER SMPS again failed once current began to flow. Since the transformer was not destroyed in this failure, it was determined that the location of the fault was across the transformer terminals on the underside of the board.

After the second failure of the power supply, a new board was populated in order to avoid any additional failures in the circuit. The circuit was once again working properly, and tuning of the PI controller was performed, and adjustments to the dsPIC 
program were made. The testing period of the module later commenced, and it worked as it was designed. Prior to shipping the DC-DC module to A.O. Smith for additional evaluation, it was decided that a small fan, and LED should be mounted to the enclosure in order to provide some additional cooling, and an indication for when the DC bus was energized. The modifications were made, but when the module was energized, it failed to operate. At first, it was believed that there was some nonlinearity in the voltage feedback circuit that was causing the program to operate is if the bus voltage was at a higher level than it was in reality, and therefore send the duty cycle ratio to zero in order to prevent overdriving of the bus voltage. This turned out to be incorrect. The feedback voltage was measured for several different bus voltages, and it was determined that the feedback circuit was indeed linear, although there was some noise present was filtered out in the dsPIC program. 


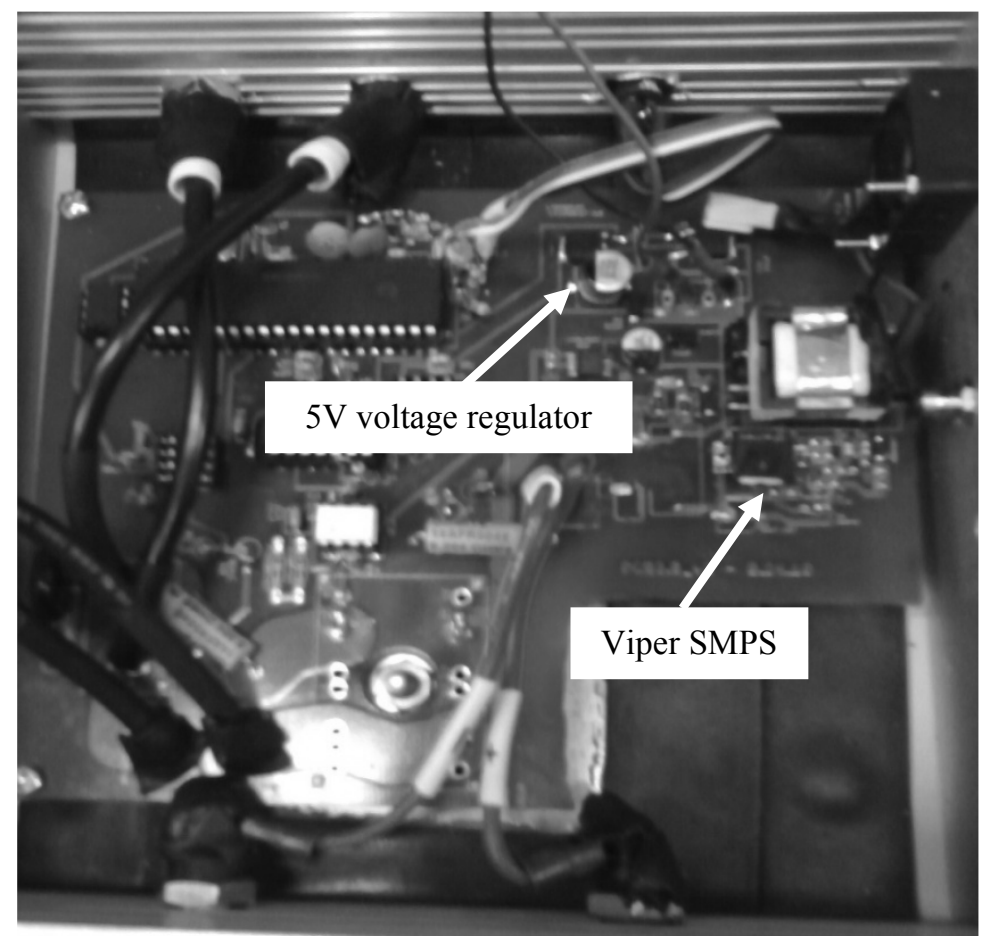

Figure 5-11 DC-DC Module Replacement Parts

It was later discovered that the $5 \mathrm{~V}$ regulator output was only $4.2 \mathrm{~V}$. The next step was to measure the temperature of the linear voltage regulator, which was found to be varying between $170 \mathrm{~F}$, and $191 \mathrm{~F}$. This led to the conclusion that the $5 \mathrm{~V}$ regulator needed to be replaced, see Figure 5-11. The regulator was replaced, the circuit was checked again, and then the hybrid motor drive prototype was was energized. The SMPS chip exploded upon energization. Repetitive system failures made it clear that a new design was necessary.

\subsubsection{Software Challenges}


After a sequence of successful tests of the fourth prototype, it was decided to change the switching frequency from $5 \mathrm{kHz}$, to $4 \mathrm{kHz}$. The reason for this, is that according to the equation for power sharing, the power output of the module is much higher at lower switching frequencies. During testing, the drive encountered a DC bus overvoltage. The overvoltage condition shut down the motor drive, and the high voltage levels caused a metal oxide varistor to explode. The failure of the MOV was violent, and removed the insulation from the two traces on which it is connected. This subsequently caused a direct short across the traces in the circuit, and both the DC-DC module and the rectifier in the pump were damaged.

The overvoltage in the DC bus was caused by saturation in the PI controller of the DC-DC module. The reaction speed of the PI controller was fast enough to prevent any significant voltage rise at $5 \mathrm{kHz}$, but not at $4 \mathrm{kHz}$. As the input voltage was in creased from $40 \mathrm{~V}$ to $50 \mathrm{~V}$, the $\mathrm{DC}$ bus voltage of the drive increased from $310 \mathrm{~V}$ to well over $500 \mathrm{~V}$ in less than a second. Consequently, the DC module and the pump went into shutdown as they were designed. However, there were two consequences of the drive shutting down which added to the failure. The first is the regeneration of the mechanical energy stored in the pump which maintained the voltage levels, and possibly contributed to the rise in voltage even though the DC module was off. The second consequence is that the shutdown of the motor removes most of the load from the bus, and the remaining load was not enough to rapidly reduce the bus voltage. 
Although the module caused the overvoltage in the first place, it should be specified that removal of the output MOV would prevent a catastrophic failure in the event of a temporary overvoltage. The parameters of the test were as follows:

RPM: 1750

Total input power of the drive: $400 \mathrm{~W}$

Input Voltage of the DC module: $0-100 \mathrm{~V}$

Fs: $4.096 \mathrm{kHz}$

A block diagram of the control system is visible below in Figure 5-12.

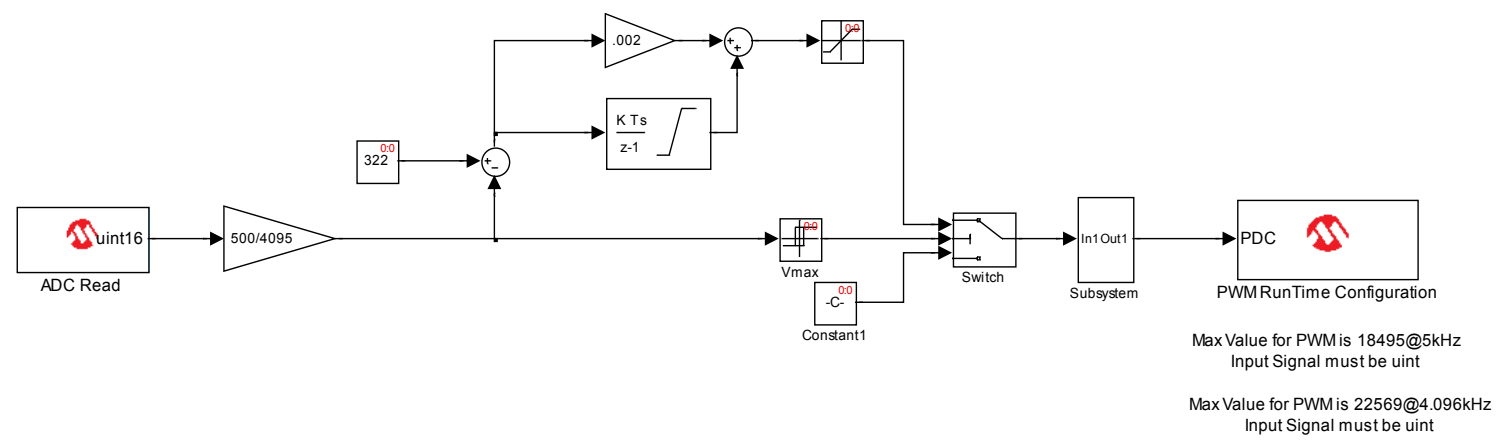

Figure 5-12 DC-DC Module Block Diagram

In Figure 5-13, at the original location of the MOV, the location where the insulation was removed from the top of the traces can be seen. On the upper portion, bare copper is exposed, and on the lower a combination of copper and solder can be seen. The damage to the board is significantly greater than from the failure of the MOV alone, which is further evidence that an arc-flash occurred. 


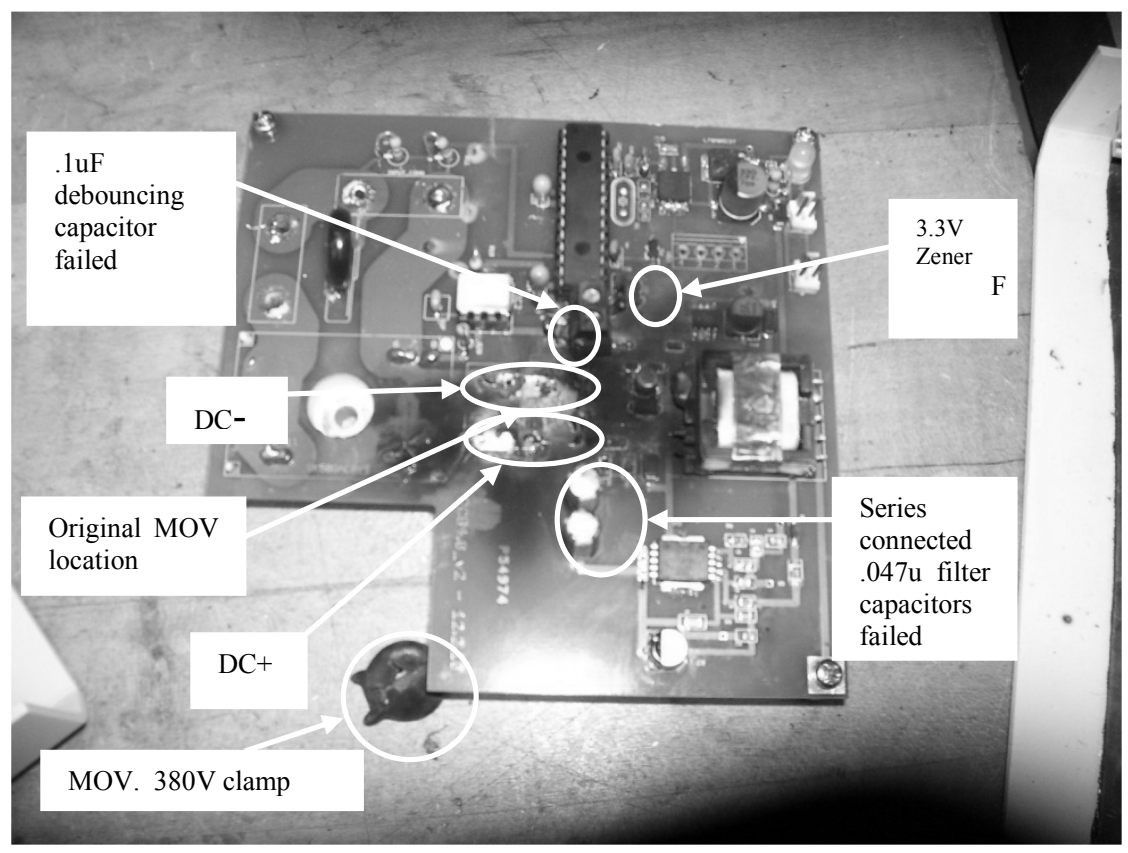

Figure 5-13 DC-DC Module Post Failure Analysis - Top Side

5.5. Final Design

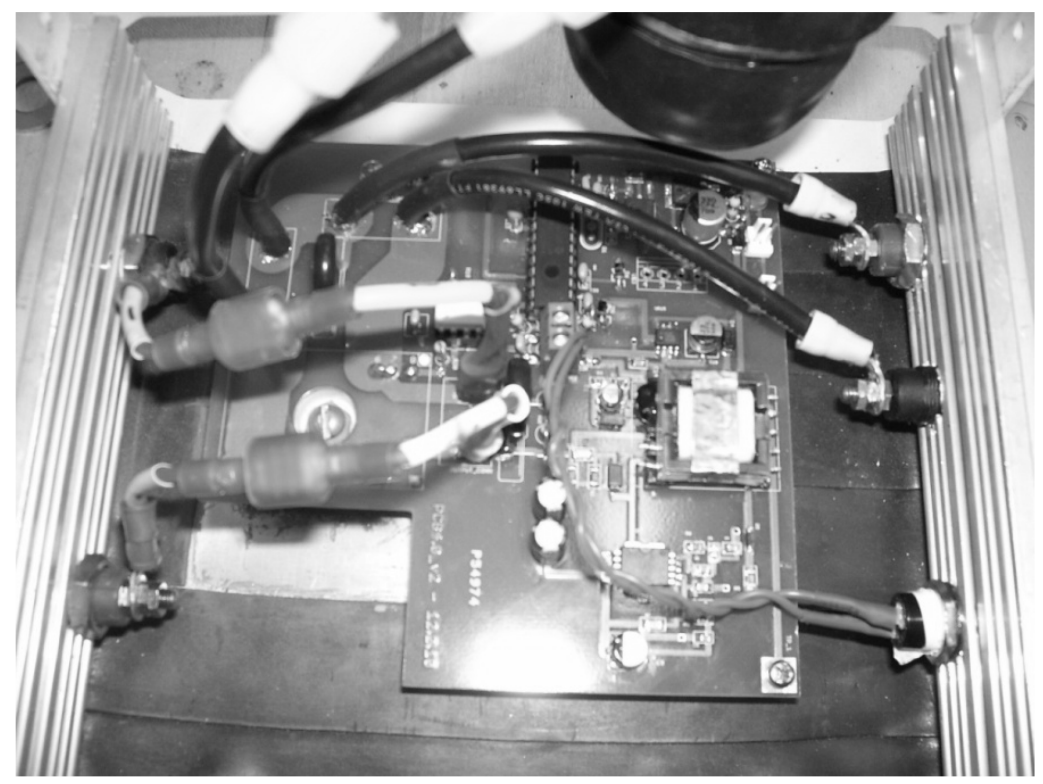

Figure 5-14 Final Circuit Board - Top Side 
The final prototype of the DC-DC module can be seen inside of its enclosure in the following figures, as well as the enclosure with the lid shut. A journal has been placed in the picture to add perspective.

The parameters of the prototype are listed below:

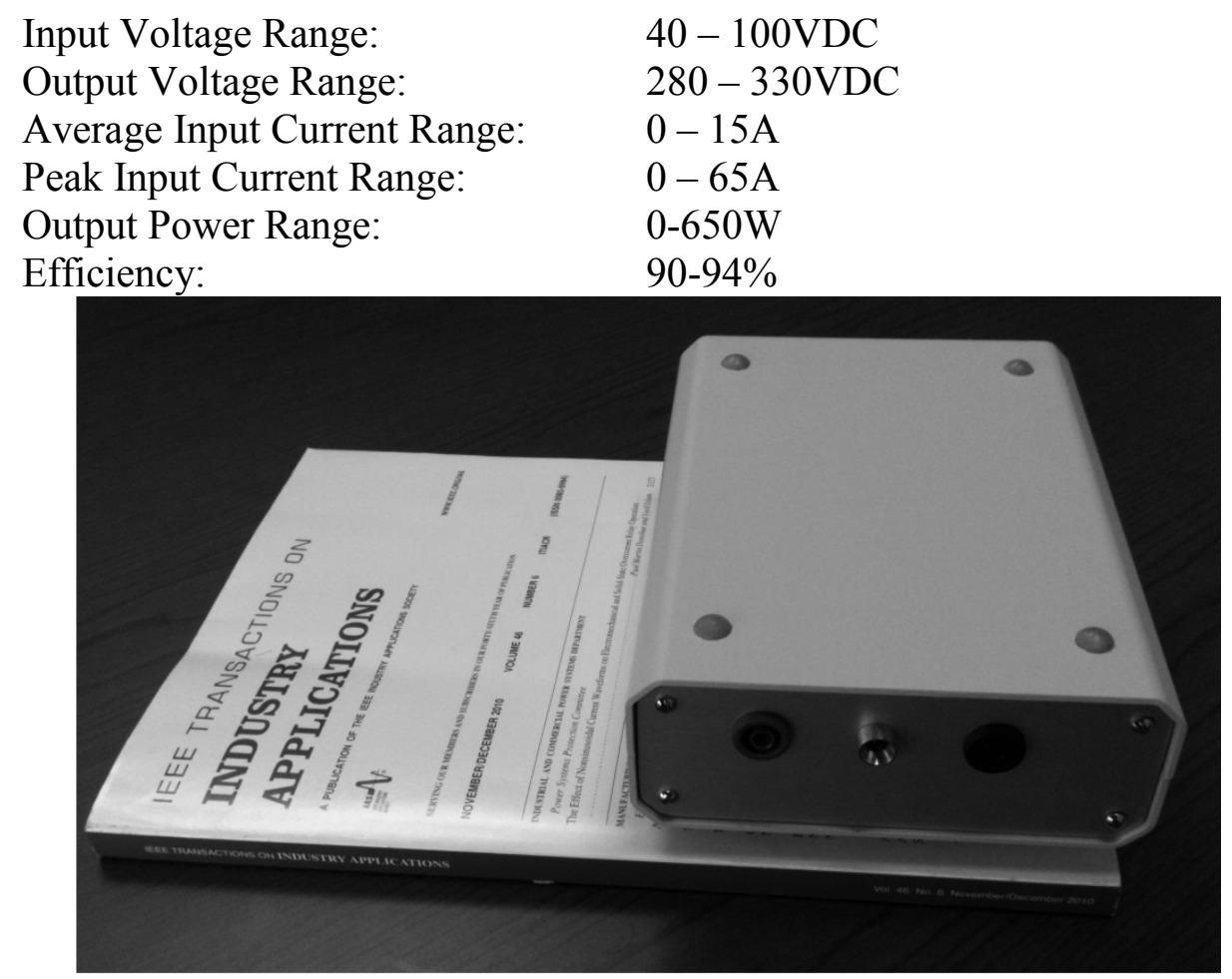

Figure 5-15 Final Prototype - Enclosure 


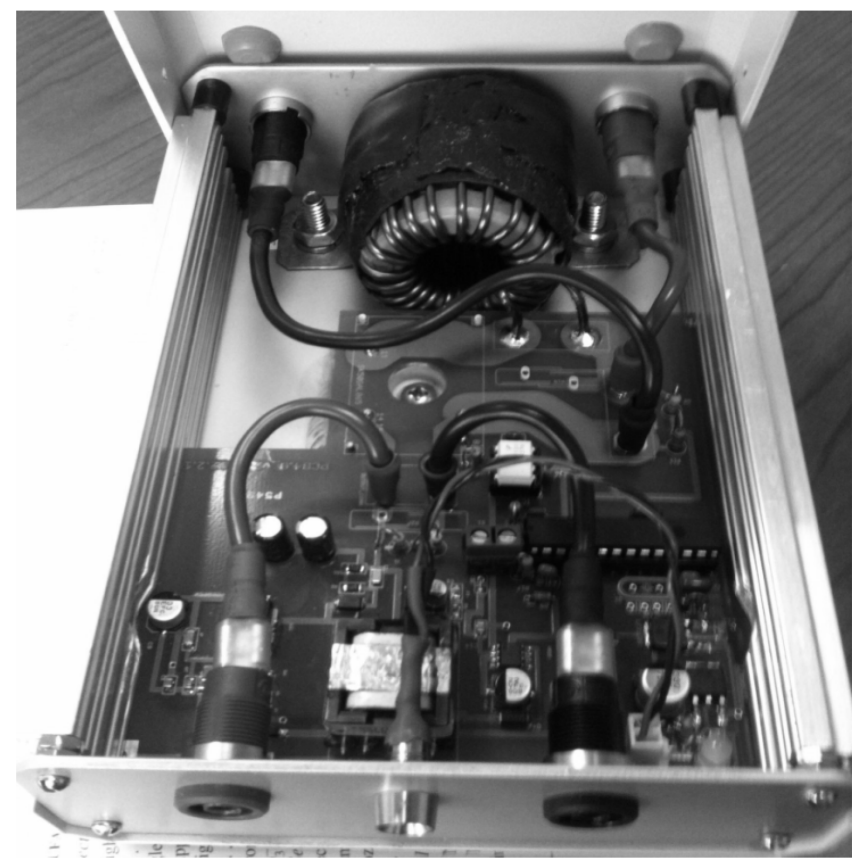

Figure 5-16 Final Prototype Circuit Board Close-up

The printed circuit board for each of the four prototypes was designed using EagleCad 5.8. Due to errors generated in by the system autorouter. Each circuit was laid out manually. A picture of the PCB, and some schematics of the system are visible in Appendix (A).

The DC-DC module contols the power injected into the pump by means of a constant voltage control scheme. In the previous section, some technical challenges were mentioned in regard to the disadvantages of a PI controller. A directly proportional control scheme was used to increase the reliability of the system. Since the dynamics of the pump are slow, a the acceleration and deceleration rates of the motor are also slow, a directly proportional control scheme will increase the response of the converter, and prevent the system from creating a DC bus overvoltage. The concept is simple, once the 
DC bus voltage increases to above a threshold, the converter begins switching at a predefined duty ratio ceiling limit. As the bus voltage increases, the duty ratio decreases. The rate of decrease in the duty ratio continues to rise as the voltage gets higher, until the converter is shut off completely.

One disadvantage of this methed is that the duty ratio of the converter sometimes begins to oscillate once the DC bus voltage approaches the reference voltage. However, this issue can be reduced by modifying the slope of the duty ratio decrease as the bus voltage gets closer to the reference point. A block diagram of the control scheme is visible in Figure 5-17, and the proportional control method is displayed in the expanded view of the Simulink subsystem in Figure 5-18.
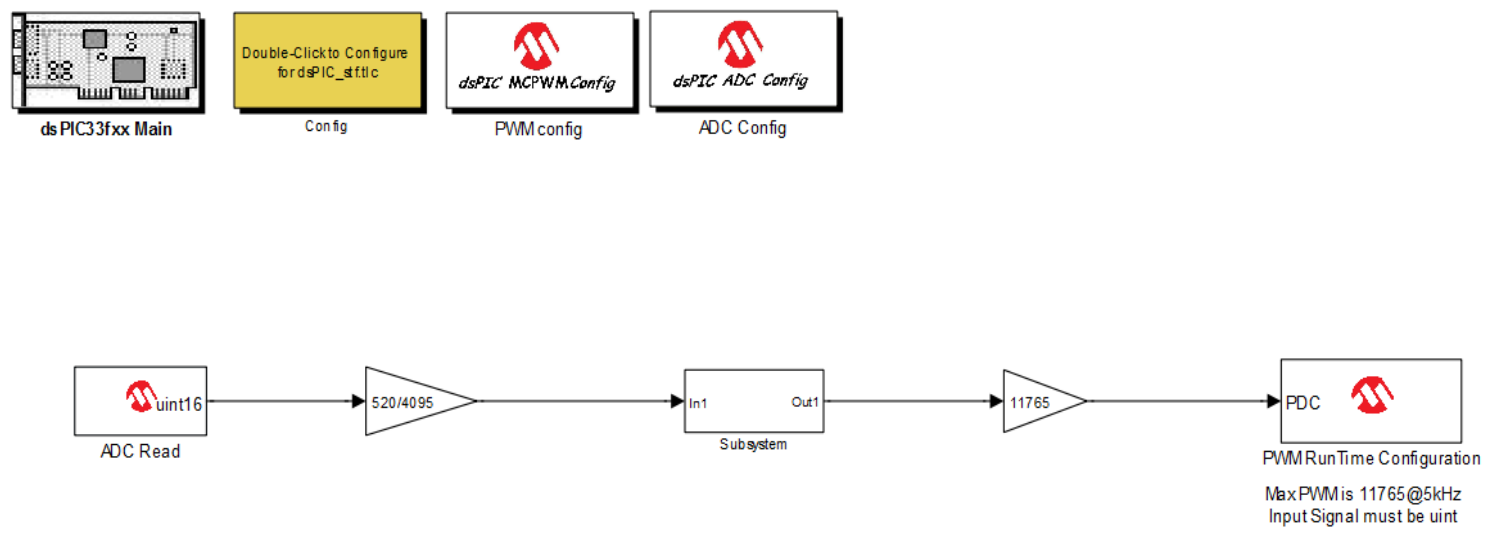

5-17 Simulink Microchip Blockset Model 


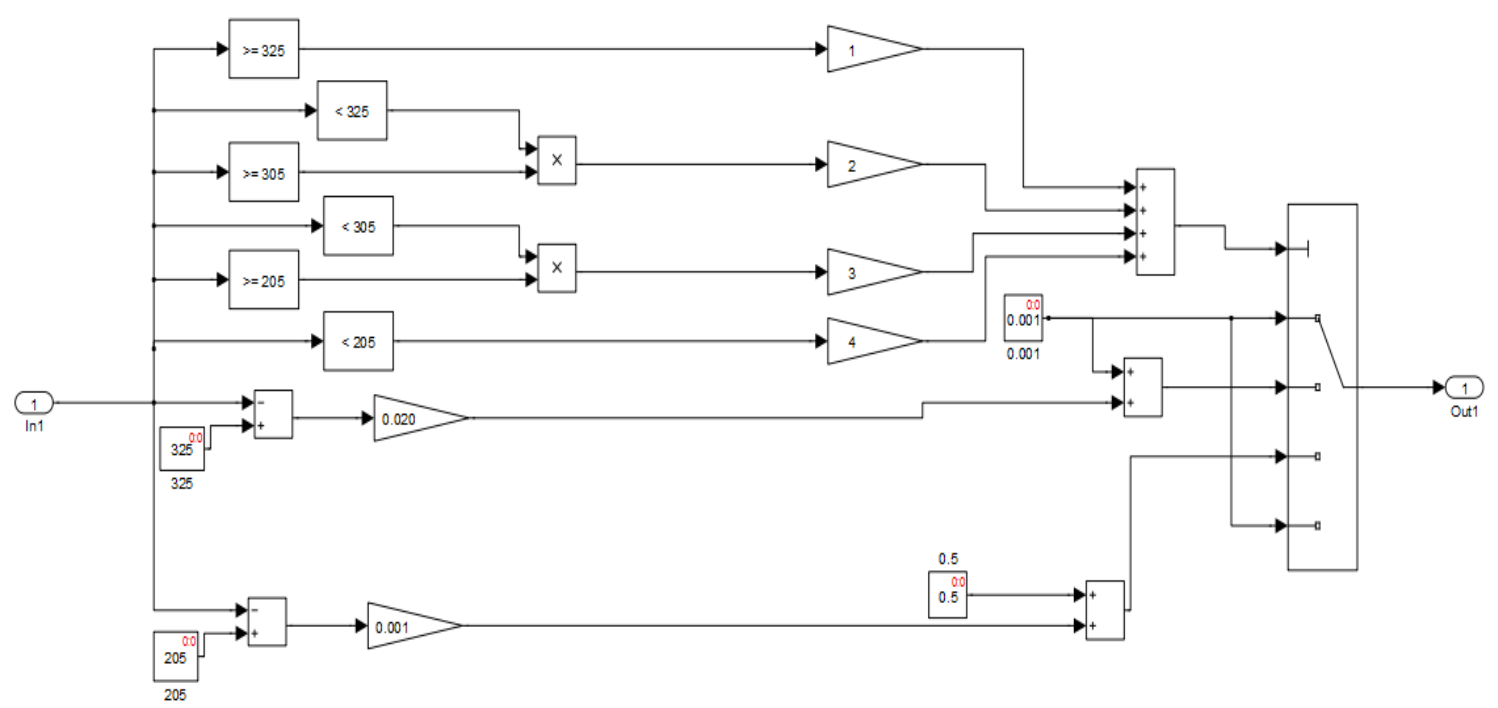

5-18 Simulink Model Subsystem 


\section{CHAPTER 6}

\section{EXPERIMENTAL RESULTS}

\subsection{Hybrid-Drive Steady State Operation}

In this section, the steady-state behaviors of the hybrid motor-drive system are studied through experimentally obtained data. The first step is to demonstrate the degree of system robustness in the presence of line-loss, which can also give us an idea about the capability of the system islanding phenomenon. In Figure 6-2, the DC-bus and the ACgrid voltage waveforms are shown while the AC-grid was disconnected for about 200 msec. As can be seen, the DC bus voltage maintains at its steady-state value during the line-loss test. This test was performed while the motor was running at $1500 \mathrm{rpm}$ and the DC-DC module duty cycle ratio was $30 \%$ at $5 \mathrm{kHz}$ switching frequency. Of course, at a higher motor speed the duty cycle ratio should be automatically tuned into an appropriate value in order to keep the DC-bus voltage stable.

In Figure 6-1, the input current of the DC-DC module is displayed in contrast to the module's output current. As can be seen from the figure, the input current of the module conforms to the expected current waveform in Figure 4-6 and the output current decreases from the peak input current over the time period $\gamma T_{s}$. The motor was running at $1500 \mathrm{rpm}$, and the input voltage to the DC-DC module was $33.5 \mathrm{~V}$, while it was operating at $5 \mathrm{kHz}$, with a constant $30 \%$ duty cycle ratio. The motor and DC-DC module were operating under these same characteristics in Fig. 7, where the AC input current to the drive is shown over the motor current out of the drive. In this case, motor was 
operating at $230 \mathrm{~W}$. The power injected to the DC bus from the DC-DC module was approximately $45 \mathrm{~W}$, and the power from the grid was around $195 \mathrm{~W}$. As can be seen from the figures, the injected power from the DC-DC module does not cause any disruptions in the motor current waveform, while relieving some of the demand on the grid.
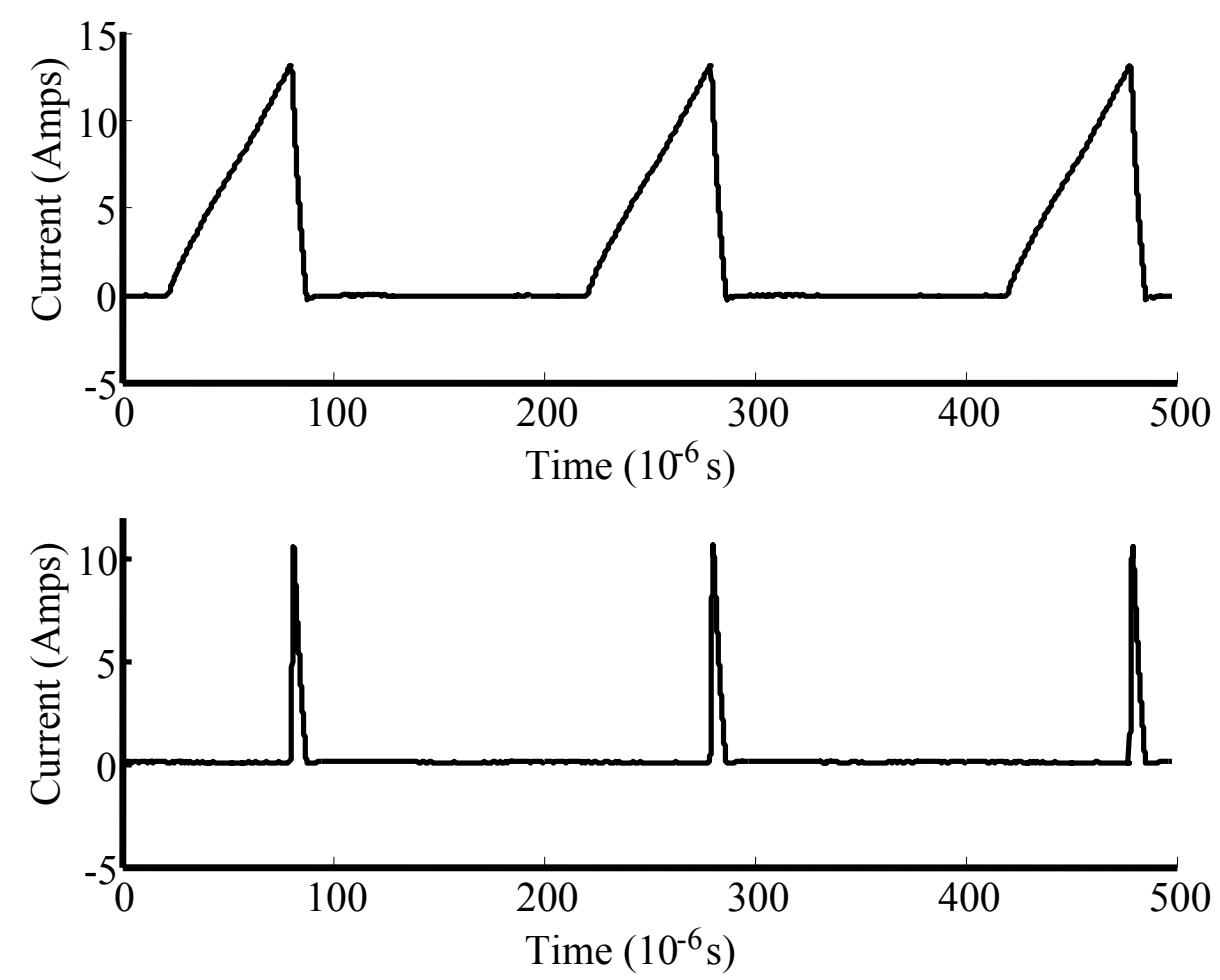

Figure 6-1 DC-DC input current and output current while the motor was running at $1500 \mathrm{rpm}$, with the module at $33.5 \mathrm{~V} \mathrm{PV}$ input voltage, $30 \%$ duty cycle, and $\mathrm{fs}=5$ $\mathbf{k H z}$ 

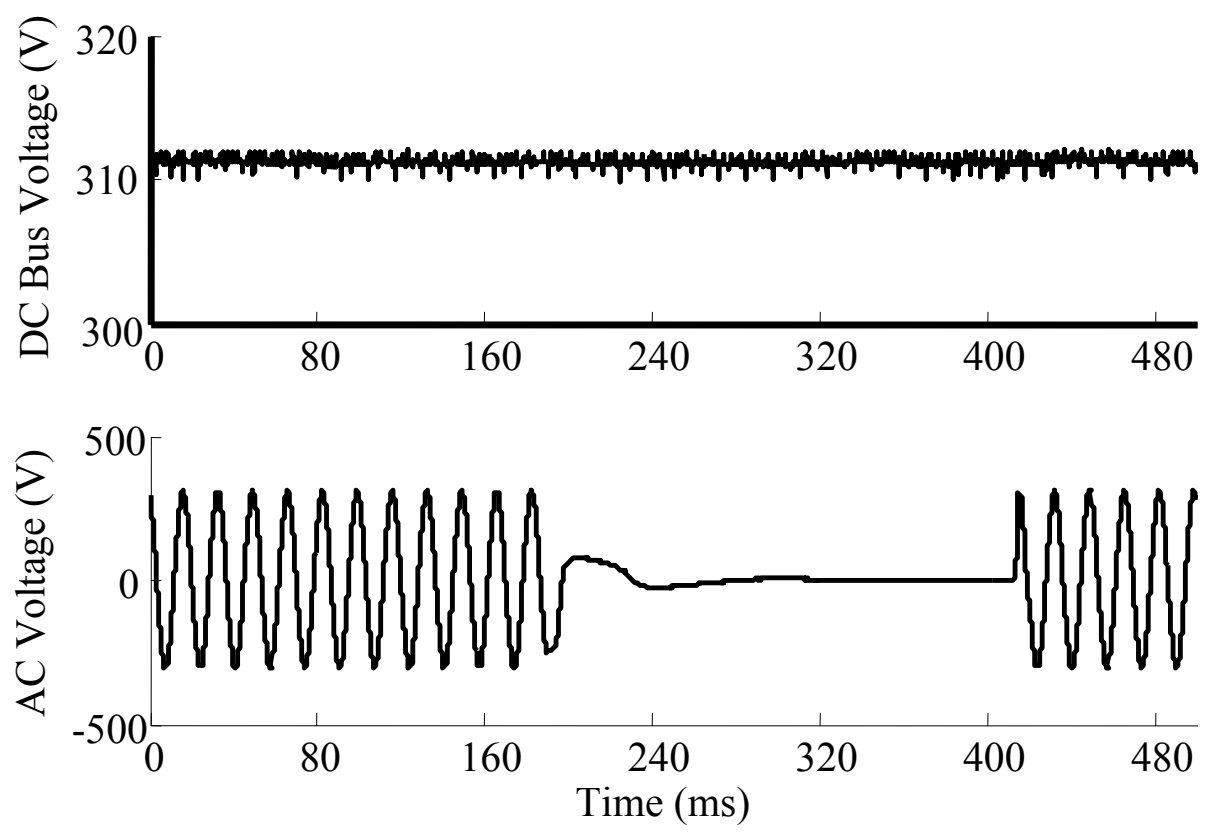

Figure 6-2 Line loss (AC-grid voltage loss) test, while motor was running at 1500 rpm.

\subsection{Output Power Versus inductance}

In Figure 6-3, the output power of the DC-DC module has been plotted versus the magnitude of the input inductance. In this test, the motor was running continuously $1500 \mathrm{rpm}$, and the input voltage to the DC-DC module was incrementally increased. As can be seen in the figure, as the input inductance is increased, the output power of the DC-DC module is reduced. This figure is in keeping with eqn. (4) where, for comparable input voltage levels, the output power of the DC-DC module should linearly decrease with an increase in the input inductance. 


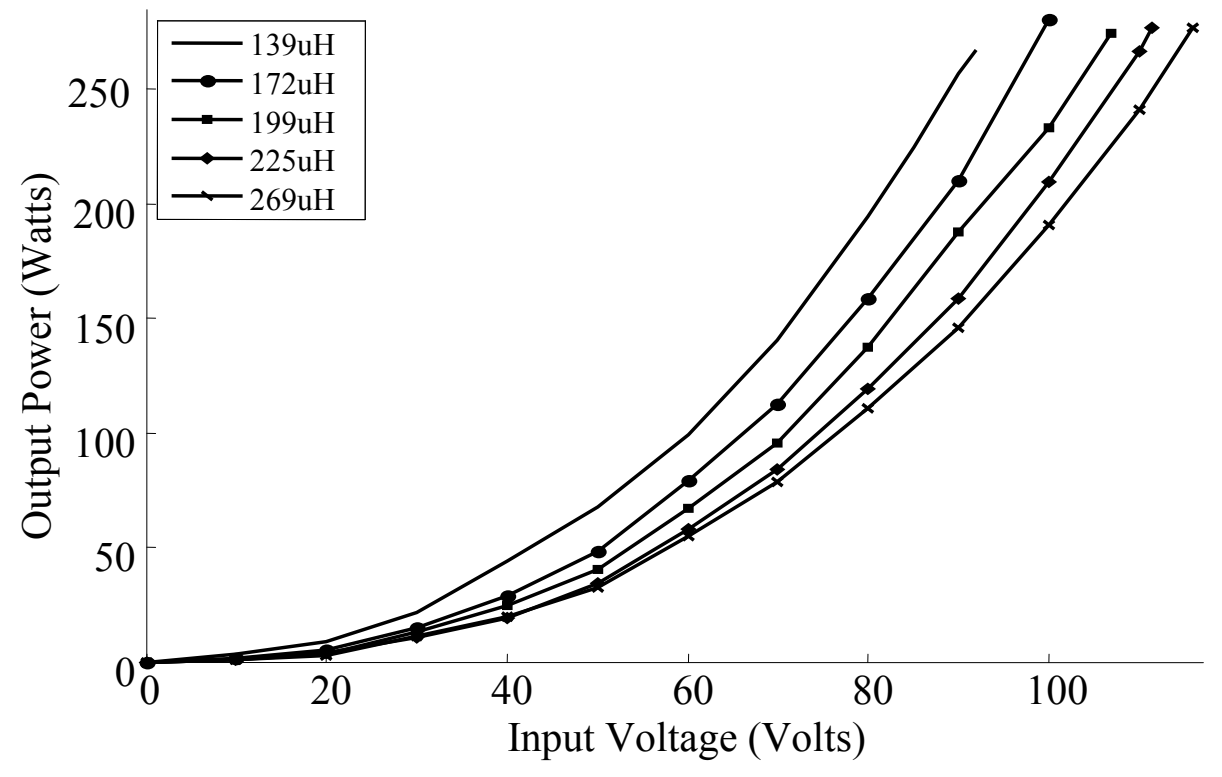

Figure 6-3 Experimentally obtained output power of the DC-DC module vs. input inductance, while the motor was running at $1500 \mathrm{rpm}$.

For this test, the inductance levels were verified through a pulse test, whereby a voltage is applied across the inductor for a brief moment of time, and the peak current level is measured and used to determine the actual inductance at that frequency. Therefore, these values are true for a switching frequency of $10 \mathrm{kHz}$, but may be different at $5 \mathrm{kHz}$.

\subsection{Power Sharing}

The instantaneous powers of the AC-grid and PV (DC-DC input) are shown in Figure 6-4. As can be seen, the DC-DC module is design to operate in discontinuous conduction mode. The experimental results illustrate that PV power-sharing is not a function of motor speed in hybrid solar-based motor-drives, as long as the average power 
contribution of the AC-grid stays above zero, see Figures. 6-5 and 6-6. In these figures, the average output power of the DC-DC module, and the average input power to the motor drive is plotted versus the motor speed under various duty cycles. In Figure 6-5, the input voltage to the DC-DC module is maintained at $75 \mathrm{~V}$, the switching frequency $\mathrm{f}_{\mathrm{s}}$ is maintained at $10 \mathrm{kHz}$, and the experiment is performed for three duty cycles. The same test is performed in Figure 6-6, but the switching frequency has been changed to 5 $\mathrm{kHz}$, and the input voltage has been reduced to $52.4 \mathrm{~V}$. In both figures, the solid black line displays the power drawn by the motor drive when there is zero contribution to the DC bus other than that provided from the AC-DC rectifier. It is important to take notice of the differences not of just the duty cycles in each individual experiment, but also of the differences between the two experiments in their entirety. For example, it is easily noticed that the power supplied to the drive from the DC-DC module is significantly higher at $10 \mathrm{kHz}$ if the duty cycle ratio is $40 \%$ instead of $20 \%$, but there is also a distinguishable difference between the magnitudes of the power contributed at the $40 \%$ duty cycle from $10 \mathrm{kHz}$ to $5 \mathrm{kHz}$. The power injected into the DC bus at $10 \mathrm{kHz}$ is on average $280 \mathrm{~W}$, while the power injected into the DC bus at $5 \mathrm{kHz}$ averages $300 \mathrm{~W}$. This increase in power is due to the reduction in switching losses. Additionally, it is important to mention the fact that the input voltage to the DC-DC module is significantly lower at 5 $\mathrm{kHz}$, where instead of an input voltage of $75 \mathrm{~V}$, the module was able to operate at $52.4 \mathrm{~V}$, with a higher efficiency due to the reduction losses. The efficiency of the module averaged $83.8 \%$ at $5 \mathrm{kHz}$, and $73.6 \%$ at $10 \mathrm{kHz}$. These figures also show that the power injected by the DC-DC module is nearly constant, regardless of the changes in motor speed, and that depending on the speed of the motor, the DC-DC module and the AC-grid 
can either contribute equally to the motor input power, or the DC-DC module can act as the sole power source.

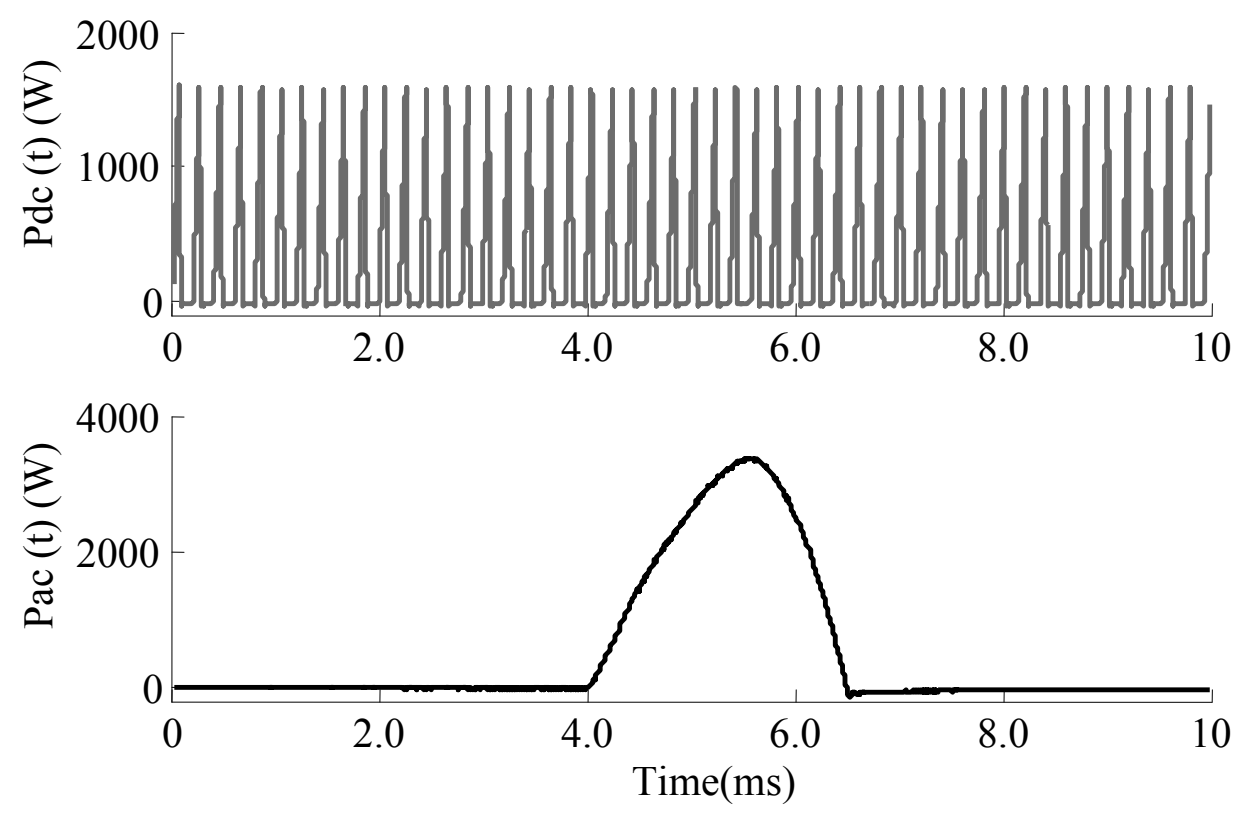

Figure 6-4 Experimentally obtained instantaneous powers of PV (top) and singlephase $230 \mathrm{~V}$ AC-grid (bottom) vs. time over $10 \mathrm{msec}$

Reductions in solar insolation due to inclement weather, or the collection of debris on solar module surfaces result in reductions in voltage at solar module output terminals. To account for these variations, a demonstration of power sharing during variations in the input terminal voltage of the DC-DC module is visible in Figure 6-7. In this figure, the average input power to the motor drive, and the power injected by the DC-DC module is plotted versus the input voltage at two different switching frequencies $\left(\mathrm{f}_{\mathrm{s}}=10 \mathrm{kHz}\right.$, and $\mathrm{f}_{\mathrm{s}}$ $=5 \mathrm{kHz}$ ) when the speed of the motor is maintained at a constant $1500 \mathrm{rpm}$. It can be seen in this figure, that the point at which the power injected to the motor becomes equal to the power drawn from the AC grid is the same magnitude for both switching 
frequencies, but is reached at a lower input voltage when the frequency is $5 \mathrm{kHz}$. This demonstrates the relationship between output power and input voltage to the DC-DC module shown enumerated in (5-8). It can be seen that there exists a linear relationship between the output power of the module and the supply voltage when the load and duty cycle are constant, and that as the output power of the DC-DC module declines, the average AC-grid power increases to compensate, and the operation of the motor is unaffected. This change in source without interruption makes the pump more robust, as was shown in figure 6-2 with the $\mathrm{AC}$ line loss test. In figure 6-8, the average $\mathrm{AC}$ input power to the motor drive and the DC-DC injected power is plotted versus the input voltage at various duty cycles. In this case, the switching frequency was maintained at $f_{s}$ $=5 \mathrm{kHz}$.

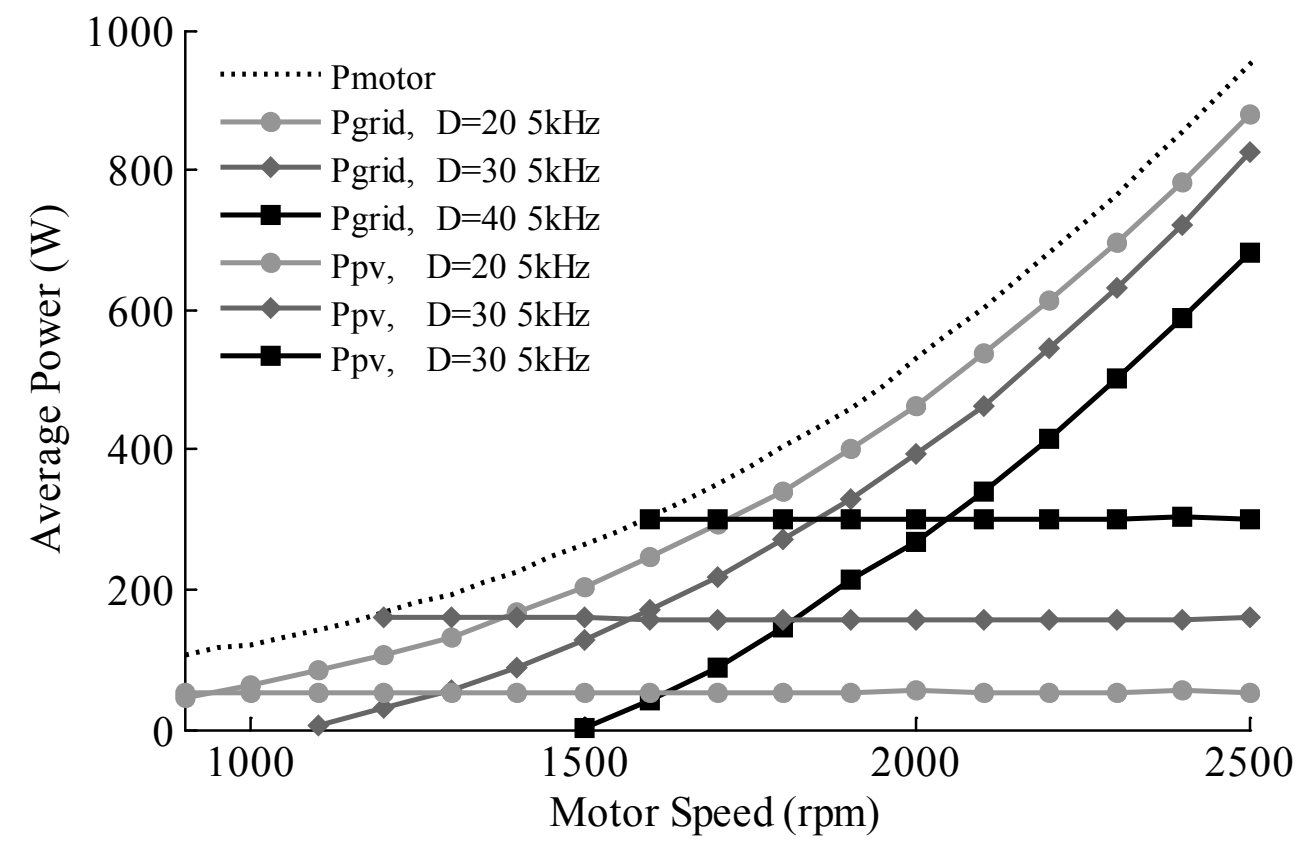

Figure 6-5 Experimentally obtained average power of the grid, PV (horizontal lines), and motor in watts vs. motor speed in rpm for the duty cycles of $D=20 \%$, D $=30 \%$, and $\mathrm{D}=40 \%$ at the switching frequency of $5 \mathrm{kHz}$ for the DC-DC module. 


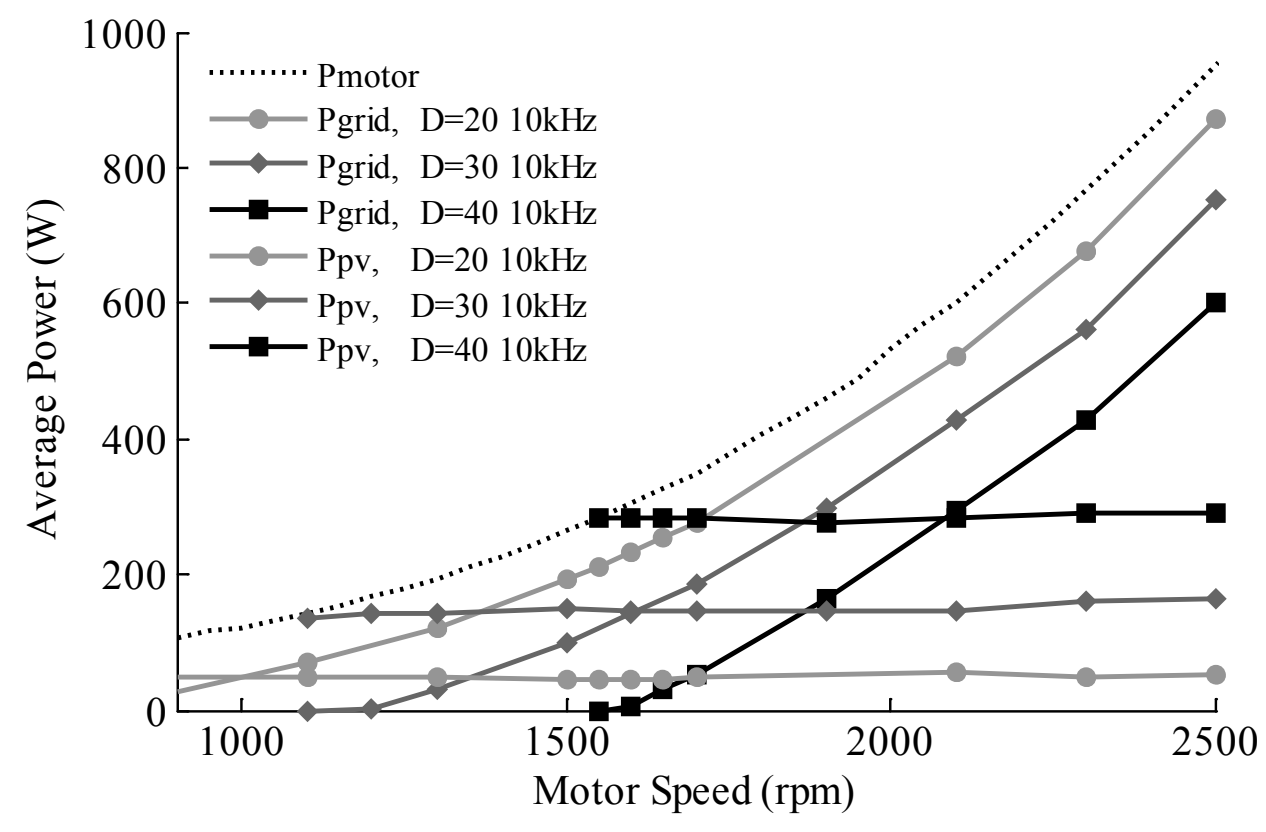

Figure 6-6 Experimentally obtained average power of the grid, PV (horizontal lines), and motor in watts vs. motor speed in rpm for the duty cycles of $D=20 \%, D$ $=30 \%$, and $D=40 \%$ at the switching frequency of $10 \mathrm{kHz}$ for the DC-DC module.

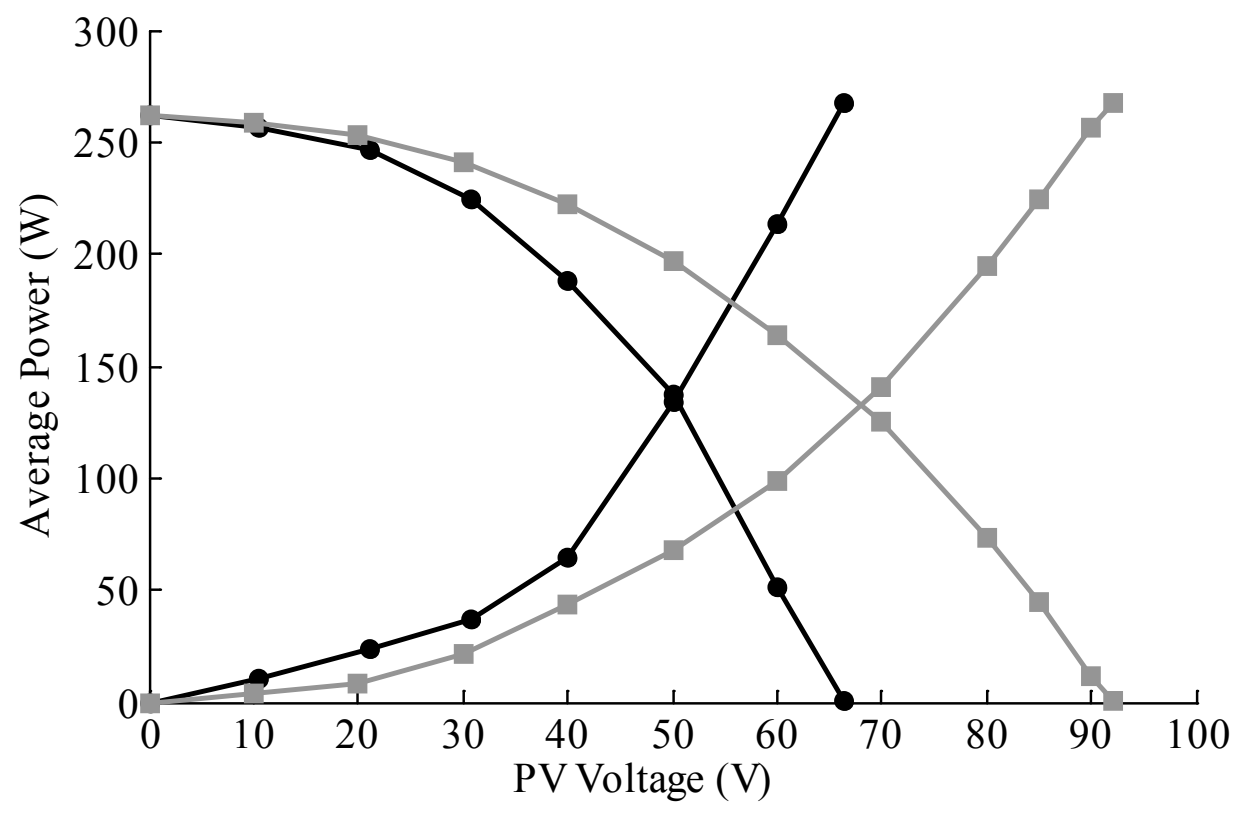

Figure 6-7 Experimentally obtained average power-sharing in watts vs. PV (DC power supply) voltage in volts, while the pump is running at a constant speed (1500 rpm), the duty cycle of $D=30 \%$ with the switching frequencies $10 \mathrm{kHz}$ (gray) and 5 kHz (black). 


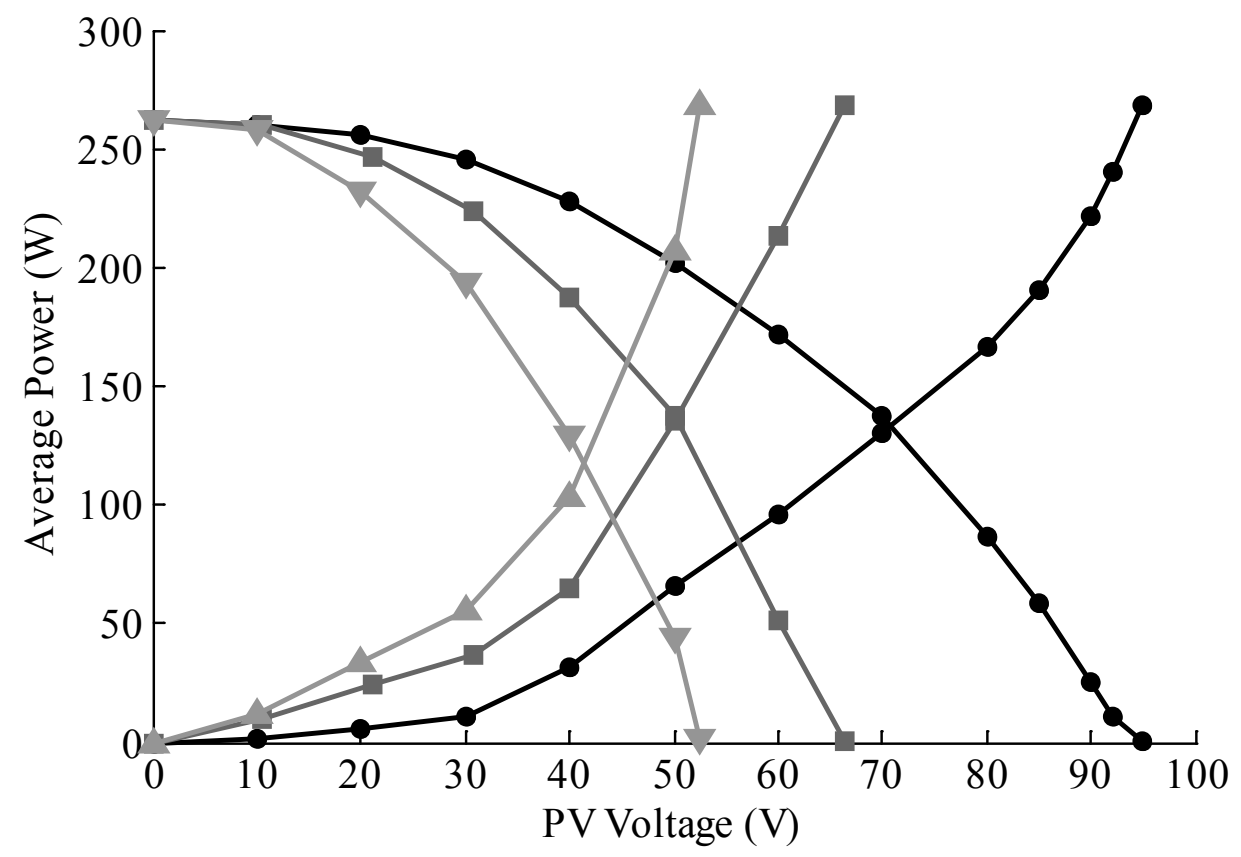

Figure 6-8 Experimentally obtained average power-sharing in watts vs. PV (DC power supply) voltage in volts, while the pump is running at a constant speed (1500 rpm), the switching frequency of $5 \mathrm{kHz}$ and the duty cycle of $\mathrm{D}=\mathbf{2 0 \%}$ (black), $\mathrm{D}=$ $30 \%$ (dark-gray), and $\mathrm{D}=\mathbf{4 0} \%$ (light-gray)

Notice the way that the point at which the AC and DC average power intersect decreases as the duty cycle ratio increases. This is due the $\mathrm{D}^{2}$ relationship that exists between the DC-DC output power and the DC-DC duty cycle ratio. Therefore, this point of intersection will decrease non- linearly as the duty cycle ratio increases. 


\section{CHAPTER 7}

\section{CONCLUSION}

The objective of this Thesis was to investigate power sharing in a hybrid motor drive system through the design, implementation, experimental validation, and the evaluation of experimental data. Moreover, the objective was also to indentify the parameters which allow one to control the power sharing in this system. This effort required a fundamental understanding of power electronics in addition to the ability to learn new disciplines in electrical engineering. These new disciplines included printed circuit board design, magnetic design for switching circuits, embedded control, and microcontroller programming. Moreover, the work performed during this effort served to reinforce this candidate's skills in testing and evaluation of data, analog circuit design and troubleshooting, control theory, and modeling and simulation.

Through the experimental validation of the test case hybrid motor drive system, it has been determined that this method is a simple, but effective method of reducing the amount of energy used from the AC grid, while increasing the reliability of a solar pumping system. From the previous figures, it can be seen that the concept of powersharing between a PV source, and a hybrid motor drive is not a function of motor speed, as long as there is a minimum contribution from the grid. Moreover, equation (5-4) clearly identifies the parameters that can be used to modulate the amount of power injected into the drive by the DC-DC module, and it can be seen that the dynamic behavior of the motor is decoupled from the grid if the PV-DC-DC module can sufficiently cover the load. 
The learning process that occurred during this research are noticeable through the increases in efficiency were achieved in each successive prototype. In the final prototype, the module was able to supply approximately $650 \mathrm{~W}$ at $90-94 \%$ efficiency. This is a huge increase in capability over the first prototype, which only managed $450 \mathrm{~W}$ at $75 \%$ efficiency. In addition, the reduction in size from the original prototype board which had a surface area of 48 square inches, with a height of 2.1 inches, to the final prototype which was 25.5 square inches, and less than 1 inch tall was a major achievement. Another notable achievement in this research is the fact that the original prototype contained no internal control system, as it was controlled by a dSPACE CLP1104, which was programmed on a lab computer through Simulink. The final prototype contained all of the relevant components that were necessary to allow it to function independently, only two connections are necessary: the PV input, and the DC bus output. It is important to mention, that the final prototype is currently in Tipp City, Ohio, at the offices of the A.O. Smith, Inc. Motor Drives department, being evaluated for suitability as an aftermarket device for their variable speed e-pump.

\section{CHAPTER 8}

\section{FUTURE WORK}

In the future, the application studied in this Thesis may be a standardized process that is integral to the design of motor drives. However, prior to widespread hybridization 
of drive systems, it is necessary to identify, and overcome some technical challenges in this technology.

Firstly, as mentioned in subsection 5.4.1, the control scheme used to share power in these systems must be able to handle the nonlinearities of the circuits, as well as variations in load, and input power. Integrating the DC-DC module into the initial design of a motor drive instead of utilizing an external DC-DC module would offer an opportunity to overcome this issue, because the power injected to the DC bus of the motor drive can be modulated according to the motor speed in order to reduce the possibility of a DC bus overvoltage. This can also be accomplished through establishment of a communication link between the drive and the DC-DC module. Another approach is a fuzzy logic control scheme or a sliding mode controller in the external DC-DC module. Both of these methods would offer an interesting opportunity to increase the capabilities of an externally connected DC-DC module.

Another interesting topic to explore in the future is the suitability of other converter topologies for this application, such as the topology mentioned in [21]. Due to the discontinuous conduction mode of the DC-DC boost converter, the peak current values are very high, which increases the electrical stress on the semiconductor switch, and increases the cost of the system. There are other topologies which may be explored that may offer enhanced performance, and/or lower cost.

The final topic of interest for future work is to study the dynamic behavior of a hybrid motor drive. Although this work has identified the control parameters of this 
system, the transient behavior of a hybrid motor drive, and sensitivity to rapid changes in load, or operating parameters, as well as operation in other types of motor drive systems would be an interesting investigation. 


\section{REFERENCES}

[1] Florida, Dept. of Health, Survey of residential swimming pools assessed by Florida county property appraisers, 2006.

http://www.floridashealth.com/Workforce/InjuryPrevention/PDF/

ResidentialSwimmingPoolSurvey.pdf

[2] U.S., Dept. of Energy, Energy Savers: Installing and Operating a Swimming Pool for Energy Efficiency. 2009.

http://www.energysavers.gov/your_home/water_heating/index.cfm/mytopic= 13290

[3] Reshef, B., Suehrcke, H., Appelbaum, J., "Analysis of a photovoltaic water pumping system," Eighteenth Convention of Electrical and Electronics Engineers in Israel, 1995, pp.1.5.3/1-1.5.3/5, 7-8 Mar 1995

[4] M., Kappali, R.Y., Uday Kumar, "An approach to reduce the size and cost of PV panel in solar water pumping," Industrial and Information Systems (ICIIS), 2010 International Conference on, vol., no., pp.608-613, July 29 2010-Aug. 12010

[5] Ecos Consulting, Synergies in Swimming Pool Efficiency: How much can be saved? Portland,OR: Ecos Consulting, 2009.

http://www.scribd.com/doc/17720453/NRDC-Report-Synergies-in-SwimmingPool-Efficiency

[6] Florida Energy Office, Measured Energy Savings of a Comprehensive Retrofit in an Existing Florida Residence, December, 1997.

[7] J.A. Roger, et al., "Calculations and in Situ Experimental Data on a Water Pumping System Directly Connected to an $1 / 2 \mathrm{~kW}$ Photovoltaic Converter Array", Presented at 1977 Photovoltaic Solar Energy Engineering Conference, Sept. 2730, 1977, Luxembourg

[8] J. Appelbaum, J. Bany, "Performance Analysis of DC Converter System - I, Separately Excited Motor", Solar Energy, vol. 22, pp. 439-445, 1979.

[9] J.A. Roger, "Theory of the Direct Coupling DC Motors and Photovoltaic Solar Array", Solar Energy, vol. 23, pp. 193-198, 1979.

[10] Z.M.Salameh, F. Dagher, "The effect of electrical array reconfiguration on the performance of a PV-powered volumetric water pump," IEEE Transactions on Energy Conversion, vol.5, no.4, pp.653-658, Dec 1990

[11] R.D.W. Scott, "Photovoltaic systems for rural communities in Indonesia," IEE Colloquium on Energy for Isolated Communities, pp.1/1-1/5, 18 May 1988 
[12] T.S. Surendra, S.V.V. Subbaraman, "Solar PV water pumping comes of age in India," Conference Record of the Photovoltaic Specialists Conference, 2002. Twenty-Ninth IEEE , pp. 1485- 1488, 19-24 May 2002

[13] J.N. Shrestha,"Solar PV water pumping system for rural development in Nepal: problems and prospects," Proceedings of the 31st Intersociety Energy Conversion Engineering Conference, 1996. IECEC 96. , vol.3, pp.1657-1662, 11-16 Aug 1996

[14] M.S. Taha, K. Suresh, "Maximum power point tracking inverter for photovoltaic source pumping applications," Proceedings of the 1996 International Conference on Power Electronics, Drives and Energy Systems for Industrial Growth, 1996., vol.2, pp.883-886, 8-11 Jan 1996

[15] B.N. Singh, B. Singh, B.P. Singh, A. Chandra, K. Al-Haddad, "Optimized performance of solar powered variable speed induction motor drive," Proceedings of the 1996 International Conference on Power Electronics, Drives and Energy Systems for Industrial Growth,1996, vol.1, pp.58-66, 8-11 Jan 1996

[16] C.L.P. Swamy, B. Singh, B.P. Singh, S.S. Murthy, "Experimental investigations on a permanent magnet brushless DC motor fed by PV array for water pumping system," Proceedings of the 31st Intersociety Energy Conversion Engineering Conference, 1996. , vol.3, pp.1663-1668, 11-16, Aug 1996

[17] C. Adnene, J. Moncef, "Modelling and simulation of a PV-inverter-asychronous motor association in photovoltaic pumping systems," Large Engineering Systems Conference on Power Engineering, 2001., pp.146-151, 2001

[18] C. Slabbert, M. Malengret, "Grid connected/solar water pump for rural areas," Proceedings of the IEEE International Symposium on Industrial Electronics, 1998, , vol.1, pp.31-34, 7-10 Jul 1998

[19] C. Li, X. He, W. Gu, "Application of distributed wind (solar)/grid complement system for oil pumping machines in oilfields," World Non-Grid-Connected Wind Power and Energy Conference, 2010 , vol., pp.1-3, 5-7 Nov. 2010

[20] D.D. Lu, V.G. Agelidis, "Photovoltaic-Battery-Powered DC Bus System for Common Portable Electronic Devices," IEEE Transactions on Power Electronics, vol.24, no.3, pp.849-855, March 2009

[21] C. Jian, A. Emadi, "A new battery/ultra-capacitor hybrid energy storage system for electric, hybrid and plug-in hybrid electric vehicles," Vehicle Power and Propulsion Conference, 2009. IEEE, pp.941-946, 7-10 Sept. 2009 
[22] E. Becquerel, "Mémoire sur les effets électriques produits sous l'influence des rayons solaires". Comptes Rendus 9: 561-567, 1839

http://gallica.bnf.fr/ark:/12148/bpt6k2968p/f561.chemindefer.

[23] W.G. Adams, R.E. Day, "The Action of Light on Selenium", Proceedings of the Royal Society, Vol. A25, p.113, 1877.

[24] A. Einstein, "Über einen die Erzeugung und Verwandlung des Lichtes betreffenden heuristischen Gesichtspunkt". Annalen der Physik, 17: 132-148, 1905

[25] F.M. Smits,"History of silicon solar cells," IEEE Transactions on Electron Devices, , vol.23, no.7, pp. 640- 643, Jul 1976

[26] D. Trivich,"'Photovoltaic Cells and Their Possible Use as Power Converters for Solar Energy", The Ohio Journal of Science. ,vol.53, no.5, pp.300-314, September, 1953

[27] C. Feldman et al., "Evaluation of Vacuum Deposited Silicon Films \& Junctions for Solar Cell Applications", Proceedings of the National Workshop on Low Cost Polycrystalline Silicon Solar Cells, 1976, pp. 267-291, May 1976

[28] D. E. Carlson, C. R. Wronski, J. I. Pankove, P. J. Zanzucchi, D. L. Staebler, "Properties of amorphous silicon and a-Si solar cells", RCA Review, vol. 38, pp. 211-225, June, 1977.

[29] First Solar, "First Solar Passes \$1 per Watt Industry Milestone". Press release, (February 24, 2009).

http://investor.firstsolar.com/phoenix.zhtml?c=201491\&p=irol-newsArticle\& $\mathrm{ID}=1259614$ \&highlight. Retrieved 2010-01-07.

[30] O. Mah, "Fundamentals of Photovoltaic Materials". National Solar Power Research Institute (NSPRI) Report, December, 1998.

[31] Y. Kuang, K.H.M. van der Werf, Z. Houweling, S. Silvester, E.I. Ruud,” Nanorod solar cell with an ultrathin a-Si:H absorber layer", Applied Physics Letters, vol.98 , no.11, 2011

[32] H. S. Rauschenbach, Solar Cell Array Design Handbook. NewYork: Van Nostrand Reinhold, 1980.

[33] M.G. Villalva, J.R. Gazoli, E.R. Filho, "Comprehensive Approach to Modeling and Simulation of Photovoltaic Arrays," IEEE Transactions on Power Electronics, vol.24, no.5, pp.1198-1208, May 2009 
[34] T. Esram, P.L. Chapman,"Comparison of Photovoltaic Array Maximum Power Point Tracking Techniques," IEEE Transactions on Energy Conversion, vol.22, no.2, pp.439-449, June 2007

[35] M. H. Rashid, Power Electronics Handbook. San Diego: Academic Press, 2001.

[36] W. Fei, S. Wei, D. Boroyevich, S. Ragon, V. Stefanovic, M. Arpilliere, "Voltage source inverter," Industry Applications Magazine, IEEE, vol.15, no.2, pp.24-33, March-April 2009

[37] R. Errabelli, P. Mutschler, "Fault Tolerant Voltage Source Inverter for Permanent Magnet Drives," IEEE Transactions on Power Electronics, vol.PP, no.99, pp.1, 2011

[38] J.R. Hendershot, Jr., T.J.E. Miller, Design of Brushless Permanent-Magnet Motors, Magna Physics Pub.; Clarendon Press, Hillsboro, OH : Oxford : 1994

[39] [Absolute Encoder, image]. June 1,2011 retrieved from http://images.machinedesign.com/images/archive/talk3jpg_00000038653.jpg -

[40] [Incremental Encoder, image]. June 1,2011 retrieved from http://www.automotsys.com.au/incdisk3.jpg - incremental encoder

[41] N. Mohan, W.P. Robbins, T.M. Undeland, Power electronics: Converters, applications, and design. Hoboken, NJ: Wiley. 2007

[42] C. Klumper, F. Blaabjerg, P. Thoegersen, "Alternate ASDs: evaluation of the converter topologies suited for integrated motor drives," Industry Applications Magazine, IEEE, vol.12, no.2, pp. 71- 83, March-April 2006

[43] A. Emadi, J.L. Young, K. Rajashekara, "Power Electronics and Motor Drives in Electric, Hybrid Electric, and Plug-In Hybrid Electric Vehicles," IEEE Transactions on Industrial Electronics, vol.55, no.6, pp.2237-2245, June 2008

[44] F.L. Mapelli, D. Tarsitano, M. Mauri, "Plug-In Hybrid Electric Vehicle: Modeling, Prototype Realization, and Inverter Losses Reduction Analysis," IEEE Transactions on Industrial Electronics, vol.57, no.2, pp.598-607, Feb. 2010

[45] J.L. Young, A. Khaligh, A. Emadi, "Advanced Integrated Bidirectional AC/DC and DC/DC Converter for Plug-In Hybrid Electric Vehicles," IEEE Transactions on Vehicular Technology, vol.58, no.8, pp.3970-3980, Oct. 2009

[46] R. D. Middlebrook, S. Cuk, "A General Unified Approach to Modeling Switching Converter Stages," Power Electronics Specialists Conference, NASA Lewis Research Center, 1967, pp. 73-87. 
[47] G.W Wester, R.D. Middlebrook, "Low-Frequency Characterization of Switched DC-DC Converters," IEEE Transactions on Aerospace and Electronic Systems, vol.AES-9, no.3, pp.376-385, May 1973

[48] A. Davoudi, J. Jatskevitch, T. De Rybel, "Numerical State-Space Averaging of PWM Converters Operating in Discontinuous Mode", IEEE Transactions on Power Electronics, Vol. 21, No. 4, July 2006

[49] P. T. Krein, J. Bentsman, R. M. Bass, B. C. Lesieutre, "On the Use of Averaging for the Analysis of Power of Electronic Systems," IEEE Transactions on Power Electronics, Vol. 5, No. 2, pp. 182-190, April 1990.

[50] S. Freeland, R. D. Middlebrook, "A Unified Analysis of Converters with Resonant Switches," IEEE Power Electronics Specialists Conference, 1987 Record, pp. 20-30.

[51] V. Vorperian, R. Tymerski, F.C. Lee, "Equivalent Circuit Models for Resonant and PWM Switches," IEEE Transactions on Power Electronics, vol.4, no.2, pp. 205-214, April 1989.

[52] V. Vorperian, "Simplified Analysis of PWM Converters Using the Model of the PWM Switch: Parts I and II," IEEE Transactions on Aerospace and Electronic Systems, Vol. AES-26, pp. 490-505, May 1990.

[53] A. Witulski, R. Erickson, "Extension of State-Space Averaging to Resonant Switches and Beyond," IEEE Transactions on Power Electronics, vol.5, no.1, pp. 98-109, January 1990.

[54] D. Maksimovic, S. Cuk, "A Unified Analysis of PWM Converters in Discontinuous Modes," IEEE Transactions on Power Electronics, vol. 6, no.3, pp. 476-490, July 1991. 


\section{Appendices}

Appendix (A) PCB Design Information

In this section is a printout of each of the design layers for the printed circuit board prototype, followed by an explanation of some of the notable aspects of the DC-DC module, and the PCB design process.

On the following page, Figure A-1 shows an image of the Gerber file for the Top Silkscreen layer of the DC-DC module. Figures A-2, and A-3, show the Gerber file image for the Top Copper, Bottom Copper layers, respectively. A very important step in the design of printed circuit boards is the final review process prior to submitting the Gerber files for production. This process is referred to as a Design For Manufacturability (DFM) check. It entails a thorough inspection of the printout of the Gerber files for any erroneous marks, or variations in the intended circuit. At this point in the PCB design, the layout of the circuit has been completed, and all appropriate calculations have been made for ampacities, and spacing, at this procedure stands as a final review. In addition, the DFM check is also the last opportunity to verify that the circuit design does not violate the design rules set forth by the $\mathrm{PCB}$ manufacturing company. Often, these companies will offer their services to perform the DFM check, for free, or at a reduced price. However, although the company's DFM check can be a valuable reference tool, the final DFM check is the responsibility of the designer, and should be performed personally. 


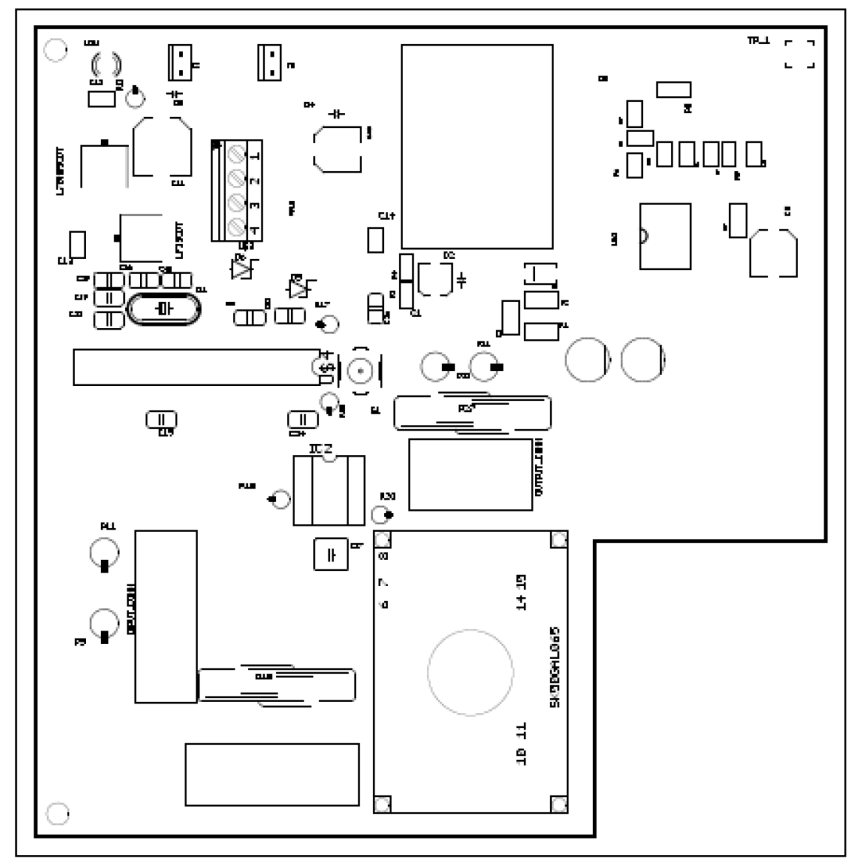

Figure A - 1 DC-DC Module Prototype 4.2 (Final Prototype) Top Silkscreen Layer

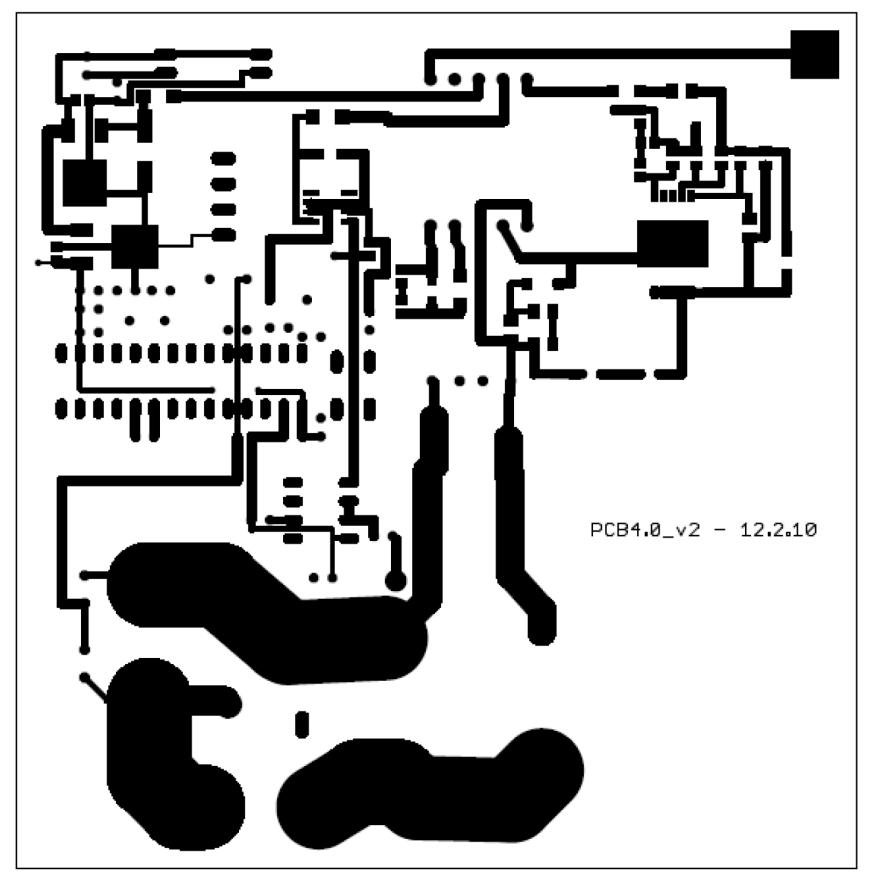

Figure A - 2 DC-DC Module Prototype 4.2 (Final Prototype) Top Copper Layer 


\section{PCB Characteristics}

Dimensions: 4.475 x 4.575

Copper weight: $1 \mathrm{oz}$

Material: FR4

Thickness: .125in

Soldermask Color: Green

Silkscreen Color: White

Power Trace Ampacity(Input Side):

17 Amps(rms)

Power Trace Ampacity(Output Side):

5 Amps(rms)

Voltage Clearance on High Voltage Traces:

$150 \mathrm{mils} / .15 \mathrm{in}$

Voltage Clearance on Low Voltage Traces:

25mils

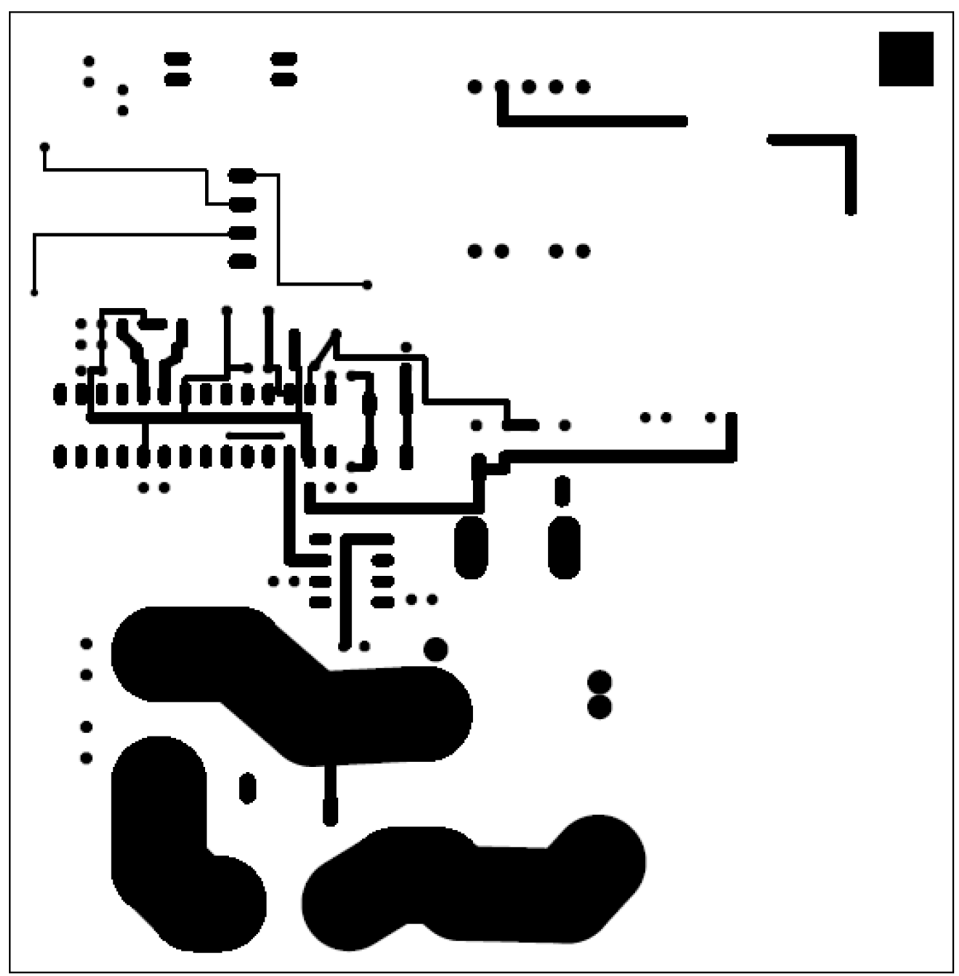

Figure A - 3 DC-DC Module Prototype 4.2 (Final Prototype) Bottom Copper Layer 


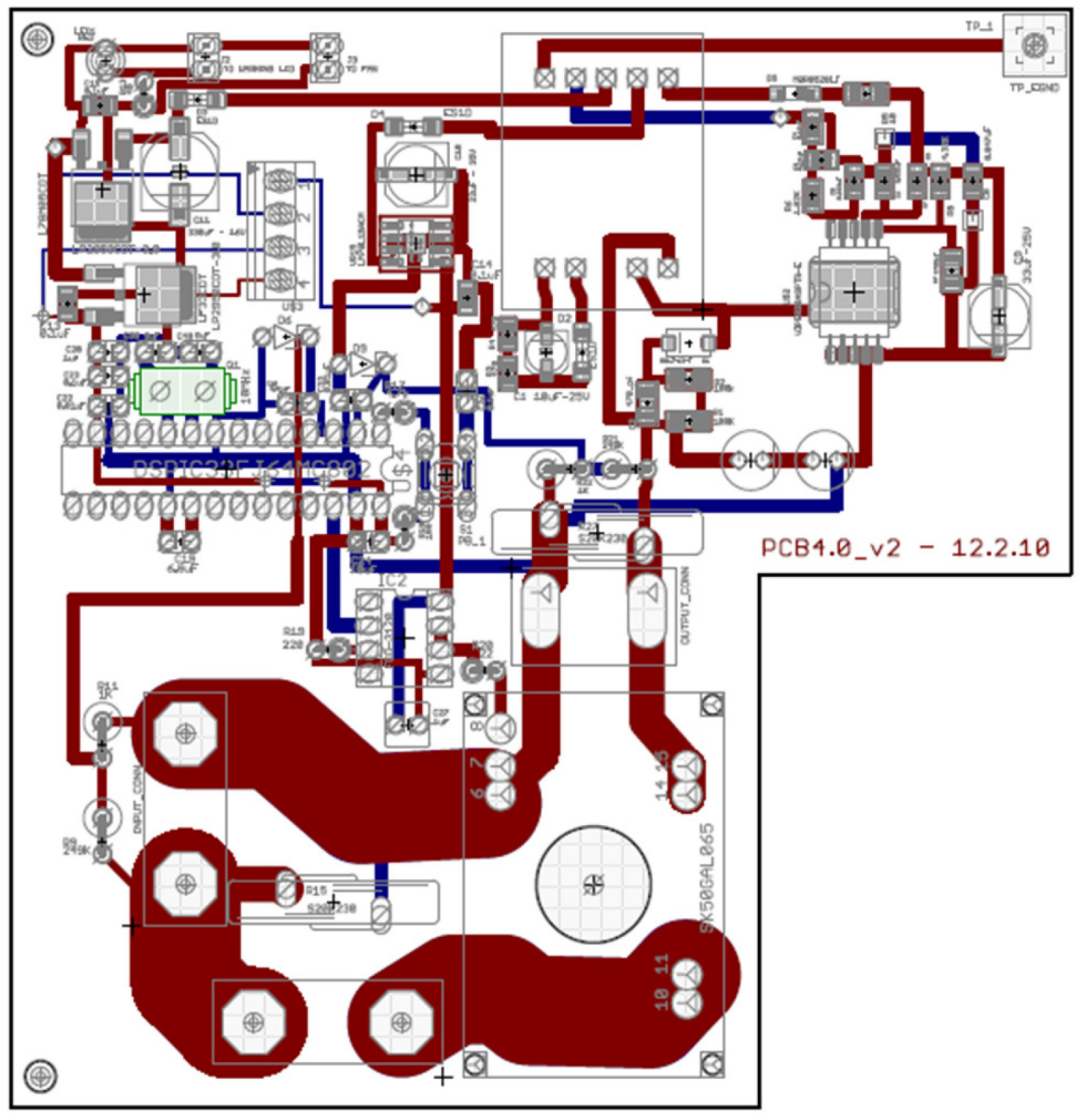

Figure A - 4 DC-DC Module Prototype 4.2, All Layers

In Figure A-3, all of the layers of the PCB have been printed. The input traces at the bottom left of both the Top Copper Layer, and the Bottom Copper Layer have been intentionally mirrored. Due to cost restrictions, the thickness of the top and bottom copper layers has to be reduced to $10 \mathrm{z}$. In order to maintain the required widths 
(454mils), the traces were paralleled on the top and bottom layers. Although this prevents any other traces from being able to cross through that region, the loss of routing space is minimal due to the location of the traces. In addition, it is a general rule of thumb to minimize the number of crossovers in a PCB route, especially if one of those tracks is conducting high currents such as in this case. Therefore, this method prevents that from being possible. It should be noted that this method is useful and does not result in any significant transient effects in this circuit, however, that may be due to the circuit topology, and not to any inherent tendencies of the technique. 


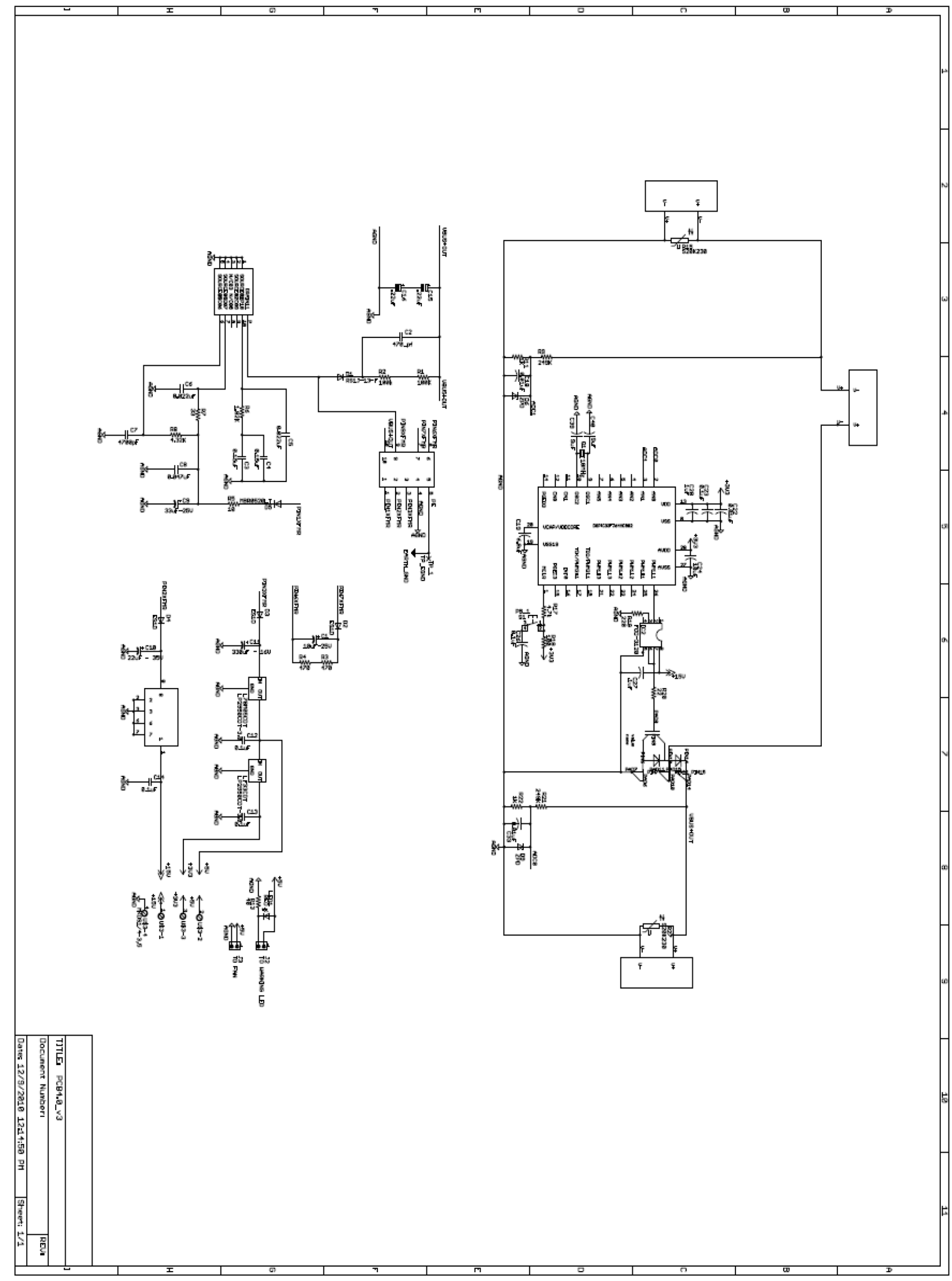

Figure A - 5 DC-DC Module Prototype 4.2 (Final Prototype) Schematic 


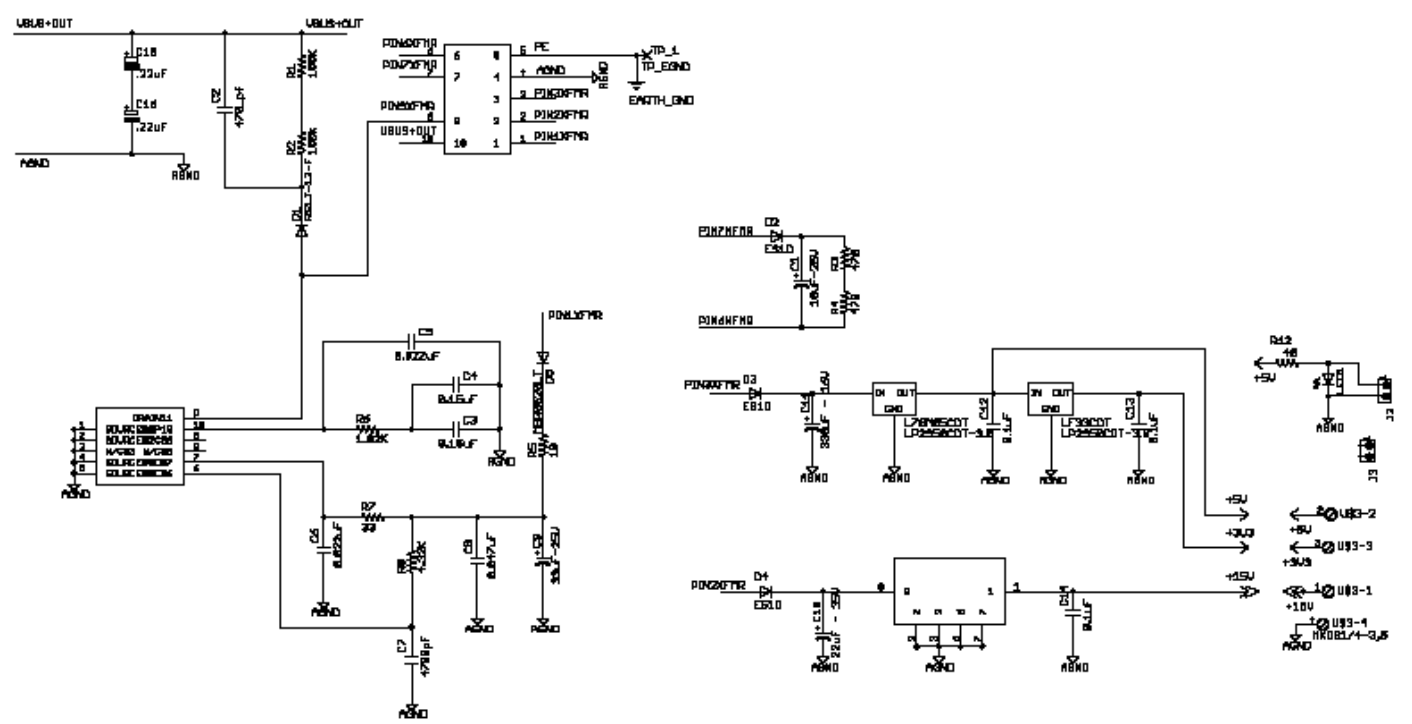

Figure A - 6 DC-DC Module Prototype 4.2 Schematic - Offline Power Supply

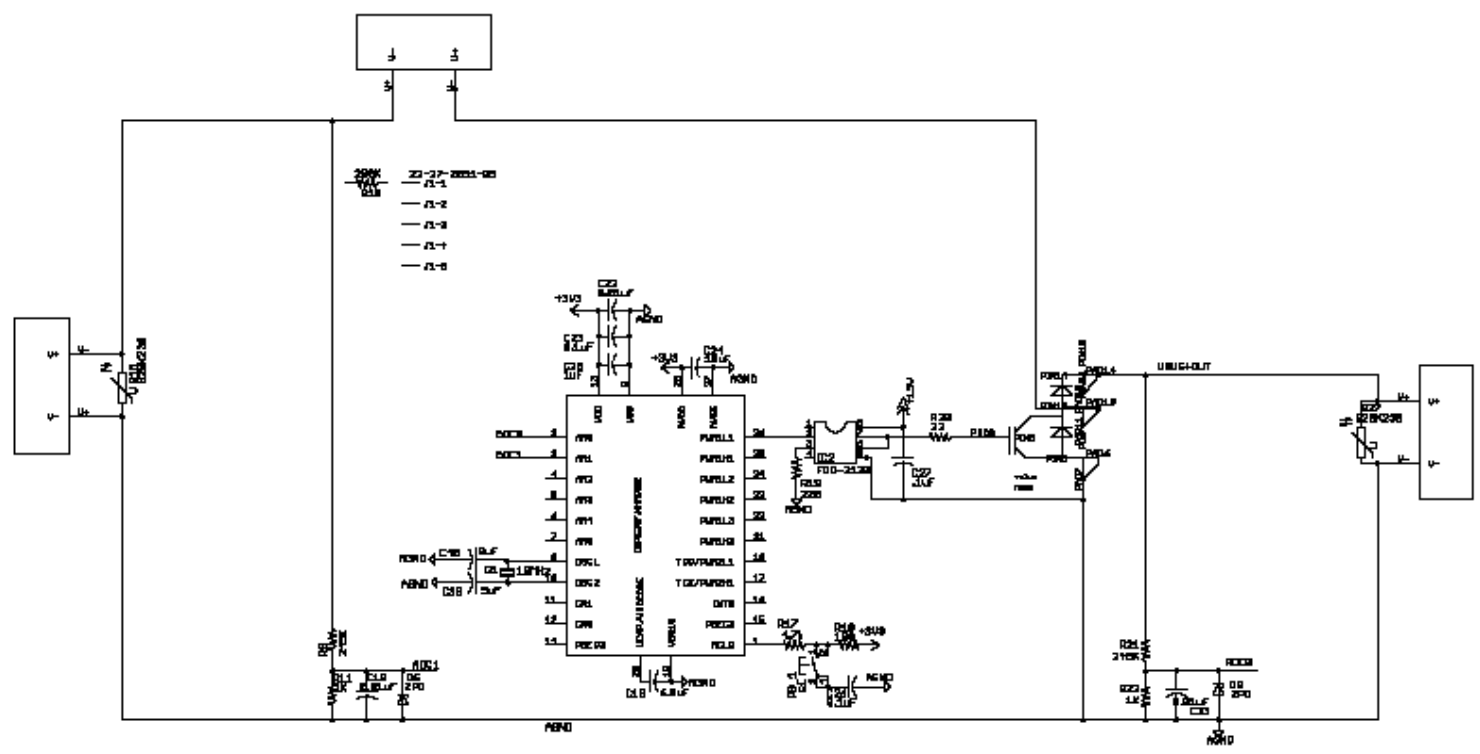

Figure A - 7 DC-DC Module Prototype 4.2 Schematic - Power and Control Circuit 
Appendix (B) Design and System Data

\begin{tabular}{|c|c|c|c|c|}
\hline Part & Value & Device & Package & Description \\
\hline $\mathrm{C} 1$ & $10 \mathrm{uF}-25 \mathrm{~V}$ & CP_SV-B & CSV-B & POLARI CAP \\
\hline $\mathrm{C} 2$ & $470 \_\mathrm{pf}$ & C_1206 & C1206 & $\begin{array}{c}\text { NON-POLAR } \\
\text { CAP }\end{array}$ \\
\hline C3 & $0.15 \mathrm{uF}$ & C_0805 & $\mathrm{C} 0805$ & $\begin{array}{c}\text { NON- } \\
\text { POLARCAP }\end{array}$ \\
\hline $\mathrm{C} 4$ & $0.15 \mathrm{uF}$ & C_0805 & $\mathrm{C} 0805$ & $\begin{array}{c}\text { NON-POLAR } \\
\text { CAP }\end{array}$ \\
\hline $\mathrm{C} 5$ & $0.022 \mathrm{uF}$ & C_0805 & $\mathrm{C} 0805$ & $\begin{array}{c}\text { NON-POLAR } \\
\text { CAP }\end{array}$ \\
\hline C6 & $0.022 \mathrm{uF}$ & C_0805 & $\mathrm{C} 0805$ & $\begin{array}{c}\text { NON-POLAR } \\
\text { CAP }\end{array}$ \\
\hline $\mathrm{C} 7$ & $4700 \mathrm{pF}$ & C_1206 & C1206 & $\begin{array}{c}\text { NON-POLAR } \\
\text { CAP }\end{array}$ \\
\hline $\mathrm{C} 8$ & $0.047 \mathrm{uF}$ & C_0805 & $\mathrm{C} 0805$ & $\begin{array}{c}\text { NON-POLAR } \\
\text { CAP }\end{array}$ \\
\hline C9 & $33 \mathrm{uF}-25 \mathrm{~V}$ & CP_SV-D & CSV-D & POLAR CAP \\
\hline $\mathrm{C} 10$ & $22 \mathrm{uF}-35 \mathrm{~V}$ & CP_SV-D & CSV-D & POLAR CAP \\
\hline $\mathrm{C} 11$ & $330 u F-16 V$ & CP_SV-E/F & CSV-E/F & POLAR CAP \\
\hline $\mathrm{C} 12$ & $0.1 \mathrm{uF}$ & $\bar{C} 0805$ & $\mathrm{C} 0805$ & $\begin{array}{c}\text { NON-POLAR } \\
\text { CAP }\end{array}$ \\
\hline $\mathrm{C} 13$ & $0.1 \mathrm{uF}$ & C_0805 & $\mathrm{C} 0805$ & $\begin{array}{c}\text { NON-POLAR } \\
\text { CAP }\end{array}$ \\
\hline $\mathrm{C} 14$ & $0.1 \mathrm{uF}$ & C_0805 & $\mathrm{C} 0805$ & $\begin{array}{l}\text { NON-POLAR } \\
\text { CAP }\end{array}$ \\
\hline $\mathrm{C} 15$ & $.22 \mathrm{uF}$ & $\begin{array}{c}\text { CPOL- } \\
\text { EUUVY2DR22MED }\end{array}$ & $\begin{array}{c}\text { UVY22DR22ME } \\
\text { D }\end{array}$ & $\begin{array}{l}\text { POLAR CAP, } \\
\text { Euro }\end{array}$ \\
\hline $\mathrm{C} 16$ & $.22 \mathrm{uF}$ & $\begin{array}{c}\text { CPOL- } \\
\text { EUUVY2DR22MED }\end{array}$ & $\begin{array}{c}\text { UVY22DR22ME } \\
\text { D }\end{array}$ & $\begin{array}{l}\text { POLAR } \\
\text { CAP,Euro }\end{array}$ \\
\hline $\mathrm{C} 18$ & $0.01 \mathrm{uF}$ & C-US025-024X044 & C025-024X044 & $\begin{array}{c}\text { CAP, American } \\
\text { sym }\end{array}$ \\
\hline C19 & $10 \mathrm{uF}$ & C-US025-024X044 & C025-024X044 & $\begin{array}{c}\text { CAP, American } \\
\text { sym }\end{array}$ \\
\hline $\mathrm{C} 22$ & $0.01 \mathrm{uF}$ & C-US025-024X044 & C025-024X044 & $\begin{array}{c}\text { CAP, American } \\
\text { sym }\end{array}$ \\
\hline $\mathrm{C} 23$ & $0.1 \mathrm{uF}$ & C-US025-024X044 & C025-024X044 & $\begin{array}{c}\text { CAP, American } \\
\text { sym }\end{array}$ \\
\hline $\mathrm{C} 24$ & $.1 \mathrm{uF}$ & C-US025-024X044 & C025-024X044 & $\begin{array}{c}\text { CAP, American } \\
\text { sym }\end{array}$ \\
\hline
\end{tabular}




\begin{tabular}{|c|c|c|c|c|}
\hline $\mathrm{C} 26$ & $0.1 \mathrm{uF}$ & C-US025-024X044 & C025-024X044 & $\begin{array}{l}\text { CAP, American } \\
\text { sym }\end{array}$ \\
\hline $\mathrm{C} 27$ & $.1 \mathrm{uF}$ & C-US025-050X050 & $\mathrm{C} 025-050 \times 050$ & $\begin{array}{c}\text { CAP, American } \\
\text { sym }\end{array}$ \\
\hline $\mathrm{C} 28$ & $10 \mathrm{uF}$ & C-US025-024X044 & C025-024X044 & $\begin{array}{c}\text { CAP, American } \\
\text { sym }\end{array}$ \\
\hline $\mathrm{C} 33$ & $0.01 \mathrm{uF}$ & C-US025-024X044 & C025-024X044 & $\begin{array}{c}\text { CAP, American } \\
\text { sym }\end{array}$ \\
\hline C39 & $9 \mathrm{uF}$ & C-US025-024X044 & C025-024X044 & $\begin{array}{c}\text { CAP, American } \\
\text { sym }\end{array}$ \\
\hline $\mathrm{C} 40$ & $9 \mathrm{uF}$ & C-US025-024X044 & C025-024X044 & $\begin{array}{c}\text { CAP, American } \\
\text { sym }\end{array}$ \\
\hline D1 & RS1J-13-F & DIODESMA & SMA-DIODE & DIODE \\
\hline $\mathrm{D} 2$ & ES1D & GF1 & SMA-DO214AC & DIODE \\
\hline D3 & ES1D & GF1 & SMA-DO214AC & DIODE \\
\hline D4 & ES1D & GF1 & SMA-DO214AC & DIODE \\
\hline D5 & MBR0520LT & MBR0520LT & SOD123 & $\begin{array}{l}\text { SCHOTTKY } \\
\text { BARRIER } \\
\text { RECTIFIER }\end{array}$ \\
\hline D6 & ZPD & ZENER-DIODEZD-5 & ZDIO-5 & Z-Diode \\
\hline D7 & ZPD & ZENER-DIODEZD-5 & ZDIO-5 & Z-Diode \\
\hline D9 & ZPD & ZENER-DIODEZD-5 & ZDIO-5 & Z-Diode \\
\hline IC2 & FOD-3120 & DIL8S & SOCKET-08 & $\begin{array}{c}\text { Dual In Line / } \\
\text { Socket }\end{array}$ \\
\hline $\mathrm{J} 1$ & $22-27-2051-05$ & $22-27-2051-05$ & $6410-05$ & CONNECTOR \\
\hline $\mathrm{J} 2$ & MTA02-100 & 10X02MTA & AMP connector & 1 \\
\hline $\mathrm{J} 3$ & MTA02-100 & 10X02MTA & AMP connector & 1 \\
\hline VR2 & L78M05CDT & LP2950CDT-3.0 & LP2950CDT-3.0 & DPACK \\
\hline LED1 & LED3MM & LED3MM & LED & RED \\
\hline VR1 & LF33CDT & LP2950CDT-3.0 & LP2950CDT-3.0 & DPACK \\
\hline Q1 & $10 \mathrm{MHz}$ & CRYSTALHC49S & $\mathrm{HC} 49 / \mathrm{S}$ & CRYSTAL \\
\hline R1 & $100 \mathrm{~K}$ & R 1206 & R1206 & RESISTOR \\
\hline $\mathrm{R} 2$ & $100 \mathrm{k}$ & R_1206 & R1206 & RESISTOR \\
\hline R3 & 470 & R_0805 & R0805 & RESISTOR \\
\hline R4 & 470 & R_0805 & R0805 & RESISTOR \\
\hline R5 & 10 & R_1206 & R1206 & RESISTOR \\
\hline R6 & $1.82 \mathrm{~K}$ & R_0805 & R0805 & RESISTOR \\
\hline R7 & 33 & R_0805 & R0805 & RESISTOR \\
\hline R8 & $4.32 \mathrm{~K}$ & R_0805 & R0805 & RESISTOR \\
\hline R9 & $249 \mathrm{~K}$ & R-US_0411/3V & $0411 \mathrm{~V}$ & $\begin{array}{l}\text { RESISTOR, Amr } \\
\text { sym }\end{array}$ \\
\hline R10 & $200 \mathrm{~K}$ & R-US_0411/3V & $0411 \mathrm{~V}$ & $\begin{array}{l}\text { RESISTOR,Amr } \\
\text { sym }\end{array}$ \\
\hline
\end{tabular}




\begin{tabular}{|c|c|c|c|c|}
\hline R11 & $1 \mathrm{~K}$ & R-US_0411/3V & $0411 \mathrm{~V}$ & $\begin{array}{c}\text { RESISTOR, Amr } \\
\text { sym }\end{array}$ \\
\hline $\mathrm{R} 12$ & 40 & R-US_0207/2V & $0207 / 2 \mathrm{~V}$ & $\begin{array}{c}\text { RESISTOR, Amr } \\
\text { sym }\end{array}$ \\
\hline R15 & S20K230 & S20K230 & S20K230 & VARISTOR \\
\hline R17 & $4.7 \mathrm{k}$ & R-US_0207/2V & $0207 / 2 \mathrm{~V}$ & $\begin{array}{c}\text { RESISTOR, Amr } \\
\text { sym }\end{array}$ \\
\hline R18 & 100 & R-US_0207/2V & $0207 / 2 \mathrm{~V}$ & $\begin{array}{c}\text { RESISTOR, Amr } \\
\text { sym }\end{array}$ \\
\hline R19 & 220 & R-US_0207/2V & $0207 / 2 \mathrm{~V}$ & $\begin{array}{c}\text { RESISTOR, Amr } \\
\text { sym }\end{array}$ \\
\hline R20 & 22 & R-US_0207/2V & $0207 / 2 \mathrm{~V}$ & $\begin{array}{c}\text { RESISTOR, Amr } \\
\text { sym }\end{array}$ \\
\hline R21 & $249 \mathrm{~K}$ & R-US_0411/3V & $0411 \mathrm{~V}$ & $\begin{array}{c}\text { RESISTOR, Amr } \\
\text { sym }\end{array}$ \\
\hline R22 & $1 \mathrm{~K}$ & R-US_0411/3V & $0411 \mathrm{~V}$ & \begin{tabular}{|c|} 
RESISTOR, Amr \\
sym
\end{tabular} \\
\hline R27 & $\mathrm{S} 20 \mathrm{~K} 230$ & $\mathrm{~S} 20 \mathrm{~K} 230$ & S20K230 & VARISTOR \\
\hline S1 & PB_1 & $10-X X$ & B3F-10XX & $\begin{array}{l}\text { OMRON } \\
\text { SWITCH }\end{array}$ \\
\hline $\mathrm{TP}_{-} 1$ & TP_EGND & $3,81 / 1,4$ & $3,81 / 1,4$ & $\begin{array}{c}\text { THRU-HOLE } \\
\text { PAD }\end{array}$ \\
\hline U\$1 & A0S775 & A0S775 & $\begin{array}{c}\text { TRANSFORME } \\
\text { R }\end{array}$ & $\begin{array}{c}\text { POWER SUPPLY } \\
\text { XFMR }\end{array}$ \\
\hline U\$2 & \begin{tabular}{|c|} 
VIPER20ASPTR- \\
$\mathrm{E}$
\end{tabular} & VIPER20ASPTR-E & POWER-SO10 & SMPS Switcher \\
\hline U\$3 & MKDS1/4-3,5 & MKDS1/4-3,5 & 4POL350 & MKDS 1/4-3,5 \\
\hline U\$4 & \begin{tabular}{|c|} 
DSPIC33FJ64MC \\
802 \\
\end{tabular} & DSPIC33FJ64MC802 & DIL28-3 & Microchip dsPIC \\
\hline U\$5 & BOOSTCONN & BOOSTCONN & BOOSTCONN & Connector \\
\hline U\$6 & BOOSTCONN & BOOSTCONN & BOOSTCONN & Connector \\
\hline U\$7 & $\begin{array}{c}\text { IGBTSK50GAL06 } \\
5 \\
\end{array}$ & IGBTSK50GAL065 & IGBT-MODULE & Semikron IGBT \\
\hline U\$8 & $\begin{array}{c}\text { BOOSTCONN_O } \\
\text { UT }\end{array}$ & BOOSTCONN_OUT & $\begin{array}{c}\text { BOOSTCONN } \\
\text { OUT }\end{array}$ & Connector \\
\hline VR15 & LM78L15ACM & LM78L15ACM & SO-08 & Voltage Regulator \\
\hline L1 & $150 \mathrm{uH}$ & Inductor & Inductor & Inductor \\
\hline
\end{tabular}

Table B - 2 DC-DC Module Prototype 4.1 (Final Prototype) Bill of Material 
Appendix (C) Microcontroller Design

Microcontroller: Microchip dsPIC33fj64mc802

Internal oscillator: $7.37 \mathrm{MHz}$

External oscillator:10.0 MHz - unused

Instructions per second: 40MIPS

I/O used: AN0 - Output voltage

$$
\begin{aligned}
& \text { AN1 - Input voltage } \\
& \text { RB15 - PWM1L } \\
& \text { RB14 - PWM1H - Spare }
\end{aligned}
$$

Close attention must be paid to the data types when utilizing the dsPIC blockset for MATLAB. In the case that a data type is incorrect, a warning message may be displayed upon attempting to compile a model, however, this is no always true, and often errors will go undetected, yet the microcontroller will not function properly. 
Appendix (D) Experimental Data

\begin{tabular}{|c|c|c|c|c|c|c|c|}
\hline 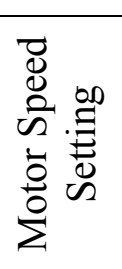 & 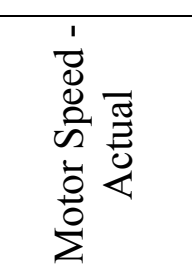 & 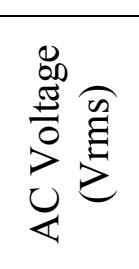 & 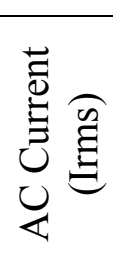 & 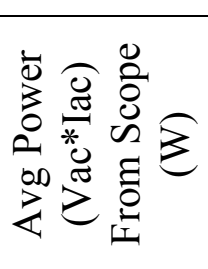 & 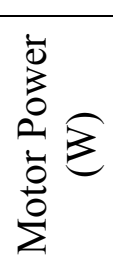 & 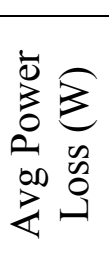 & 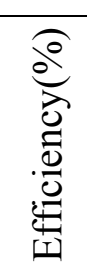 \\
\hline 700 & 765 & 214.69 & 0.946 & 84 & 84 & 0 & $\begin{array}{c}100 . \\
0\end{array}$ \\
\hline 750 & 765 & 214.69 & 0.946 & 84 & 84 & 0 & $\begin{array}{c}100 . \\
0\end{array}$ \\
\hline 800 & $\begin{array}{c}778-823 \\
\text { (marginal } \\
\text { stability) }\end{array}$ & 214.15 & 1.01 & 87 & 87 & 0 & $\begin{array}{c}100 . \\
0\end{array}$ \\
\hline 850 & 850 & 213.64 & 1.043 & 97 & 98 & 0 & $\begin{array}{c}100 . \\
0\end{array}$ \\
\hline 900 & 900 & 213.79 & 1.131 & 106 & 106 & 0 & $\begin{array}{c}100 . \\
0\end{array}$ \\
\hline 950 & $\begin{array}{c}935-969 \\
\text { (marginal } \\
\text { stability) }\end{array}$ & 213.9 & 1.153 & 116 & 111 & 5 & $\begin{array}{c}95.6 \\
9\end{array}$ \\
\hline 1000 & 1000 & 213.79 & 1.295 & 122 & 118 & 4 & $\begin{array}{c}96.7 \\
2\end{array}$ \\
\hline 1050 & 1050 & 213.75 & 1.379 & 131 & 127 & 4 & $\begin{array}{c}96.9 \\
5\end{array}$ \\
\hline 1100 & 1100 & 213.87 & 1.501 & 143 & 133 & 10 & $\begin{array}{c}93.0 \\
1\end{array}$ \\
\hline 1150 & 1150 & 213.74 & 1.602 & 154 & 143 & 11 & $\begin{array}{c}92.8 \\
6\end{array}$ \\
\hline 1200 & 1200 & 213.49 & 1.716 & 167 & 152 & 15 & $\begin{array}{c}91.0 \\
2\end{array}$ \\
\hline 1250 & 1250 & 213.79 & 1.824 & 180 & 163 & 17 & $\begin{array}{c}90.5 \\
6\end{array}$ \\
\hline 1300 & 1300 & 213.61 & 1.951 & 194 & 175 & 19 & $\begin{array}{c}90.2 \\
1\end{array}$ \\
\hline 1350 & 1350 & 213.42 & 2.088 & 212 & 189 & 23 & $\begin{array}{c}89.1 \\
5\end{array}$ \\
\hline 1400 & 1400 & 212.94 & 2.243 & 226 & 199 & 27 & $\begin{array}{c}88.0 \\
5\end{array}$ \\
\hline 1450 & 1450 & 212.47 & 2.428 & 245 & 218 & 27 & $\begin{array}{c}88.9 \\
8\end{array}$ \\
\hline 1500 & 1500 & 212.69 & 2.588 & 266 & 237 & 29 & $\begin{array}{c}89.1 \\
0\end{array}$ \\
\hline 1550 & 1550 & 212.65 & 2.781 & 284 & 249 & 35 & 87.6 \\
\hline
\end{tabular}




\begin{tabular}{|c|c|c|c|c|c|c|c|}
\hline & & & & & & & 8 \\
\hline 1600 & 1600 & 212.58 & 2.963 & 305 & 270 & 35 & $\begin{array}{c}88.5 \\
3\end{array}$ \\
\hline 1650 & 1650 & 212.55 & 3.15 & 325 & 291 & 34 & $\begin{array}{c}89.5 \\
4\end{array}$ \\
\hline 1700 & 1700 & 212.57 & 3.348 & 350 & 309 & 41 & $\begin{array}{c}88.2 \\
9\end{array}$ \\
\hline 1750 & 1750 & 212.83 & 3.556 & 376 & 335 & 41 & $\begin{array}{c}89.1 \\
0\end{array}$ \\
\hline 1800 & 1800 & 212.59 & 3.744 & 406 & 357 & 49 & $\begin{array}{c}87.9 \\
3\end{array}$ \\
\hline 1850 & 1850 & 212.54 & 3.991 & 431 & 382 & 49 & $\begin{array}{c}88.6 \\
3 \\
\end{array}$ \\
\hline 1900 & 1900 & 212.37 & 4.233 & 460 & 409 & 51 & $\begin{array}{c}88.9 \\
1 \\
\end{array}$ \\
\hline 1950 & 1950 & 214.31 & 4.495 & 490 & 441 & 49 & $\begin{array}{c}90.0 \\
0\end{array}$ \\
\hline 2000 & 2000 & 214.7 & 4.781 & 531 & 468 & 63 & $\begin{array}{c}88.1 \\
4 \\
\end{array}$ \\
\hline 2050 & 2050 & 214.67 & 5.083 & 567 & 505 & 62 & $\begin{array}{c}89.0 \\
7 \\
\end{array}$ \\
\hline 2100 & 2100 & 214.8 & 5.367 & 602 & 536 & 66 & $\begin{array}{c}89.0 \\
4 \\
\end{array}$ \\
\hline 2150 & 2150 & 214.57 & 5.699 & 642 & 572 & 70 & $\begin{array}{c}89.1 \\
0 \\
\end{array}$ \\
\hline 2200 & 2200 & 214.35 & 5.949 & 681 & 615 & 66 & $\begin{array}{c}90.3 \\
1 \\
\end{array}$ \\
\hline 2250 & 2250 & 213.81 & 6.313 & 722 & 657 & 65 & $\begin{array}{c}90.9 \\
9 \\
\end{array}$ \\
\hline 2300 & 2300 & 213.69 & 6.675 & 766 & 698 & 68 & $\begin{array}{c}91.1 \\
2 \\
\end{array}$ \\
\hline 2350 & 2350 & 213.43 & 7.013 & 811 & 743 & 68 & $\begin{array}{c}91.6 \\
2 \\
\end{array}$ \\
\hline 2400 & 2400 & 213.83 & 7.412 & 853 & 786 & 67 & $\begin{array}{c}92.1 \\
5\end{array}$ \\
\hline 2450 & 2450 & 213.34 & 7.715 & 900 & 830 & 70 & $\begin{array}{c}92.2 \\
2 \\
\end{array}$ \\
\hline 2500 & 2500 & 213.53 & 8.082 & 952 & 881 & 71 & $\begin{array}{c}92.5 \\
4 \\
\end{array}$ \\
\hline 2550 & 2550 & 213.21 & 8.478 & 997 & 933 & 64 & $\begin{array}{c}93.5 \\
8\end{array}$ \\
\hline 2600 & 2600 & 213.41 & 8.903 & 1060 & 982 & 78 & $\begin{array}{c}92.6 \\
4 \\
\end{array}$ \\
\hline 2650 & 2650 & 213.49 & 9.301 & 1107 & 1038 & 69 & 93.7 \\
\hline
\end{tabular}




\begin{tabular}{|c|c|c|c|c|c|c|c|}
\hline & & & & & & & 7 \\
\hline 2700 & 2700 & 213.18 & 9.671 & 1155 & 1089 & 66 & $\begin{array}{c}94.2 \\
9\end{array}$ \\
\hline 2750 & 2750 & 213.01 & 10.222 & 1231 & 1143 & 88 & $\begin{array}{c}92.8 \\
5\end{array}$ \\
\hline 2800 & 2800 & 212.74 & 10.57 & 1290 & 1231 & 59 & $\begin{array}{c}95.4 \\
3\end{array}$ \\
\hline 2850 & 2850 & 212.83 & 10.896 & 1350 & 1289 & 61 & $\begin{array}{c}95.4 \\
8\end{array}$ \\
\hline 2900 & 2900 & 212.84 & 11.371 & 1402 & 1324 & 78 & $\begin{array}{c}94.4 \\
4\end{array}$ \\
\hline 2950 & 2948 & 212.86 & 11.714 & 1435 & 1373 & 62 & $\begin{array}{c}95.6 \\
8\end{array}$ \\
\hline 3000 & 2298 & 212.64 & 12.177 & 1498 & 1419 & 79 & $\begin{array}{c}94.7 \\
3\end{array}$ \\
\hline 3050 & 3051 & 212.54 & 12.675 & 1563 & 1507 & 56 & $\begin{array}{c}96.4 \\
2\end{array}$ \\
\hline 3100 & 3100 & 212.57 & 12.979 & 1616 & 1553 & 63 & $\begin{array}{c}96.1 \\
0\end{array}$ \\
\hline 3150 & 3151 & 212.26 & 13.333 & 1665 & 1634 & 31 & $\begin{array}{c}98.1 \\
4\end{array}$ \\
\hline 3200 & 3200 & 212.51 & 12.647 & 1705 & 1642 & 63 & $\begin{array}{c}96.3 \\
1\end{array}$ \\
\hline 3250 & 3249 & 212.09 & 14.34 & 1787 & 1724 & 63 & $\begin{array}{c}96.4 \\
8\end{array}$ \\
\hline 3300 & 3305 & 211.67 & 14.74 & 1853 & 1748 & 105 & $\begin{array}{c}94.3 \\
3\end{array}$ \\
\hline 3350 & 3348 & 211.79 & 15.22 & 1916 & 1849 & 67 & $\begin{array}{c}96.5 \\
0\end{array}$ \\
\hline 3400 & 3401 & 211.84 & 15.62 & 1995 & 1903 & 92 & $\begin{array}{c}95.3 \\
9\end{array}$ \\
\hline 3450 & 3451 & 211.71 & 16.15 & 2040 & 2001 & 39 & $\begin{array}{c}98.0 \\
9\end{array}$ \\
\hline
\end{tabular}

Table D - 1 Motor Operating Parameters 
$10 \mathrm{kHz}$ Switching Frequency Data

\begin{tabular}{|c|c|c|c|c|c|c|c|c|c|c|c|}
\hline 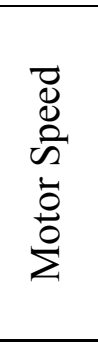 & 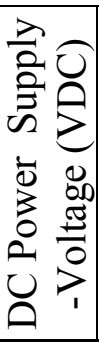 & 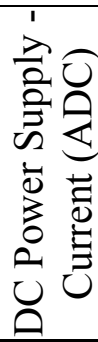 & 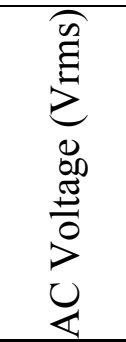 & 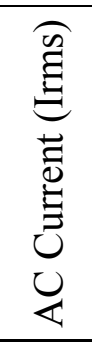 & 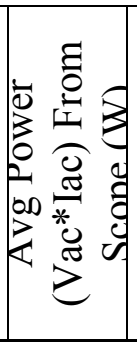 & 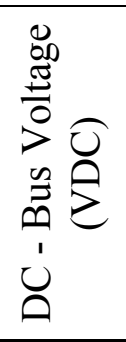 & 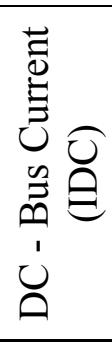 & 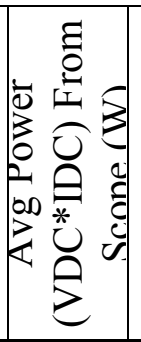 & 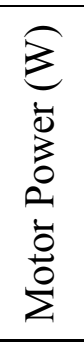 & 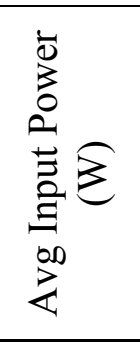 & $\begin{array}{l}0 \\
0 \\
0 \\
1 \\
\dot{0} \\
0 \\
0 \\
0 \\
0 \\
0 \\
\sum\end{array}$ \\
\hline 1500 & 91 & 3.48 & 215.7 & 0.20 & 4 & 306.10 & 0.711 & 217 & 230 & 316.68 & 99.68 \\
\hline 1650 & 91 & 3.48 & 215.1 & 0.75 & 67 & 304.80 & 0.723 & 216 & 287 & 316.59 & 100.59 \\
\hline 1800 & 91 & 3.83 & 216.9 & 1.23 & 114 & 304.00 & 0.73 & 220 & 354 & 348.53 & 128.53 \\
\hline 1950 & 91 & 3.51 & 216.7 & 2.20 & 221 & 303.00 & 0.695 & 210 & 436 & 319.41 & 109.41 \\
\hline 2100 & 91 & 3.52 & 217.62 & 3.18 & 334 & 303.42 & 0.75 & 225 & 538 & 320.05 & 95.05 \\
\hline 2252 & 91 & 3.55 & 217.77 & 4.14 & 453 & 302.59 & 0.743 & 223 & 647 & 322.96 & 99.96 \\
\hline 2303 & 91 & 3.54 & 217.93 & 4.41 & 482 & 302.05 & 0.737 & 221 & 692 & 322.50 & 101.50 \\
\hline
\end{tabular}

Table D - 2 DC-DC Module Prototype v1.0 first test

\begin{tabular}{|c|c|c|c|c|c|c|c|c|c|c|c|c|}
\hline 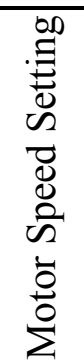 & 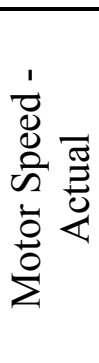 & 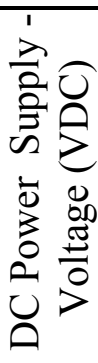 & 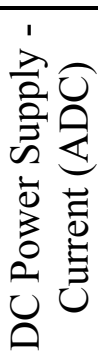 & 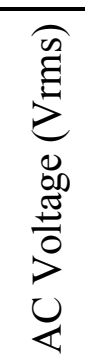 & 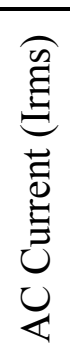 & 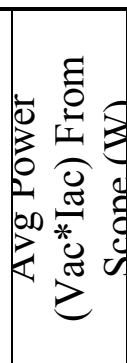 & $\begin{array}{l}\stackrel{0}{0} \\
\stackrel{\Xi}{ \pm} \\
0 \\
>\end{array}$ & 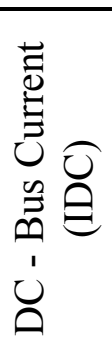 & 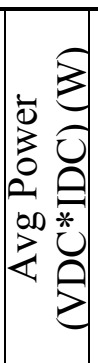 & $\begin{array}{l}\sum \\
\dot{0} \\
3 \\
0 \\
0 \\
\dot{0} \\
\dot{0} \\
\dot{0}\end{array}$ & 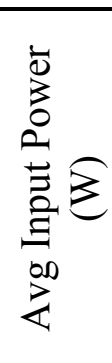 & 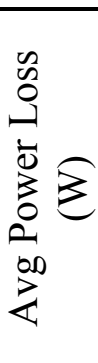 \\
\hline 700 & 779 & $\begin{array}{c}77 . \\
7\end{array}$ & $\begin{array}{c}1.1 \\
9\end{array}$ & $\begin{array}{c}215 . \\
4\end{array}$ & $\begin{array}{c}0.2 \\
0\end{array}$ & 9 & 304.2 & 0.15 & 46 & 9 & 92.54 & $\begin{array}{c}46.5 \\
4\end{array}$ \\
\hline 900 & 900 & $\begin{array}{c}77 . \\
7\end{array}$ & $\begin{array}{c}1.1 \\
9\end{array}$ & $\begin{array}{c}215 . \\
6\end{array}$ & $\begin{array}{c}0.4 \\
1\end{array}$ & 28 & 303.4 & $\begin{array}{c}0.15 \\
7\end{array}$ & 48 & 104 & 92.54 & $\begin{array}{c}44.5 \\
4\end{array}$ \\
\hline 110 & 110 & 77. & $\begin{array}{c}1.1 \\
9\end{array}$ & 215. & $\begin{array}{c}0.7 \\
8\end{array}$ & 72 & 3032 & 0.16 & 48 & 132 & 0258 & $\begin{array}{c}44.5 \\
8\end{array}$ \\
\hline 130 & 130 & 77. & 1.1 & 217. & 1.3 & & & 0.15 & & & & 45.7 \\
\hline 0 & 0 & 7 & 9 & 6 & 4 & 121 & 304.2 & 5 & 47 & 171 & 92.77 & 7 \\
\hline 150 & 150 & 77. & 1.2 & 215. & 1.9 & & & 0.11 & & & & 50.2 \\
\hline 0 & 0 & 9 & 4 & 9 & 5 & 192 & 300.1 & 3 & 46 & 231 & 96.21 & 1 \\
\hline 155 & 155 & 77. & 1.1 & 215. & 2.1 & & & 0.11 & & & & 41.5 \\
\hline 0 & 0 & 7 & 3 & 6 & 2 & 210 & 299.9 & 4 & 46 & 246 & 87.57 & 7 \\
\hline 160 & 160 & 77. & 1.1 & 215. & 2.3 & & & 0.11 & & & & 41.4 \\
\hline 0 & 0 & 6 & 3 & 6 & 2 & 233 & 300.5 & 5 & 46 & 268 & 87.46 & 6 \\
\hline 165 & 165 & 77. & 1.1 & 215. & 2.2 & 232 & 300.4 & 0.11 & 46 & 287 & 85.55 & 39.5 \\
\hline
\end{tabular}




\begin{tabular}{|c|c|c|c|c|c|c|c|c|c|c|c|c|}
0 & 0 & 7 & 0 & 2 & 9 & & & 6 & & & & 5 \\
\hline 170 & 170 & 78 & 1.1 & 215. & 2.7 & & & 0.12 & & & & 39.6 \\
0 & 0 & 5 & 0 & 2 & 5 & 276 & 300.3 & 7 & 47 & 307 & 86.66 & 6 \\
\hline 210 & 210 & 78. & 1.2 & 217. & 4.6 & & & 0.18 & & & & 42.2 \\
0 & 0 & 7 & 4 & 1 & 5 & 520 & 300.8 & 2 & 55 & 532 & 97.27 & 7 \\
\hline 230 & 230 & 78 & 1.3 & 213. & 5.7 & & & 0.16 & & & 104.5 & 57.5 \\
0 & 0 & 7 & 3 & 4 & 0 & 678 & 293.7 & 6 & 47 & 690 & 9 & 9 \\
\hline 250 & 250 & 78 & 1.3 & 213. & 7.6 & & & 0.18 & & & 103.4 & 50.4 \\
0 & 0 & 7 & 1 & 3 & 1 & 872 & 291.3 & 3 & 53 & 870 & 1 & 1 \\
\hline 270 & 270 & 78 & 1.3 & 213. & 9.0 & 108 & 289.1 & 0.18 & & 109 & 102.9 & 49.9 \\
0 & 0 & 7 & 1 & 3 & 1 & 4 & 2 & 5 & 53 & 3 & 4 & 4 \\
\hline
\end{tabular}

Table D - 3 DC-DC module prototype v1.0 - Electrical performance test data for $f_{s}=$ $10 \mathrm{kHz}$, constant $20 \%$ duty ratio, and constant $78.7 \mathrm{~V}$ input voltage vs. motor speed

\begin{tabular}{|c|c|c|c|c|c|c|c|c|c|c|c|c|}
\hline 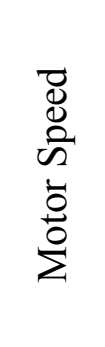 & 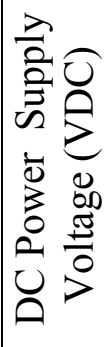 & 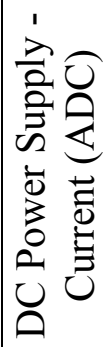 & 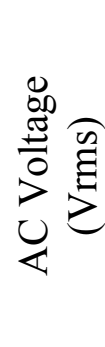 & 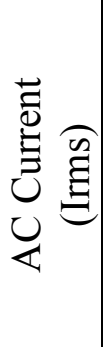 & 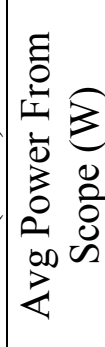 & 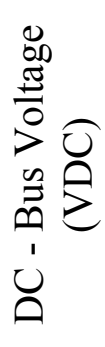 & 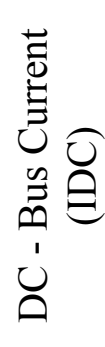 & 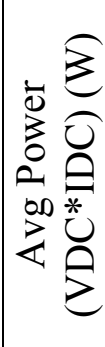 & $\begin{array}{l}\hat{z} \\
\overline{0} \\
0 \\
0 \\
0 \\
\overline{0} \\
\dot{0} \\
\Sigma\end{array}$ & 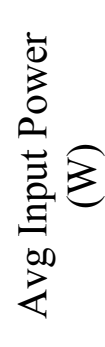 & 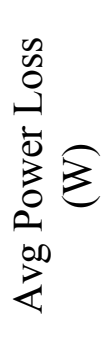 & 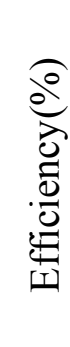 \\
\hline 1100 & $\begin{array}{c}78 . \\
1\end{array}$ & $\begin{array}{c}2.6 \\
4 \\
\end{array}$ & $\begin{array}{c}217 . \\
4\end{array}$ & $\begin{array}{c}0.1 \\
1\end{array}$ & 0 & $\begin{array}{c}356 . \\
3\end{array}$ & $\begin{array}{c}0.38 \\
2\end{array}$ & 135 & 132 & $\begin{array}{c}206 . \\
3\end{array}$ & $\begin{array}{c}71.3 \\
4\end{array}$ & $\begin{array}{r}65 \\
4 \\
\end{array}$ \\
\hline 1200 & $\begin{array}{c}78 . \\
1\end{array}$ & $\begin{array}{c}2.7 \\
4\end{array}$ & $\begin{array}{c}217 . \\
9\end{array}$ & $\begin{array}{c}0.1 \\
2\end{array}$ & 3 & $\begin{array}{c}309 . \\
3\end{array}$ & $\begin{array}{c}0.46 \\
3\end{array}$ & 143 & 150 & $\begin{array}{c}213 . \\
8\end{array}$ & $\begin{array}{c}70.7 \\
6\end{array}$ & $\begin{array}{c}66 . \\
9\end{array}$ \\
\hline 1300 & $\begin{array}{c}78 . \\
1\end{array}$ & $\begin{array}{c}2.7 \\
2\end{array}$ & $\begin{array}{c}217 . \\
9\end{array}$ & $\begin{array}{c}0.4 \\
3\end{array}$ & 30 & $\begin{array}{c}307 . \\
4\end{array}$ & $\begin{array}{c}0.46 \\
1\end{array}$ & 141 & 172 & $\begin{array}{c}212 . \\
6\end{array}$ & $\begin{array}{c}71.5 \\
9\end{array}$ & $\begin{array}{c}66 . \\
3\end{array}$ \\
\hline 1500 & $\begin{array}{c}78 . \\
8\end{array}$ & $\begin{array}{c}2.6 \\
7\end{array}$ & $\begin{array}{c}217 . \\
8\end{array}$ & $\begin{array}{c}1.1 \\
1\end{array}$ & 99 & $\begin{array}{c}306 . \\
8\end{array}$ & $\begin{array}{c}0.48 \\
5\end{array}$ & 149 & 231 & $\begin{array}{c}210 . \\
7\end{array}$ & $\begin{array}{c}61.7 \\
1\end{array}$ & $\begin{array}{c}70 . \\
7\end{array}$ \\
\hline 1600 & $\begin{array}{c}79 . \\
0\end{array}$ & $\begin{array}{c}2.6 \\
7\end{array}$ & $\begin{array}{c}217 . \\
7\end{array}$ & $\begin{array}{c}1.5 \\
1\end{array}$ & 141 & $\begin{array}{c}306 . \\
4\end{array}$ & $\begin{array}{c}0.48 \\
0\end{array}$ & 145 & 265 & $\begin{array}{c}211 . \\
0\end{array}$ & $\begin{array}{c}66.0 \\
1\end{array}$ & $\begin{array}{c}68 . \\
7\end{array}$ \\
\hline 1700 & $\begin{array}{c}79 . \\
0\end{array}$ & $\begin{array}{c}2.7 \\
4\end{array}$ & $\begin{array}{c}217 . \\
3\end{array}$ & $\begin{array}{c}1.9 \\
1\end{array}$ & 186 & $\begin{array}{c}305 . \\
5\end{array}$ & $\begin{array}{c}0.48 \\
1\end{array}$ & 146 & 307 & $\begin{array}{c}216 . \\
3\end{array}$ & $\begin{array}{c}70.3 \\
0\end{array}$ & $\begin{array}{r}67 . \\
5\end{array}$ \\
\hline 1900 & $\begin{array}{c}79 . \\
0 \\
\end{array}$ & $\begin{array}{c}2.7 \\
4 \\
\end{array}$ & $\begin{array}{c}217 . \\
3\end{array}$ & $\begin{array}{c}2.8 \\
9 \\
\end{array}$ & 299 & $\begin{array}{c}303 . \\
7 \\
\end{array}$ & $\begin{array}{c}0.48 \\
3 \\
\end{array}$ & 146 & 405 & $\begin{array}{c}216 . \\
5\end{array}$ & $\begin{array}{c}70.5 \\
4 \\
\end{array}$ & $\begin{array}{r}67 . \\
4 \\
\end{array}$ \\
\hline 2100 & $\begin{array}{c}79 . \\
1\end{array}$ & $\begin{array}{c}2.7 \\
2\end{array}$ & $\begin{array}{c}217 . \\
3\end{array}$ & $\begin{array}{c}3.8 \\
9\end{array}$ & 427 & $\begin{array}{c}302 . \\
5\end{array}$ & $\begin{array}{c}0.48 \\
3\end{array}$ & 146 & 532 & $\begin{array}{c}215 . \\
2\end{array}$ & $\begin{array}{c}69.2 \\
3\end{array}$ & $\begin{array}{r}67 . \\
8\end{array}$ \\
\hline 2300 & $\begin{array}{c}79 . \\
1\end{array}$ & $\begin{array}{c}2.9 \\
0\end{array}$ & $\begin{array}{c}214 \\
3\end{array}$ & $\begin{array}{c}5.0 \\
3\end{array}$ & 562 & $\begin{array}{c}295 . \\
1\end{array}$ & $\begin{array}{c}0.54 \\
8\end{array}$ & 159 & 690 & $\begin{array}{c}229 . \\
2\end{array}$ & $\begin{array}{c}70.1 \\
5\end{array}$ & $\begin{array}{r}69 . \\
4\end{array}$ \\
\hline 2500 & $\begin{array}{c}79 . \\
1\end{array}$ & $\begin{array}{c}2.9 \\
1\end{array}$ & $\begin{array}{c}213 . \\
8\end{array}$ & $\begin{array}{c}6.5 \\
4\end{array}$ & 754 & $\begin{array}{c}293 . \\
3\end{array}$ & $\begin{array}{c}0.55 \\
9\end{array}$ & 163 & 870 & $\begin{array}{c}229 . \\
8\end{array}$ & $\begin{array}{c}66.7 \\
9\end{array}$ & $\begin{array}{c}70 . \\
9\end{array}$ \\
\hline 2700 & $\begin{array}{c}79 . \\
0\end{array}$ & $\begin{array}{c}2.9 \\
2\end{array}$ & $\begin{array}{c}213 . \\
3\end{array}$ & $\begin{array}{c}8.2 \\
0\end{array}$ & 981 & $\begin{array}{c}290 . \\
1\end{array}$ & $\begin{array}{c}0.59 \\
2\end{array}$ & 174 & 1093 & $\begin{array}{c}230 . \\
8\end{array}$ & $\begin{array}{c}56.7 \\
6\end{array}$ & $\begin{array}{r}75 \\
4 \\
\end{array}$ \\
\hline
\end{tabular}


Table D - 4 DC-DC module prototype v1.0 - Electrical performance test data for $f_{s}=$ $10 \mathrm{kHz}$, constant $30 \%$ duty ratio, and constant $79.1 \mathrm{~V}$ input voltage vs. motor speed

\begin{tabular}{|c|c|c|c|c|c|c|c|c|c|c|c|c|}
\hline 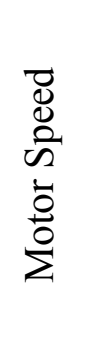 & 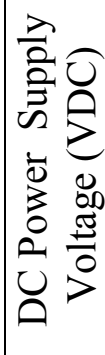 & 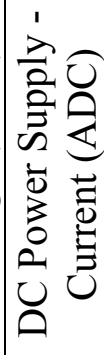 & 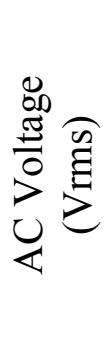 & 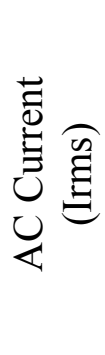 & 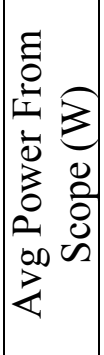 & 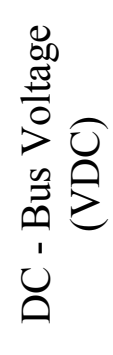 & 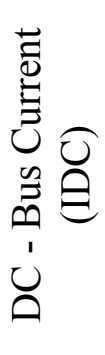 & 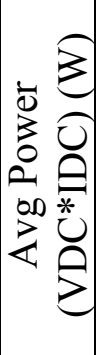 & $\begin{array}{l}3 \\
\dot{0} \\
0 \\
0 \\
0 \\
\dot{0} \\
0 \\
\dot{0}\end{array}$ & 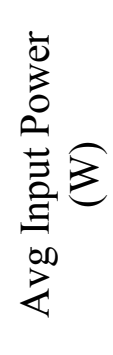 & 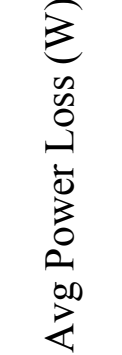 & 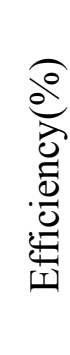 \\
\hline $\begin{array}{c}155 \\
0\end{array}$ & $\begin{array}{c}79 . \\
6\end{array}$ & $\begin{array}{c}4.7 \\
7\end{array}$ & $\begin{array}{c}215 . \\
7\end{array}$ & $\begin{array}{c}0.05 \\
3\end{array}$ & 0 & $\begin{array}{c}336 . \\
6\end{array}$ & $\begin{array}{c}0.81 \\
2\end{array}$ & $\begin{array}{c}28 \\
3\end{array}$ & 242 & $\begin{array}{c}379.2 \\
9\end{array}$ & 96.29 & $\begin{array}{c}74 . \\
6\end{array}$ \\
\hline $\begin{array}{c}160 \\
0\end{array}$ & $\begin{array}{c}79 . \\
9\end{array}$ & $\begin{array}{c}4.8 \\
2\end{array}$ & $\begin{array}{c}216 . \\
5\end{array}$ & $\begin{array}{c}0.12 \\
1\end{array}$ & 4 & $\begin{array}{c}305 . \\
9\end{array}$ & $\begin{array}{c}0.92 \\
3\end{array}$ & $\begin{array}{c}28 \\
3\end{array}$ & 265 & $\begin{array}{c}385.4 \\
4\end{array}$ & $\begin{array}{c}102.4 \\
4\end{array}$ & $\begin{array}{c}73 . \\
4\end{array}$ \\
\hline $\begin{array}{c}165 \\
0\end{array}$ & $\begin{array}{c}79 . \\
9\end{array}$ & $\begin{array}{c}4.8 \\
5\end{array}$ & $\begin{array}{c}217 . \\
6\end{array}$ & $\begin{array}{c}0.40 \\
5\end{array}$ & 32 & $\begin{array}{c}308 . \\
7\end{array}$ & $\begin{array}{c}0.92 \\
4\end{array}$ & $\begin{array}{c}28 \\
4\end{array}$ & 283 & $\begin{array}{c}387.8 \\
3\end{array}$ & $\begin{array}{c}103.8 \\
3\end{array}$ & $\begin{array}{r}73 . \\
2\end{array}$ \\
\hline $\begin{array}{c}170 \\
0\end{array}$ & $\begin{array}{c}79 . \\
7\end{array}$ & $\begin{array}{c}4.8 \\
5\end{array}$ & $\begin{array}{c}218 . \\
0\end{array}$ & $\begin{array}{c}0.67 \\
0\end{array}$ & 54 & $\begin{array}{c}308 . \\
5\end{array}$ & $\begin{array}{c}0.92 \\
2\end{array}$ & $\begin{array}{c}28 \\
3\end{array}$ & 307 & $\begin{array}{c}386.7 \\
0\end{array}$ & $\begin{array}{c}103.7 \\
0\end{array}$ & $\begin{array}{c}73 . \\
2\end{array}$ \\
\hline $\begin{array}{c}190 \\
0\end{array}$ & $\begin{array}{c}79 . \\
7\end{array}$ & $\begin{array}{c}4.9 \\
8\end{array}$ & $\begin{array}{c}218 . \\
1\end{array}$ & $\begin{array}{c}1.78 \\
6\end{array}$ & $\begin{array}{c}16 \\
6\end{array}$ & $\begin{array}{c}306 . \\
2\end{array}$ & $\begin{array}{c}0.90 \\
6\end{array}$ & $\begin{array}{c}27 \\
7\end{array}$ & 409 & $\begin{array}{c}396.9 \\
9\end{array}$ & $\begin{array}{c}119.9 \\
9\end{array}$ & $\begin{array}{c}69 . \\
8\end{array}$ \\
\hline $\begin{array}{c}210 \\
0\end{array}$ & $\begin{array}{c}79 . \\
6 \\
\end{array}$ & $\begin{array}{c}4.9 \\
9 \\
\end{array}$ & $\begin{array}{c}217 . \\
1\end{array}$ & $\begin{array}{c}2.86 \\
9\end{array}$ & $\begin{array}{c}29 \\
4 \\
\end{array}$ & $\begin{array}{c}304 . \\
3\end{array}$ & $\begin{array}{c}0.94 \\
2 \\
\end{array}$ & $\begin{array}{c}28 \\
5 \\
\end{array}$ & 532 & $\begin{array}{c}397.8 \\
8\end{array}$ & $\begin{array}{c}112.8 \\
8\end{array}$ & $\begin{array}{r}71 . \\
6 \\
\end{array}$ \\
\hline $\begin{array}{c}230 \\
0\end{array}$ & $\begin{array}{c}79 . \\
6\end{array}$ & $\begin{array}{c}5.2 \\
4\end{array}$ & $\begin{array}{c}214 . \\
3\end{array}$ & $\begin{array}{c}3.90 \\
9\end{array}$ & $\begin{array}{c}42 \\
8\end{array}$ & $\begin{array}{c}296 . \\
9\end{array}$ & $\begin{array}{c}1.05 \\
9\end{array}$ & $\begin{array}{c}31 \\
6\end{array}$ & 690 & $\begin{array}{c}416.7 \\
1\end{array}$ & $\begin{array}{c}101.0 \\
1\end{array}$ & $\begin{array}{c}75 . \\
8\end{array}$ \\
\hline $\begin{array}{c}230 \\
0\end{array}$ & $\begin{array}{c}79 . \\
6\end{array}$ & $\begin{array}{c}5.2 \\
4\end{array}$ & $\begin{array}{c}213 . \\
5\end{array}$ & $\begin{array}{c}5.32 \\
2\end{array}$ & $\begin{array}{c}60 \\
3\end{array}$ & $\begin{array}{c}295 . \\
3\end{array}$ & 1.08 & $\begin{array}{c}31 \\
6\end{array}$ & 870 & $\begin{array}{c}416.7 \\
1\end{array}$ & $\begin{array}{c}100.8 \\
1\end{array}$ & $\begin{array}{c}75 . \\
8\end{array}$ \\
\hline $\begin{array}{c}270 \\
0\end{array}$ & $\begin{array}{c}79 . \\
6\end{array}$ & $\begin{array}{c}5.2 \\
5\end{array}$ & $\begin{array}{c}213 . \\
3\end{array}$ & $\begin{array}{c}7.17 \\
8\end{array}$ & $\begin{array}{c}83 \\
4\end{array}$ & $\begin{array}{c}292 . \\
4\end{array}$ & 1.1 & $\begin{array}{c}31 \\
6\end{array}$ & $\begin{array}{c}109 \\
3\end{array}$ & $\begin{array}{c}417.9 \\
0\end{array}$ & $\begin{array}{c}102.3 \\
0\end{array}$ & $\begin{array}{c}75 . \\
5\end{array}$ \\
\hline
\end{tabular}

Table D - 5 DC-DC module prototype v1.0 - Electrical performance test data for $f_{s}$ $=10 \mathrm{kHz}$, constant $20 \%$ duty ratio, and constant $79.6 \mathrm{~V}$ input voltage vs. motor speed

\begin{tabular}{|c|c|c|c|c|c|c|c|c|c|c|c|c|}
\hline $\begin{array}{l}\vec{d} \\
\tilde{D} \\
\tilde{2} \\
\tilde{0} \\
\dot{0} \\
\dot{0}\end{array}$ & 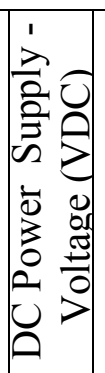 & 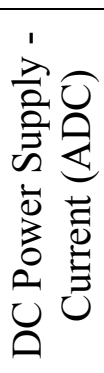 & 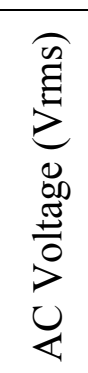 & 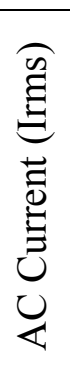 & 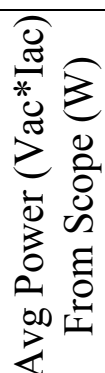 & 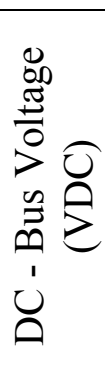 & 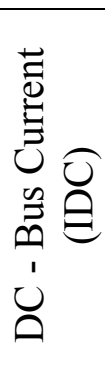 & 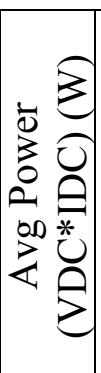 & 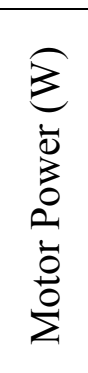 & 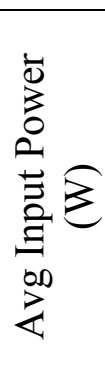 & 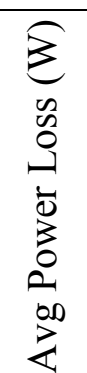 & 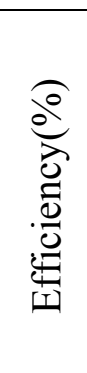 \\
\hline $\begin{array}{c}150 \\
0\end{array}$ & 60 & 2.01 & $\begin{array}{c}218 . \\
6\end{array}$ & $\begin{array}{c}1.8 \\
1\end{array}$ & 177 & $\begin{array}{c}305 . \\
4\end{array}$ & $\begin{array}{c}0.17 \\
6\end{array}$ & 54 & 230 & $\begin{array}{c}120.5 \\
4\end{array}$ & $\begin{array}{c}66.5 \\
4\end{array}$ & $\begin{array}{c}44.8 \\
0\end{array}$ \\
\hline & 75 & 2.62 & $\begin{array}{c}218 . \\
7\end{array}$ & $\begin{array}{c}1.2 \\
2\end{array}$ & 114 & $\begin{array}{c}306 . \\
7\end{array}$ & $\begin{array}{c}0.39 \\
9\end{array}$ & $\begin{array}{c}12 \\
1\end{array}$ & 230 & $\begin{array}{c}196.8 \\
0\end{array}$ & $\begin{array}{c}75.8 \\
0\end{array}$ & $\begin{array}{c}61.4 \\
8\end{array}$ \\
\hline
\end{tabular}




\begin{tabular}{|c|c|c|c|c|c|c|c|c|c|c|c|c|}
\hline & 90 & 3.36 & 219 & $\begin{array}{c}0.3 \\
2\end{array}$ & 19 & $\begin{array}{c}309 . \\
2\end{array}$ & $\begin{array}{c}0.70 \\
4\end{array}$ & 21 & 230 & $\begin{array}{c}302.7 \\
6\end{array}$ & $\begin{array}{c}85.7 \\
6\end{array}$ & $\begin{array}{c}71.6 \\
7\end{array}$ \\
\hline $\begin{array}{c}160 \\
0\end{array}$ & 60 & 2.06 & 218 & $\begin{array}{c}2.0 \\
5\end{array}$ & $\begin{array}{c}208 . \\
2\end{array}$ & $\begin{array}{c}303 . \\
5\end{array}$ & $\begin{array}{c}0.20 \\
6\end{array}$ & 62 & 266 & $\begin{array}{c}123.6 \\
6\end{array}$ & $\begin{array}{c}61.6 \\
6\end{array}$ & $\begin{array}{c}50.1 \\
4\end{array}$ \\
\hline & 75 & 2.62 & $\begin{array}{c}215 . \\
2\end{array}$ & $\begin{array}{c}1.5 \\
3\end{array}$ & 148 & $\begin{array}{c}302 . \\
1\end{array}$ & $\begin{array}{c}0.45 \\
8\end{array}$ & $\begin{array}{c}13 \\
8\end{array}$ & 266 & $\begin{array}{c}196.2 \\
0\end{array}$ & $\begin{array}{c}58.2 \\
0\end{array}$ & $\begin{array}{c}70.3 \\
4\end{array}$ \\
\hline & 90 & 3.42 & $\begin{array}{c}215 . \\
2\end{array}$ & $\begin{array}{c}0.6 \\
7\end{array}$ & 58 & $\begin{array}{c}303 . \\
5\end{array}$ & 0.76 & 23 & 266 & $\begin{array}{c}307.8 \\
0\end{array}$ & $\begin{array}{c}77.8 \\
0\end{array}$ & $\begin{array}{c}74.7 \\
2\end{array}$ \\
\hline $\begin{array}{c}170 \\
0\end{array}$ & 60 & 1.98 & $\begin{array}{c}217 . \\
6\end{array}$ & $\begin{array}{c}2.5 \\
9\end{array}$ & 262 & $\begin{array}{c}303 . \\
0\end{array}$ & $\begin{array}{c}0.19 \\
8\end{array}$ & 60 & 307 & $\begin{array}{c}118.7 \\
4\end{array}$ & $\begin{array}{c}58.7 \\
4\end{array}$ & $\begin{array}{c}50.5 \\
3\end{array}$ \\
\hline & 75 & 2.60 & $\begin{array}{c}217 . \\
8\end{array}$ & $\begin{array}{c}2.0 \\
2\end{array}$ & 199 & $\begin{array}{c}304 . \\
3\end{array}$ & 0.42 & $\begin{array}{c}12 \\
7\end{array}$ & 307 & $\begin{array}{c}195.3 \\
0\end{array}$ & $\begin{array}{c}68.3 \\
0\end{array}$ & $\begin{array}{c}65.0 \\
3\end{array}$ \\
\hline & 90 & 3.38 & $\begin{array}{c}217 . \\
8\end{array}$ & $\begin{array}{c}1.1 \\
9\end{array}$ & 108 & $\begin{array}{c}305 . \\
5\end{array}$ & $\begin{array}{c}0.70 \\
1 \\
\end{array}$ & $\begin{array}{c}21 \\
5 \\
\end{array}$ & 307 & $\begin{array}{c}303.9 \\
3\end{array}$ & $\begin{array}{c}88.9 \\
3\end{array}$ & $\begin{array}{c}70.7 \\
4\end{array}$ \\
\hline $\begin{array}{c}180 \\
0\end{array}$ & 60 & 2.00 & $\begin{array}{c}217 . \\
8\end{array}$ & $\begin{array}{c}3.0 \\
3\end{array}$ & 318 & $\begin{array}{c}302 . \\
3\end{array}$ & $\begin{array}{c}0.19 \\
8\end{array}$ & 60 & 354 & $\begin{array}{c}119.9 \\
4\end{array}$ & $\begin{array}{c}59.9 \\
4\end{array}$ & $\begin{array}{c}50.0 \\
3\end{array}$ \\
\hline & 75 & 2.59 & $\begin{array}{c}217 \\
6\end{array}$ & $\begin{array}{c}2.5 \\
1 \\
\end{array}$ & 253 & $\begin{array}{c}302 . \\
6\end{array}$ & $\begin{array}{c}0.42 \\
2\end{array}$ & $\begin{array}{c}12 \\
7\end{array}$ & 354 & $\begin{array}{c}194.1 \\
8\end{array}$ & $\begin{array}{c}67.1 \\
8\end{array}$ & $\begin{array}{c}65.4 \\
0\end{array}$ \\
\hline & 90 & 3.40 & $\begin{array}{c}217 . \\
4\end{array}$ & $\begin{array}{c}1.7 \\
1\end{array}$ & 161 & $\begin{array}{c}304 . \\
2\end{array}$ & $\begin{array}{c}0.71 \\
6\end{array}$ & 21 & 354 & $\begin{array}{c}305.5 \\
5\end{array}$ & $\begin{array}{c}88.5 \\
5\end{array}$ & $\begin{array}{c}71.0 \\
2\end{array}$ \\
\hline $\begin{array}{c}190 \\
0\end{array}$ & 60 & 2.00 & $\begin{array}{c}217 \\
2\end{array}$ & $\begin{array}{c}3.5 \\
3\end{array}$ & 376 & $\begin{array}{c}301 . \\
2\end{array}$ & $\begin{array}{c}0.21 \\
8\end{array}$ & 66 & 408 & $\begin{array}{c}119.7 \\
6\end{array}$ & $\begin{array}{c}53.7 \\
6\end{array}$ & $\begin{array}{c}55.1 \\
1\end{array}$ \\
\hline & 75 & 2.63 & 217 & $\begin{array}{c}3.0 \\
2\end{array}$ & 311 & $\begin{array}{c}300 . \\
9\end{array}$ & $\begin{array}{c}0.42 \\
9\end{array}$ & $\begin{array}{c}12 \\
9\end{array}$ & 408 & $\begin{array}{c}197.4 \\
8\end{array}$ & $\begin{array}{c}68.4 \\
8\end{array}$ & $\begin{array}{c}65.3 \\
2\end{array}$ \\
\hline & 90 & 40 & $\begin{array}{c}216 . \\
8\end{array}$ & $\begin{array}{c}2.2 \\
2\end{array}$ & 218 & $\begin{array}{c}302 . \\
9\end{array}$ & $\begin{array}{c}0.74 \\
1\end{array}$ & $\begin{array}{c}22 \\
4\end{array}$ & 408 & $\begin{array}{c}305.1 \\
0\end{array}$ & $\begin{array}{c}81.1 \\
0\end{array}$ & $\begin{array}{c}73.4 \\
2\end{array}$ \\
\hline $\begin{array}{c}210 \\
0\end{array}$ & 60 & $2.0 J$ & $\begin{array}{c}216 . \\
1\end{array}$ & $\begin{array}{c}4.6 \\
6\end{array}$ & 509 & $\begin{array}{c}298 . \\
5\end{array}$ & $\begin{array}{c}0.22 \\
5\end{array}$ & 67 & 532 & $\begin{array}{c}121.9 \\
8\end{array}$ & $\begin{array}{c}54.9 \\
8\end{array}$ & $\begin{array}{c}54.9 \\
3\end{array}$ \\
\hline & 75 & 2.66 & $\begin{array}{c}216 . \\
1\end{array}$ & $\begin{array}{c}4.1 \\
4\end{array}$ & 443 & $\begin{array}{c}299 . \\
2\end{array}$ & $\begin{array}{c}0.46 \\
2\end{array}$ & $\begin{array}{c}13 \\
7\end{array}$ & 32 & $\begin{array}{c}199.6 \\
5\end{array}$ & $\begin{array}{c}62.6 \\
5\end{array}$ & $\begin{array}{c}68.6 \\
2\end{array}$ \\
\hline & 90 & & $\begin{array}{c}216 . \\
2\end{array}$ & $\begin{array}{c}3.3 \\
6\end{array}$ & 347 & $\begin{array}{c}300 . \\
5\end{array}$ & $\begin{array}{c}0.76 \\
2\end{array}$ & 22 & & $\begin{array}{c}307.7 \\
1\end{array}$ & $\begin{array}{c}79.7 \\
1\end{array}$ & $\begin{array}{c}74.1 \\
0\end{array}$ \\
\hline $\begin{array}{c}230 \\
0\end{array}$ & 60 & 2.02 & $\begin{array}{c}215 . \\
9\end{array}$ & 5.9 & 672 & $\begin{array}{c}297 . \\
3\end{array}$ & $\begin{array}{c}0.24 \\
3\end{array}$ & 73 & 688 & $\begin{array}{c}120.9 \\
0\end{array}$ & $\begin{array}{c}47.9 \\
0\end{array}$ & $\begin{array}{c}60.3 \\
8\end{array}$ \\
\hline & 75 & 2.66 & $\begin{array}{c}215 . \\
8\end{array}$ & $\begin{array}{c}5.4 \\
2\end{array}$ & 597 & $\begin{array}{c}297 . \\
6\end{array}$ & $\begin{array}{c}0.47 \\
5\end{array}$ & $\begin{array}{c}14 \\
0\end{array}$ & 688 & $\begin{array}{c}199.6 \\
5\end{array}$ & $\begin{array}{c}59.6 \\
5\end{array}$ & $\begin{array}{c}70.1 \\
2\end{array}$ \\
\hline & 90 & 3.4 & $\begin{array}{c}215 . \\
8\end{array}$ & $\begin{array}{c}4.6 \\
6\end{array}$ & 6 & $\begin{array}{c}298 . \\
7\end{array}$ & $\begin{array}{c}0.77 \\
5\end{array}$ & 23 & 8 & $\begin{array}{c}310.2 \\
3\end{array}$ & $\begin{array}{c}80.2 \\
3\end{array}$ & $\begin{array}{c}74.1 \\
4\end{array}$ \\
\hline $\begin{array}{c}250 \\
0\end{array}$ & 60 & 2.03 & $\begin{array}{c}215 . \\
2\end{array}$ & $\begin{array}{c}7.4 \\
4\end{array}$ & 867 & $\begin{array}{c}294 . \\
9\end{array}$ & 0.24 & 70 & 873 & $\begin{array}{c}121.8 \\
0\end{array}$ & $\begin{array}{c}51.8 \\
0\end{array}$ & $\begin{array}{c}57.4 \\
7\end{array}$ \\
\hline & 75 & $\begin{array}{c}2.53 \\
9\end{array}$ & $\begin{array}{c}216 . \\
1\end{array}$ & $\begin{array}{c}6.8 \\
0\end{array}$ & 00 & $\begin{array}{c}297 . \\
0\end{array}$ & $\begin{array}{c}0.36 \\
1\end{array}$ & $\begin{array}{c}10 \\
7\end{array}$ & 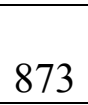 & $\begin{array}{c}190.4 \\
3\end{array}$ & $\begin{array}{c}83.4 \\
3\end{array}$ & $\begin{array}{c}56.1 \\
9\end{array}$ \\
\hline & 90 & $\begin{array}{c}3.30 \\
4\end{array}$ & $\begin{array}{c}215 . \\
9\end{array}$ & $\begin{array}{c}6.1 \\
7\end{array}$ & 697 & $\begin{array}{c}298 . \\
1\end{array}$ & $\begin{array}{c}0.68 \\
1\end{array}$ & $\begin{array}{c}20 \\
3\end{array}$ & 873 & $\begin{array}{c}297.3 \\
6\end{array}$ & $\begin{array}{c}94.3 \\
6\end{array}$ & $\begin{array}{c}68.2 \\
7\end{array}$ \\
\hline
\end{tabular}




\begin{tabular}{|c|c|c|c|c|c|c|c|c|c|c|c|c|}
\hline $\begin{array}{c}270 \\
0\end{array}$ & 60 & 1.94 & $\begin{array}{c}216 . \\
1\end{array}$ & $\begin{array}{c}8.9 \\
2\end{array}$ & 1085 & $\begin{array}{c}294 . \\
2\end{array}$ & $\begin{array}{c}0.14 \\
8\end{array}$ & 43 & $\begin{array}{c}111 \\
6\end{array}$ & $\begin{array}{c}116.3 \\
4\end{array}$ & $\begin{array}{c}73.3 \\
4\end{array}$ & $\begin{array}{c}36.9 \\
6\end{array}$ \\
\hline & 75 & 2.56 & $\begin{array}{c}216 \\
6\end{array}$ & $\begin{array}{c}8.5 \\
3\end{array}$ & 1025 & $\begin{array}{c}295 . \\
4\end{array}$ & $\begin{array}{c}0.36 \\
6\end{array}$ & $\begin{array}{c}10 \\
8\end{array}$ & $\begin{array}{c}111 \\
6\end{array}$ & $\begin{array}{c}192.0 \\
8\end{array}$ & $\begin{array}{c}84.0 \\
8\end{array}$ & $\begin{array}{c}56.2 \\
3\end{array}$ \\
\hline & 90 & 3.38 & $\begin{array}{c}216 . \\
6\end{array}$ & $\begin{array}{c}7.8 \\
3\end{array}$ & 936 & $\begin{array}{c}296 . \\
6\end{array}$ & $\begin{array}{c}0.69 \\
5\end{array}$ & $\begin{array}{c}20 \\
7\end{array}$ & $\begin{array}{c}111 \\
6\end{array}$ & $\begin{array}{c}304.2 \\
0\end{array}$ & $\begin{array}{c}97.2 \\
0\end{array}$ & $\begin{array}{c}68.0 \\
5\end{array}$ \\
\hline
\end{tabular}

Table D - 6 DC-DC module prototype v1.0 - Electrical performance test data for $f_{s}=$ $10 \mathrm{kHz}$, constant $30 \%$ duty ratio, and various input voltages vs. motor speeds

\begin{tabular}{|c|c|c|c|c|c|c|c|c|c|c|c|c|}
\hline $\begin{array}{l}\overrightarrow{0} \\
\mathbb{\Delta} \\
\text { की } \\
\vdots \\
\dot{0} \\
\dot{0}\end{array}$ & 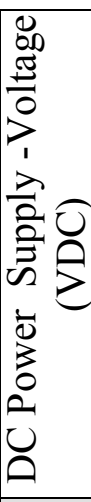 & 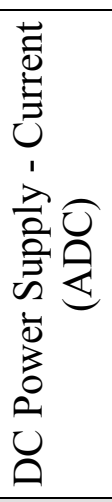 & 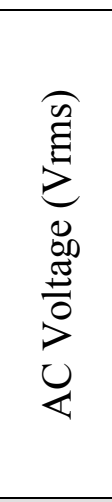 & 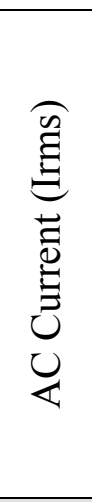 & 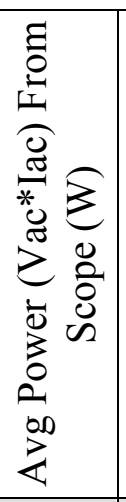 & 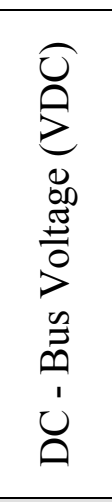 & 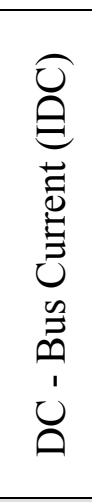 & 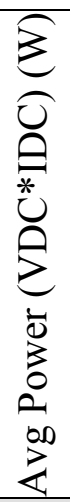 & 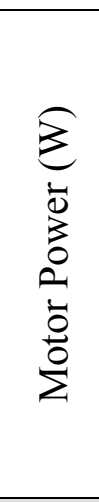 & 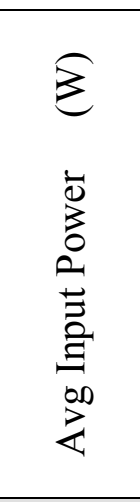 & 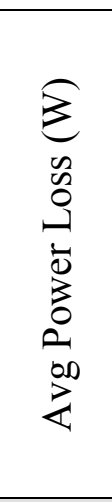 & 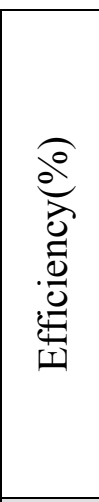 \\
\hline 1500 & 60 & 2.01 & 218.6 & 1.81 & 177 & 305.4 & 0.1 & 54 & 230 & 120.54 & 66.54 & 44.80 \\
\hline 1600 & 60 & 2.06 & 218 & 2.05 & 208.2 & 303.5 & 0.21 & 62 & 266 & 123.66 & 61.66 & 50.14 \\
\hline 1700 & 60 & 1.98 & 217.6 & 2.59 & 262 & 303 & 0.20 & 60 & 307 & 118.74 & 58.74 & 50.53 \\
\hline 1800 & 60 & 2.00 & 217.8 & 3.03 & 318 & 302.3 & 0.20 & 60 & 354 & 119.94 & 59.94 & 50.03 \\
\hline 1900 & 60 & 2.00 & 217.2 & 3.53 & 376 & 301.2 & 0.22 & 66 & 408 & 119.76 & 53.76 & 55.11 \\
\hline 2100 & 60 & 2.033 & 216.1 & 4.66 & 509 & 298.5 & 0.23 & 6 & 532 & 121.98 & 54.98 & 54.93 \\
\hline 2300 & 60 & 2.015 & 215.9 & 5.90 & 672 & 297.3 & 0.24 & 73 & 688 & 120.90 & 47.90 & 60.38 \\
\hline 2500 & 60 & 2.03 & 215.2 & 7.44 & 867 & 294.9 & 0.24 & 70 & 873 & 121.80 & 51.80 & 57.47 \\
\hline 2700 & 60 & 1.94 & 216.1 & 8.92 & 1085 & 294.2 & 0.15 & 43 & 1116 & 116.34 & 73.34 & 36.96 \\
\hline
\end{tabular}

Table D - 7 DC-DC module prototype v1.0 - Electrical performance test data for $f_{s}$ $=10 \mathrm{kHz}$, constant $30 \%$ duty ratio, and constant $60 \mathrm{~V}$ input voltage vs. motor speed 


\begin{tabular}{|c|c|c|c|c|c|c|c|c|c|c|c|c|}
\hline 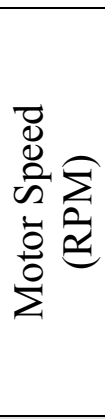 & 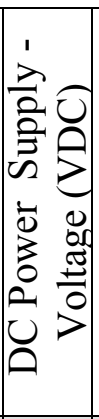 & 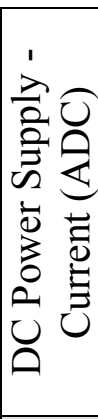 & 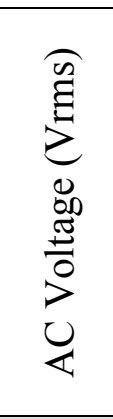 & 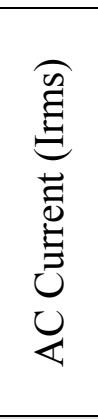 & 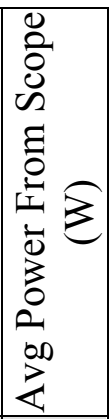 & 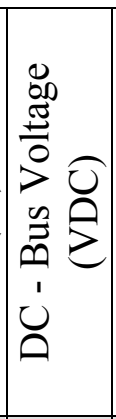 & 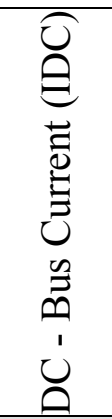 & 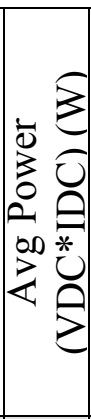 & $\begin{array}{l}3 \\
\dot{0} \\
0 \\
0 \\
0 \\
\vdots \\
0 \\
0\end{array}$ & 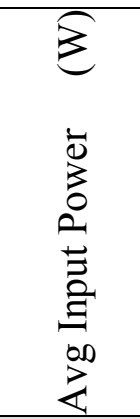 & 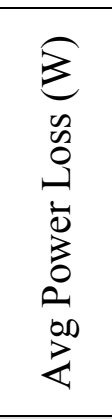 & 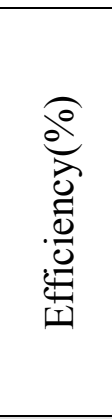 \\
\hline 1500 & 75 & 2.62 & 18.7 & 22 & 114 & 306.7 & 0.399 & 121 & 230 & 196.80 & 75.80 & 8.40 \\
\hline 1600 & 75 & 2.62 & 215.2 & 1.53 & 148 & 305.1 & 0.451 & 138 & 266 & 196.20 & .20 & 70.34 \\
\hline 1700 & 75 & 2.60 & 217.8 & 2.02 & 199 & 304.3 & 0.42 & 127 & 307 & 195.30 & .30 & 65.03 \\
\hline 1800 & 75 & 2.59 & 217.6 & 2.51 & 253 & 302.6 & 0.422 & 127 & 354 & 194.18 & 67.18 & 65.40 \\
\hline 1900 & 75 & 2.63 & 217 & 3.02 & 311 & 300.9 & 0.429 & 129 & 408 & 197.48 & 68.48 & 65.32 \\
\hline 2100 & 75 & 2.66 & 216.1 & 4.14 & 443 & 299.2 & 0.462 & 137 & 532 & 199.65 & 62.65 & 68.62 \\
\hline 2300 & 75 & 2.66 & 215.8 & 5.42 & 597 & 297.6 & 0.475 & 140 & 688 & 199.65 & 59.65 & 70.12 \\
\hline 2500 & 75 & 2.54 & 216.1 & 6.80 & 786 & 297.0 & 0.361 & 107 & 873 & 190.43 & 83.43 & 56.19 \\
\hline 2700 & 75 & 2.56 & 216.6 & 8.53 & 1025 & 295.4 & 0.366 & 108 & 1116 & 192.08 & 84.08 & 56.23 \\
\hline
\end{tabular}

Table D - 8 DC-DC module prototype v1.0 - Electrical performance test data for $f_{s}$ $=10 \mathrm{kHz}$, constant $20 \%$ duty ratio, and constant $75 \mathrm{~V}$ input voltage vs. motor speed

\begin{tabular}{|c|c|c|c|c|c|c|c|c|c|c|c|c|}
\hline 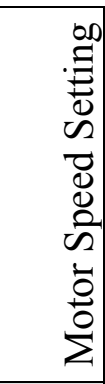 & 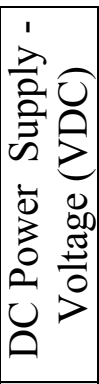 & 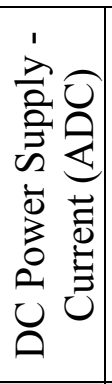 & 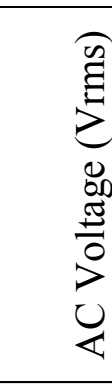 & 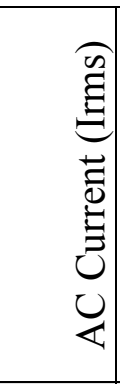 & 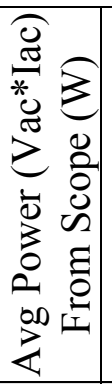 & 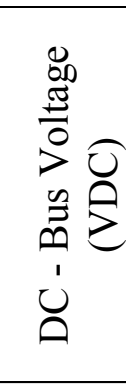 & 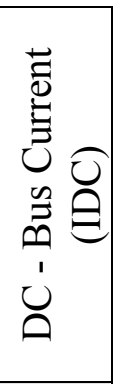 & 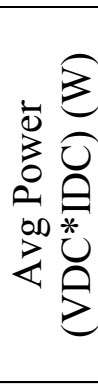 & 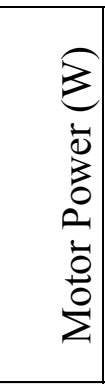 & 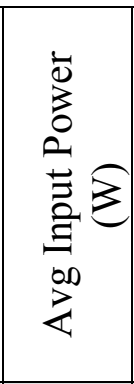 & $\begin{array}{l}3 \\
0 \\
0 \\
0 \\
1 \\
\dot{0} \\
0 \\
0 \\
2 \\
00 \\
2 \\
2\end{array}$ & $\begin{array}{l}20 \\
.0 \\
0 \\
0 \\
0\end{array}$ \\
\hline 1500 & 90 & 36 & .0 & & 19 & 9.2 & 0.1 & $21^{\prime}$ & 30 & 302.76 & 85.76 & 71.67 \\
\hline 1600 & 90 & 42 & .2 & 74 & 58 & .45 & 0.75 & 230 & 66 & 307.80 & 77.80 & 74.72 \\
\hline 1700 & 90 & 3.38 & .8 & 94 & 108 & 305.5 & 0.701 & 215 & 07 & 303.93 & 88.93 & 70.74 \\
\hline 1800 & 90 & 3.39 & 7.4 & 09 & 161 & 304.2 & 0.716 & 217 & 54 & 305.55 & 88.55 & 71.02 \\
\hline 1900 & 90 & 3.39 & 216.8 & 2.222 & 218 & 302.9 & 0.741 & 224 & 408 & 305.10 & 81.1 & 73.42 \\
\hline 2100 & 90 & 3.42 & .2 & 56 & 347 & 00.5 & 0.762 & 228 & 32 & 307.71 & .71 & 74.10 \\
\hline 2300 & 90 & 3.45 & & 64 & 506 & .7 & 5 & 230 & 8 & 310.23 & .23 & 74.14 \\
\hline 2500 & 90 & 3.30 & 215.9 & 74 & 697 & 298.1 & 0.681 & 203 & 73 & 297.36 & 94.36 & 68.27 \\
\hline 2700 & 90 & 3.38 & 216.6 & 7.826 & 936 & 296.6 & 0.695 & 207 & 1116 & 304.20 & 97.2 & 68.05 \\
\hline
\end{tabular}

Table D - 9 DC-DC module prototype v1.0 - Electrical performance test data for $f_{s}=$ $10 \mathrm{kHz}$, constant $20 \%$ duty ratio, and constant $90 \mathrm{~V}$ input voltage vs. motor speed 
$5 \mathrm{kHz}$ Switching Frequency Data

\begin{tabular}{|c|c|c|c|c|c|c|c|c|c|c|c|c|}
\hline 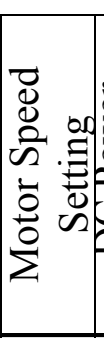 & 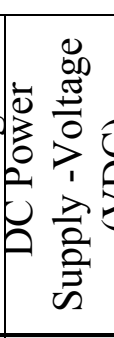 & 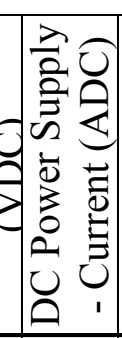 & 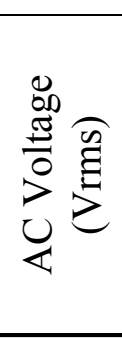 & 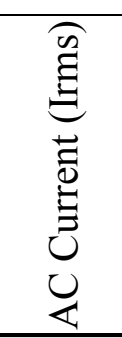 & 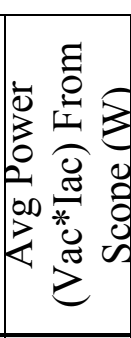 & 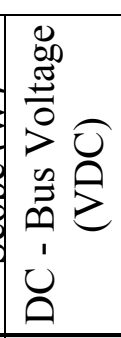 & 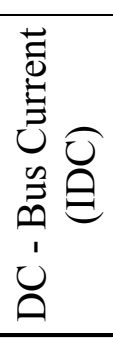 & 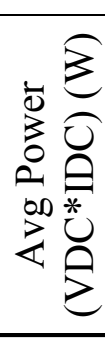 & $\begin{array}{l}\hat{z} \\
\overline{0} \\
0 \\
0 \\
0 \\
\overline{0} \\
\dot{0}\end{array}$ & 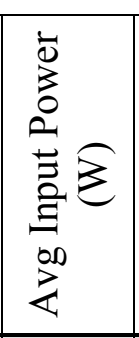 & 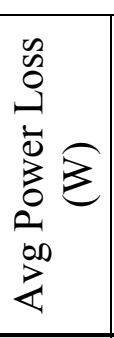 & 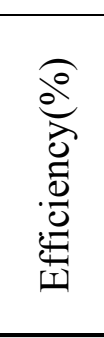 \\
\hline 1500 & 0 & 0 & 216.1 & 2.499 & 262.2 & 300.77 & 0 & 0 & 230 & 0.00 & 0.00 & 0.00 \\
\hline 1500 & 10 & 0.293 & 215.87 & 2.457 & 262.2 & 299.71 & 0.002 & 1 & 230 & 2.93 & 1.93 & 34.1 \\
\hline 1500 & 20 & 0.621 & 216.03 & 2.449 & 255.5 & 299.7 & 0.016 & 6 & 230 & 12.42 & 6.42 & 48.31 \\
\hline 1500 & 30 & 0.888 & 215.79 & 2.347 & 245.4 & 299.91 & 0.047 & 13.9 & 230 & 26.64 & 12.74 & 52.18 \\
\hline 1500 & 40 & 1.222 & 215.8 & 2.215 & 227.4 & 299.79 & 0.137 & 41.5 & 230 & 48.88 & 7.38 & 84.90 \\
\hline 1500 & 50 & 1.535 & 215.83 & 1.978 & 201.4 & 299.94 & 0.212 & 65.5 & 230 & \begin{tabular}{|l|}
76.75 \\
\end{tabular} & 11.25 & 85.34 \\
\hline 1500 & 60 & 1.894 & 215.82 & 1.715 & 171.4 & 300.31 & 0.29 & 86.4 & 230 & 113.64 & 27.24 & 76.03 \\
\hline 1500 & 70 & 2.284 & 215.99 & 1.361 & 137.8 & 301.14 & 0.437 & 130.7 & 230 & 159.88 & 29.18 & 81.75 \\
\hline 1500 & 80 & 2.704 & 215.95 & 0.933 & 86.7 & 301.67 & 0.516 & 154.9 & 230 & 216.32 & 61.42 & 71.61 \\
\hline 1500 & 85 & 2.947 & 216.02 & 0.621 & 58.2 & 302.8 & 0.622 & 187.6 & 230 & 250.50 & 62.90 & 74.89 \\
\hline 1500 & 90 & 3.175 & 215.76 & 0.2926 & 25.4 & 304.8 & 0.711 & 215.3 & 230 & 285.75 & 70.45 & 75.35 \\
\hline 1500 & 92 & 3.401 & 216.22 & 0.154 & 10.74 & 304.95 & 0.79 & 240 & 230 & 312.89 & 72.89 & 76.70 \\
\hline 1500 & 95 & 3.391 & 216.42 & 0.08 & 0.288 & 322.67 & 0.777 & 248 & 230 & 322.15 & 74.15 & 76.98 \\
\hline
\end{tabular}

Table D - 10 DC-DC module prototype v1.0 - Electrical performance test data for $f_{s}$ $=5 \mathrm{kHz}$, constant $20 \%$ duty ratio, and constant motor speed vs. input voltage

\begin{tabular}{|c|c|c|c|c|c|c|c|c|c|c|c|}
\hline 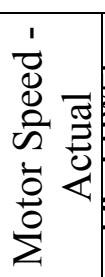 & 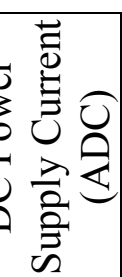 & 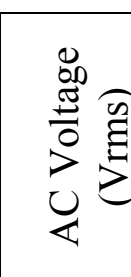 & 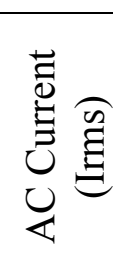 & 这 & 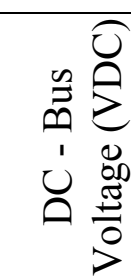 & 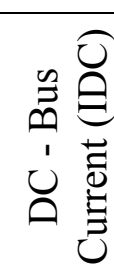 & 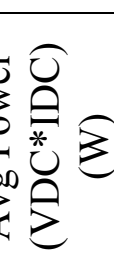 & 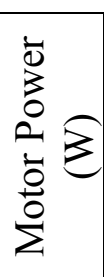 & 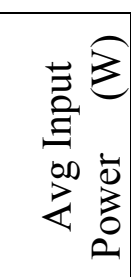 & 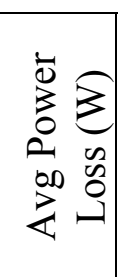 & \\
\hline 1500 & 0 & 216.1 & 2.499 & 262.2 & 300.77 & 0 & 0 & 230 & 0.00 & 0.00 & 0.00 \\
\hline 1500 & 1.145 & 215.26 & 2.463 & 259.9 & 300.92 & 0.041 & 10.5 & 230 & 12.07 & 1.57 & 87.00 \\
\hline 1500 & 1.301 & 215.46 & 2.35 & 246.4 & 300.8 & 0.08 & 23.9 & 230 & 27.31 & 3.41 & 87.50 \\
\hline 1500 & 1.905 & 215.5 & 2.013 & 224.2 & 300.47 & 0.125 & 37.1 & 230 & 58.52 & 21.42 & 63.40 \\
\hline 1500 & 2.143 & 216.58 & 1.85 & 187.8 & 301.95 & 0.205 & 64.4 & 230 & 85.72 & 21.32 & 75.13 \\
\hline 1500 & 3.332 & 216.43 & 1.415 & 137.4 & 303.33 & 0.444 & 135.6 & 230 & 166.60 & 31.00 & 81.39 \\
\hline 1500 & 4.032 & 214.9 & 0.59 & 51.1 & 300.46 & 0.721 & 213.4 & 230 & 241.92 & 28.52 & 88.21 \\
\hline 500 & 986 & 215.79 & 0.089 & 0.035 & 315.09 & 0.83 & 244 & 230 & 265.07 & 21.07 & 92.05 \\
\hline
\end{tabular}

Table D - 11 DC-DC module prototype v1.0 - Electrical performance test data for $f_{s}$ $=5 \mathrm{kHz}$, constant $30 \%$ duty ratio, and constant motor speed vs. input voltage 


\begin{tabular}{|c|c|c|c|c|c|c|c|c|c|c|c|c|}
\hline $\begin{array}{l}\overline{0} \\
0 \\
0 \\
0 \\
\vdots \\
0 \\
0 \\
\vdots\end{array}$ & 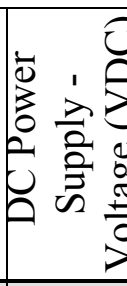 & $\begin{array}{l}1 \\
\frac{\lambda}{2} \\
\frac{2}{3} \\
\frac{1}{3}\end{array}$ & 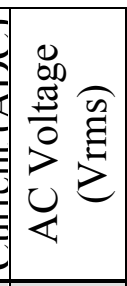 & 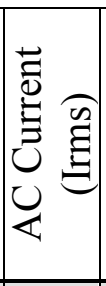 & 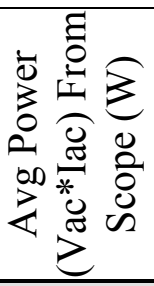 & 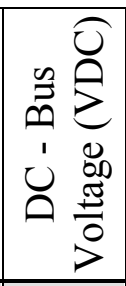 & 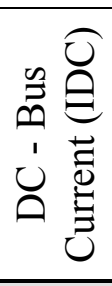 & 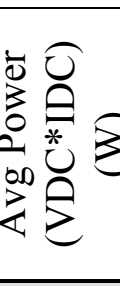 & 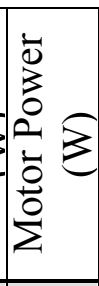 & 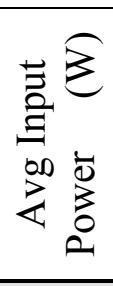 & 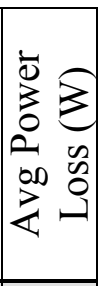 & 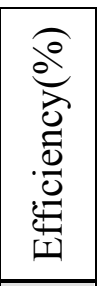 \\
\hline 00 & 0 & 0 & 216.1 & 99 & 262.2 & 300.77 & 0 & 0 & 230 & 0.00 & 0.00 & 0.00 \\
\hline 1500 & 10 & 1.241 & 215.78 & 2.432 & 257.9 & 300.51 & 0.041 & 12.29 & 230 & 12.41 & 0.12 & 9.03 \\
\hline 1500 & 20 & 2.105 & 215.95 & 2.199 & 232.1 & 300.59 & 0.111 & 33.3 & 230 & 42.10 & 8.80 & 9.10 \\
\hline 1500 & 30 & 3.18 & 215 & 72 & 193.5 & 300.41 & 0.184 & 55.8 & 230 & 95.40 & 59. & 8.49 \\
\hline 1500 & 40 & 4.485 & 216.84 & 1.315 & 129.4 & 305.4 & 0.333 & 103 & 230 & 179.40 & 0. & 7.41 \\
\hline 1500 & 50 & 5.919 & 215.38 & 0.504 & 44 & 305.1 & 0.681 & 207 & 230 & 295.95 & 58. & 69.9 \\
\hline 1500 & 52.4 & 6.581 & 216.4 & 0.092 & 1.24 & 308.7 & 0.892 & 268 & 230 & 344.8 & 6. & 77.72 \\
\hline
\end{tabular}

Table D - 12 DC-DC module prototype v1.0 - Electrical performance test data for $f_{s}$ $=5 \mathrm{kHz}$, constant $40 \%$ duty ratio, and constant motor speed vs. input voltage

\begin{tabular}{|c|c|c|c|c|c|c|c|c|c|c|c|c|}
\hline 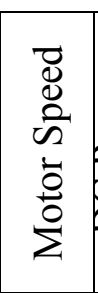 & 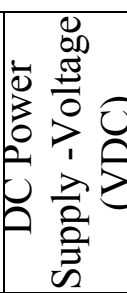 & 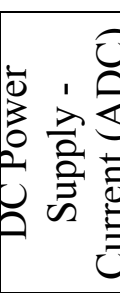 & 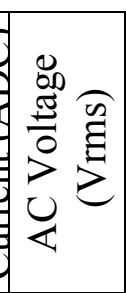 & 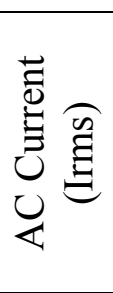 & 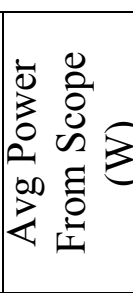 & 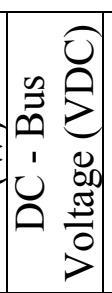 & 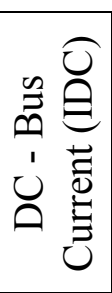 & 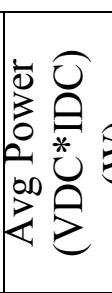 & 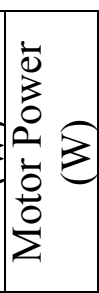 & 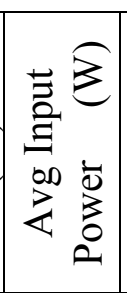 & 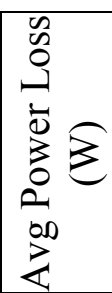 & 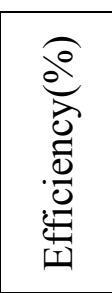 \\
\hline 1500 & 95 & 3.463 & 216.9 & 0.131 & 3 & 307.1 & 0.804 & 247 & 214 & 328.9 & 31.99 & 75.08 \\
\hline 1600 & 95 & 3.477 & 216.9 & 0.541 & 42 & 306.7 & 0.798 & 241 & 248 & 330.32 & 89.32 & 72.96 \\
\hline 1700 & 95 & 3.474 & 216.1 & 1.051 & 90 & 305.8 & 0.81 & 244 & 284 & 330.03 & 86.03 & 73.93 \\
\hline 1800 & 95 & 3.469 & 215.86 & 1.557 & 143 & 303.9 & 0.813 & 245 & 327 & 329.56 & 84.56 & 74.34 \\
\hline 1900 & 95 & 3.47 & 215.75 & 2.09 & 202 & 302.7 & 0.821 & 248 & 384 & 329.6 & 31.65 & 75.23 \\
\hline 2000 & 95 & 3.473 & 215.63 & 2.673 & 268 & 301.6 & 0.824 & 249 & 438 & 329.9 & 30.94 & 75.47 \\
\hline 2100 & 95 & 3.464 & 215.22 & 3.286 & 338 & 301 & 0.837 & 248 & 505 & 325 & .08 & 75.36 \\
\hline 2200 & 95 & 3.468 & 214.83 & 3.929 & 417 & 300.1 & 0.841 & 250 & 576 & 329.46 & 79.46 & 75.88 \\
\hline 2300 & 95 & 3.473 & 214.58 & 4.613 & 502 & 299.9 & 0.85 & 252 & 654 & 329.9 & 7.94 & 76.38 \\
\hline 2400 & 95 & 3.479 & 215.01 & 5.347 & 597 & 299.1 & 0.855 & 252 & 736 & 330.51 & 78.51 & 76.25 \\
\hline 2500 & 95 & 3.477 & 214.74 & 6.134 & 693 & 298.6 & 0.862 & 255 & 825 & 330.32 & 75.32 & 77.20 \\
\hline 2600 & 95 & 3.475 & 214.55 & 6.929 & 795 & 297.7 & 0.873 & 255 & 932 & 330.1 & 75.13 & 77.24 \\
\hline 2700 & 95 & 3.475 & 214.3 & 7.777 & 910 & 296.8 & 0.884 & 256 & 1047 & 330.13 & 74.13 & 77.55 \\
\hline
\end{tabular}

Table D - 13 DC-DC module prototype v1.0 - Electrical performance test data for $f_{s}$ $=5 \mathrm{kHz}$, constant $20 \%$ duty ratio, and constant $95 \mathrm{~V}$ input voltage vs. motor speed 


\begin{tabular}{|c|c|c|c|c|c|c|c|c|c|c|c|c|}
\hline 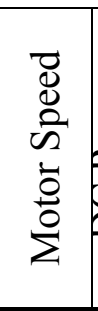 & 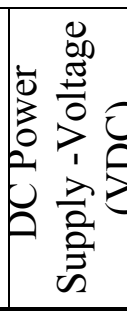 & 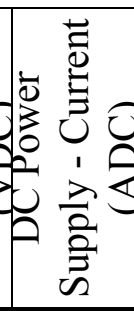 & 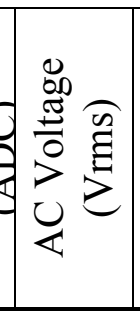 & 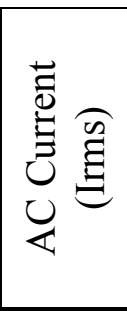 & 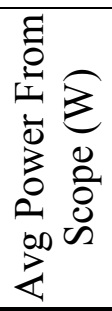 & 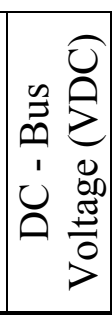 & 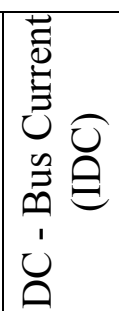 & 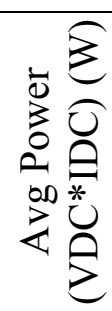 & 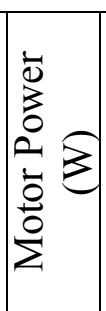 & 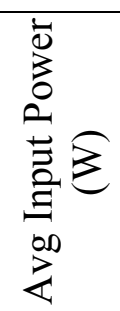 & 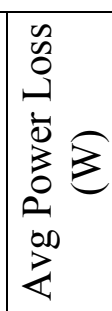 & 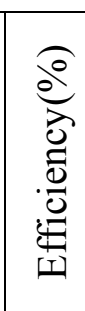 \\
\hline 900 & 52.4 & 1.563 & 215.72 & 0.605 & 44 & $\begin{array}{c}304.8 \\
9\end{array}$ & 0.167 & 53.7 & 99 & 81.90 & 28.20 & $\begin{array}{c}65.5 \\
7\end{array}$ \\
\hline 1000 & 52.4 & 1.562 & 215.4 & 0.8 & 62 & $\begin{array}{c}304.7 \\
6\end{array}$ & 0.158 & 51.3 & 109 & 81.85 & 30.55 & $\begin{array}{c}62.6 \\
8\end{array}$ \\
\hline 1100 & 52.4 & 1.574 & 215.08 & 1.012 & 83 & $\begin{array}{c}304.0 \\
1\end{array}$ & 0.165 & 51.9 & 123 & 82.48 & 30.58 & $\begin{array}{c}62.9 \\
3\end{array}$ \\
\hline 1200 & 52.4 & 1.575 & 215.53 & 1.261 & 107 & $\begin{array}{c}303.5 \\
3 \\
\end{array}$ & 0.17 & 52.2 & 139 & 82.53 & 30.33 & $\begin{array}{c}63.2 \\
5 \\
\end{array}$ \\
\hline 1300 & 52.4 & 1.572 & 215.04 & 1.532 & 133 & $\begin{array}{c}304.1 \\
9\end{array}$ & 0.174 & 53.6 & 160 & 82.37 & 28.77 & $\begin{array}{c}65.0 \\
7\end{array}$ \\
\hline 1400 & 52.4 & 1.56 & 215.34 & 1.815 & 167 & $\begin{array}{c}303.1 \\
3 \\
\end{array}$ & 0.175 & 52.2 & 185 & 81.74 & 29.54 & $\begin{array}{c}63.8 \\
6 \\
\end{array}$ \\
\hline 1500 & 52.4 & 1.564 & 215.3 & 2.138 & 203 & $\begin{array}{c}303.9 \\
1\end{array}$ & 0.174 & 51.9 & 212 & 81.95 & 30.05 & $\begin{array}{c}63.3 \\
3 \\
\end{array}$ \\
\hline 1600 & 52.4 & 1.565 & 215.01 & 2.489 & 245 & $\begin{array}{c}303.2 \\
3 \\
\end{array}$ & 0.173 & 52.8 & 246 & 82.01 & 29.21 & $\begin{array}{c}64.3 \\
9 \\
\end{array}$ \\
\hline 1700 & 52.4 & 1.576 & 215.15 & 2.904 & 292 & $\begin{array}{c}301.9 \\
3\end{array}$ & 0.178 & 53.1 & 283 & 82.58 & 29.48 & $\begin{array}{c}64.3 \\
0\end{array}$ \\
\hline 1800 & 52.4 & 1.565 & 214.98 & 3.344 & 341 & \begin{tabular}{|c}
301.6 \\
8 \\
\end{tabular} & 0.183 & 52.2 & 331 & 82.01 & 29.81 & $\begin{array}{c}63.6 \\
5 \\
\end{array}$ \\
\hline 1900 & 52.4 & 1.561 & 214.51 & 3.811 & 401 & $\begin{array}{c}300.8 \\
6 \\
\end{array}$ & 0.176 & 51.4 & 375 & 81.80 & 30.40 & $\begin{array}{c}62.8 \\
4 \\
\end{array}$ \\
\hline 2000 & 52.4 & 1.559 & 214.87 & 4.314 & 464 & $\begin{array}{c}302.1 \\
7\end{array}$ & 0.18 & 54 & 439 & 81.69 & 27.69 & $\begin{array}{c}66.1 \\
0\end{array}$ \\
\hline 2100 & 52.4 & 1.57 & 214.93 & 4.913 & 538 & $\begin{array}{c}301.4 \\
7\end{array}$ & 0.177 & 53 & 503 & 82.27 & 29.27 & $\begin{array}{c}64.4 \\
2 \\
\end{array}$ \\
\hline 2200 & 52.4 & 1.571 & 214.69 & 5.509 & 613 & $\begin{array}{c}301.5 \\
5\end{array}$ & 0.174 & 52.2 & 575 & 82.32 & 30.12 & $\begin{array}{c}63.4 \\
1\end{array}$ \\
\hline 2300 & 52.4 & 1.571 & 214.51 & 6.167 & 696 & $\begin{array}{c}300.5 \\
9\end{array}$ & 0.186 & 53.6 & 652 & 82.32 & 28.72 & $\begin{array}{c}65.1 \\
1 \\
\end{array}$ \\
\hline 2400 & 52.4 & 1.569 & 214.2 & 6.851 & 783 & $\begin{array}{c}300.3 \\
1\end{array}$ & 0.188 & 54.5 & 739 & 82.22 & 27.72 & $\begin{array}{c}66.2 \\
9 \\
\end{array}$ \\
\hline 2500 & 52.4 & 1.579 & 214.17 & 7.6 & 881 & $\begin{array}{c}299.4 \\
6 \\
\end{array}$ & 0.182 & 53.1 & 830 & 82.74 & 29.64 & \begin{tabular}{|c|}
64.1 \\
8 \\
\end{tabular} \\
\hline 2600 & 52.4 & 1.574 & 213.89 & 8.45 & 986 & $\begin{array}{c}298.5 \\
6 \\
\end{array}$ & 0.18 & 54.9 & 923 & 82.48 & 27.58 & $\begin{array}{c}66.5 \\
6 \\
\end{array}$ \\
\hline 2700 & 52.4 & 1.568 & 214.17 & 9.196 & 1101 & \begin{tabular}{|c}
297.7 \\
5 \\
\end{tabular} & 0.186 & 53.5 & 1055 & 82.16 & 28.66 & $\begin{array}{c}65.1 \\
1 \\
\end{array}$ \\
\hline
\end{tabular}


Table D - 14 DC-DC module prototype v1.0 - Electrical performance test data for $f_{s}$ $=5 \mathrm{kHz}$, constant $20 \%$ duty ratio, and constant $52.4 \mathrm{~V}$ input voltage vs. motor speed

\begin{tabular}{|c|c|c|c|c|c|c|c|c|c|c|c|c|}
\hline 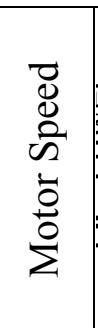 & 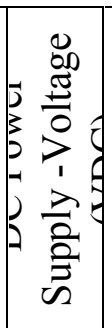 & 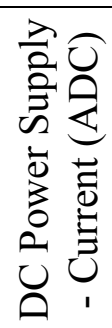 & 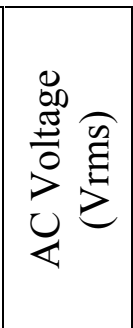 & 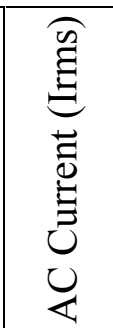 & 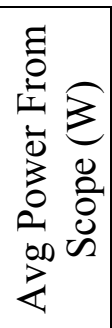 & 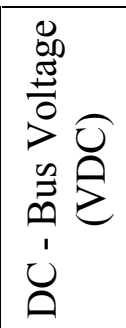 & 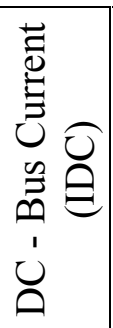 & 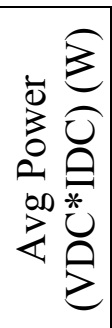 & 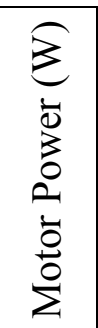 & 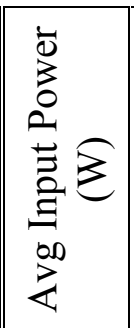 & $\begin{array}{l}n \\
0 \\
0 \\
1 \\
\dot{0} \\
3 \\
0 \\
0 \\
0 \infty \\
\sum \\
\pi\end{array}$ & 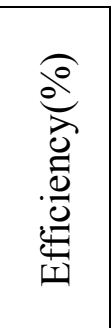 \\
\hline 1100 & 5 & 3.542 & 32 & 1 & 42 & I & 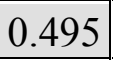 & 156.1 & 123 & & & \\
\hline 1200 & 5 & 3.544 & 71 & 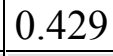 & 29.4 & 504. & 0.504 & 101 & 140 & & & \\
\hline 300 & 52.4 & 3.659 & 10.19 & 0.736 & 55.4 & (303.21 & 0.548 & 101 & 01 & 73 & 30.13 & (5. \\
\hline 400 & 52.4 & 3.662 & 13.25 & 065 & 89.1 & 303 & 0.3 & 159 & 84 & 39 & 32.89 & .80 \\
\hline 1500 & 52.4 & 3.658 & 13.04 & 429 & 127.5 & 302.55 & 0.526 & 160 & 215 & 68 & 31.68 & .47 \\
\hline 1600 & | 52.4 & 3.661 & 12.62 & 828 & 169.7 & 301.31 & 0.531 & 158 & 246 & 191.84 & 33.84 & 2.36 \\
\hline 700 & 52.4 & 3.657 & 13.11 & 256 & 18.1 & 300.33 & 25 & 158 & 285 & 63 & 33.63 & 2.45 \\
\hline 800 & 2.4 & 3.6 & L & 703 & 69.9 & 29 & 8 & 1567 & 332 & 31 & 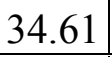 & .91 \\
\hline 900 & 2.4 & 3. & 2 & - & .5 & 2 & & 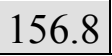 & 50 & 81 & 1 & . \\
\hline 00 & 4 & 3. & & 3.74 & 8 & 20765 & & 155.9 & 438 & & & 10 \\
\hline 100 & 52.4 & 3. & & רי & 400.0 & 2 & & 150.5 & 302 & & & 1.24 \\
\hline 200 & 52.4 & 3.6 & .09 & 5.032 & 5.6 & 29 & & 157.5 & 574 & & 2 & 2.24 \\
\hline 300 & 52.4 & 3.59 & 09 & 712 & 630.3 & 29 & & 7.5 & 655 & & 30. & .56 \\
\hline 2400 & 52.4 & 3.6 & 1175 & 38 & 722.4 & 29 & 1 & 6 & 741 & 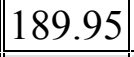 & 33.35 & 44 \\
\hline 00 & 52.4 & 3 & 7 & 7.191 & 826 & 20 & & 158.5 & 8 & נד & 4 & . \\
\hline 00 & 52.4 & 3.59 & . & 0.07 & 924 & 290.00 & J & $15 \%$ & 0 & 100.21 & 30.11 & 0.00 \\
\hline 700 & 52.4 & 3.596 & 11.72 & 8.839 & 1033 & 294.89 & 0.556 & 158.9 & 1049 & 188.43 & 29.53 & 84.33 \\
\hline
\end{tabular}

Table D - 15 DC-DC module prototype v1.0 - Electrical performance test data for $f_{s}$ $=5 \mathrm{kHz}$, constant $30 \%$ duty ratio, and constant $52.4 \mathrm{~V}$ input voltage vs. motor speed

\begin{tabular}{|c|c|c|c|c|c|c|c|c|c|c|c|c|}
\hline 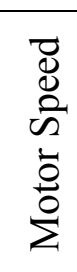 & 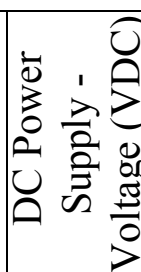 & 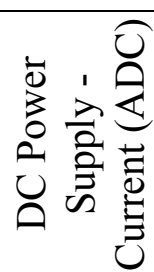 & 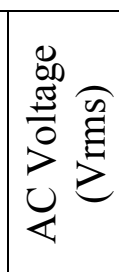 & 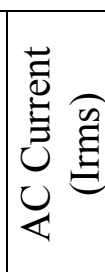 & 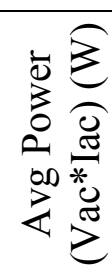 & 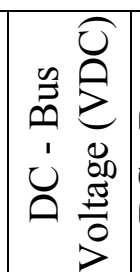 & 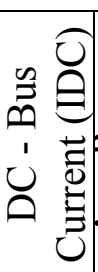 & 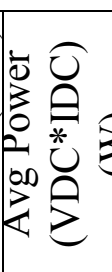 & 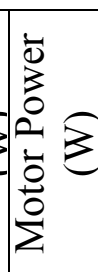 & 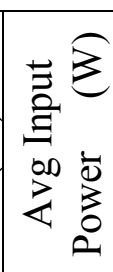 & 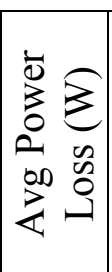 & 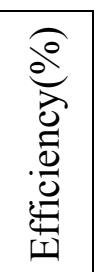 \\
\hline 1500 & 52.4 & 6.885 & 215.55 & 0.111 & 0.983 & 310.66 & 0.956 & 299.2 & 212 & 360.77 & IU & 2.93 \\
\hline 1600 & 52.4 & 6.913 & 215.23 & 0.564 & 42 & 306.51 & 0.981 & 301.1 & 247 & 362.24 & 61.14 & 83.12 \\
\hline
\end{tabular}




\begin{tabular}{|c|c|c|c|c|c|c|c|c|c|}
\hline 700 & 52.4 & 911 & 15.37 & 105 & 89.8 & 304.420 .9 & 300 & 285 & 2.1462 .1482 .8 \\
\hline 800 & 52.4 & 17 & 215.56 & 584 & 144.5 & 303.910 .991 & 300. & 329 & \begin{tabular}{|l|l|}
362.45 & 62 \\
\end{tabular} \\
\hline 900 & 52.4 & 22 & 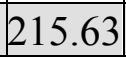 & 12 & 212.7 & 92 & 30 & 380 & 716 \\
\hline 000 & 52.4 & 22 & 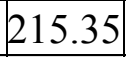 & 22 & 266.5 & - & 299.5 & 437 & \begin{tabular}{ll|l}
71 & 6 \\
\end{tabular} \\
\hline 00 & 52.4 & 4 & 1 & 39 & 338.8 & & 300.1 & 503 & 362 \\
\hline 200 & .4 & & 215.59 & 55 & .4 & & .8 & 567 & Ju \\
\hline 300 & 52.4 & & -15.41 & 06 & 502.1 & \begin{tabular}{|l|l|}
27 & 1.01 \\
\end{tabular} & 301.8 & 650 & No \\
\hline 400 & .4 & 6.923 & 214.96 & 85 & 588.7 & \begin{tabular}{|l|l|}
300 & 1.01 \\
\end{tabular} & 302.5 & 735 & 362.776 \\
\hline 500 & 52.4 & 6.946 & 215.0 & 6.18 & 681.7 & 299.951 .022 & 301.6 & 825 & 63.976 \\
\hline 600 & 4 & 6.929 & 215.01 & 6.966 & 801 & 297.071 .021 & 304.9 & 930 & 63.085 \\
\hline 700 & .4 & 6.941 & 214.81 & 82 & 904 & \begin{tabular}{|l|l|}
297.46 & 1.033 \\
\end{tabular} & 303.9 & 10 & .71 \\
\hline
\end{tabular}

Table D - 16 DC-DC module prototype v1.0 - Electrical performance test data for $f_{s}$ $=5 \mathrm{kHz}$, constant $40 \%$ duty ratio, and constant $52.4 \mathrm{~V}$ input voltage vs. motor speed

\begin{tabular}{|c|c|c|c|c|c|c|c|c|c|c|c|c|}
\hline 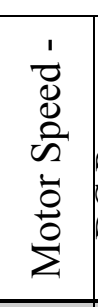 & 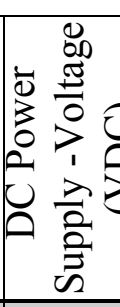 & 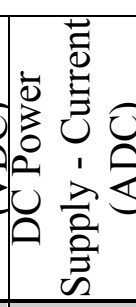 & 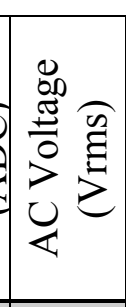 & 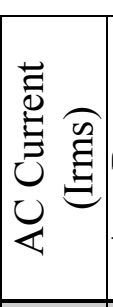 & 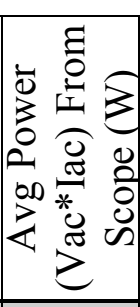 & 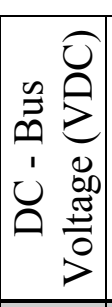 & 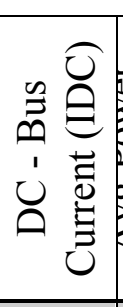 & 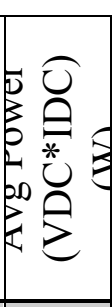 & 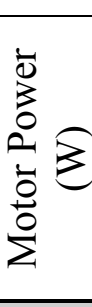 & 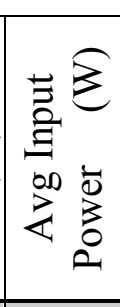 & 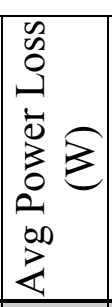 & 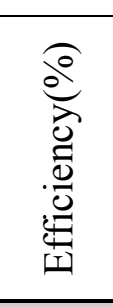 \\
\hline 1500 & 0 & 0.02 & 214.1 & 2.92 & 280.0 & 299.9 & -0.02 & -7 & 2 & 0 & 7 & 00 \\
\hline 1500 & 10 & 0.93 & 214.76 & 2.79 & 270.4 & 299.9 & 0.01 & 1.8 & 230 & 9.30 & 7.5 & 19.35 \\
\hline 1500 & 20 & 1.88 & 214.75 & 2.60 & 246.4 & 299.9 & 0.10 & 23.3 & 230 & 37.62 & 14.32 & 61.94 \\
\hline 1500 & 30 & 2.93 & 214.7 & 2.11 & 195.1 & 300.4 & 0.16 & 49.0 & 230 & 87.84 & 38.84 & 55.78 \\
\hline 1500 & 40 & 3.98 & 215.4 & 1.50 & 131.0 & 301.7 & 0.36 & 109.0 & 230 & 159.20 & 50.20 & 68.47 \\
\hline 1500 & 50 & 5.08 & 214.8 & 0.68 & 48.0 & 303.7 & 0.62 & 188.0 & 230 & 253.7 & 65.75 & 74.09 \\
\hline
\end{tabular}

Table D - 17 Electrical performance test data for DC-DC module prototype v2.0 with PI Controller, $f_{s}=4.649 \mathrm{kHz}$, and $1500 \mathrm{RPM}$ constant motor speed

\begin{tabular}{|c|c|c|c|c|c|c|}
\hline $\begin{array}{c}\text { Inductor Temperature } \\
(\mathrm{F})\end{array}$ & 75 & 75 & 76 & 78 & 82 & 86 \\
\hline Trace Temperature (F) & 76 & 77 & 78 & 80 & 83 & 88 \\
\hline IGBT Temperature (F) & 76 & 83 & 90 & 98 & 108 & 122 \\
\hline
\end{tabular}

Table D - 18 Thermal performance test data for DC-DC module prototype v2.0 with PI Controller, $f_{s}=4.649 \mathrm{kHz}$, and $1500 \mathrm{RPM}$ constant motor speed 


\begin{tabular}{|c|c|c|c|c|c|c|c|c|c|c|c|c|}
\hline 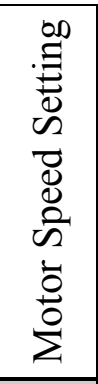 & 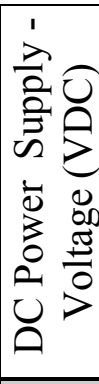 & 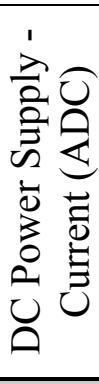 & 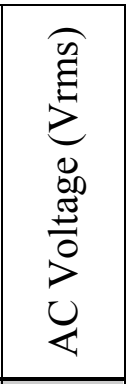 & 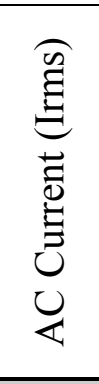 & 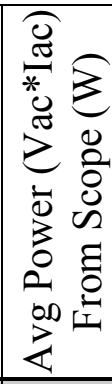 & 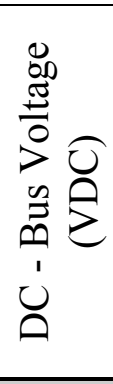 & 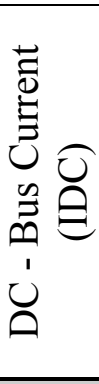 & 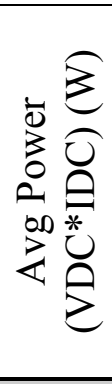 & 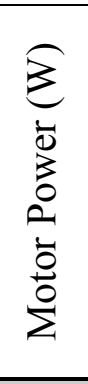 & 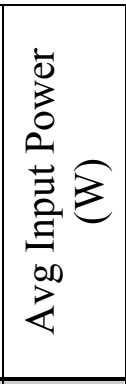 & $\begin{array}{l}3 \\
0 \\
0 \\
0 \\
1 \\
0 \\
0 \\
0 \\
0 \\
0 \\
0 \\
2 \\
1\end{array}$ & 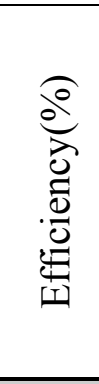 \\
\hline 1750 & 0 & 0 & 5.8 & .81 & 401.4 & 301 & & 0. & 30 & 0.00 & 0.00 & 0.0 \\
\hline 1750 & 10 & 0.89 & 215.5 & 3.80 & 390.5 & 301.1 & 0.01 & 2.0 & 230 & 8.87 & 6.87 & 22.5 \\
\hline 1750 & 20 & 1.86 & 214.8 & 3.62 & 366.0 & 300.2 & 0.04 & 10.7 & 230 & 37.22 & 26.52 & 28.75 \\
\hline 1750 & 30 & 2.87 & 215.00 & 3.24 & 319.6 & 299.9 & 0.19 & 57.2 & 230 & 86.00 & 28.80 & 66.51 \\
\hline 1750 & 40 & 4.01 & 215.32 & 2.68 & 256.3 & 300.6 & 0.35 & 104.0 & 230 & 160.52 & 56.52 & 64.79 \\
\hline 1750 & 50 & 4.92 & 215.63 & 1.95 & 180.0 & 301.7 & 0.63 & 191.0 & 230 & 246.00 & 55.00 & 77.64 \\
\hline
\end{tabular}

Table D - 19 Electrical performance test data for DC-DC module prototype v4.0 with PI controller, $f_{s}=4.649 \mathrm{kHz}$, and $1750 \mathrm{RPM}$ constant motor speed

\begin{tabular}{|c|c|c|c|c|c|c|c|}
\hline $\begin{array}{c}\text { Inductor Temperature } \\
(\mathrm{F})\end{array}$ & 76 & 79 & 79 & 80 & 84 & 90 & 96 \\
\hline Trace Temperature (F) & 76 & 78 & 79 & 80 & 83 & 87 & 92 \\
\hline IGBT Temperature (F) & 81 & 84 & 91 & 97 & 107 & 117 & 136 \\
\hline
\end{tabular}

Table D - 20 Thermal performance test data for DC-DC module prototype $\mathbf{4 . 0}$ with PI Controller, $f_{s}=4.649 \mathrm{kHz}$, and $1750 \mathrm{RPM}$ constant motor speed

\begin{tabular}{|c|c|c|c|c|c|c|c|c|c|c|c|c|c|}
\hline 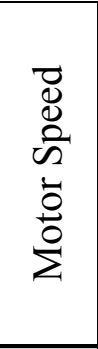 & 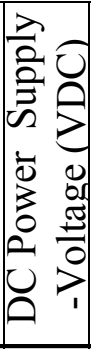 & 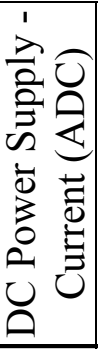 & 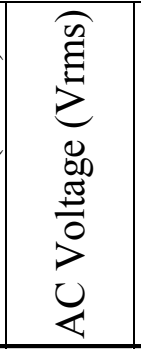 & 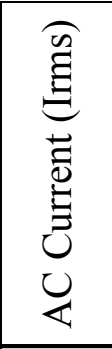 & 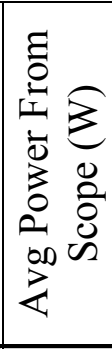 & 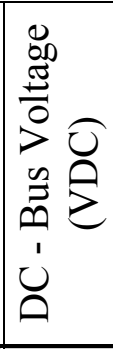 & 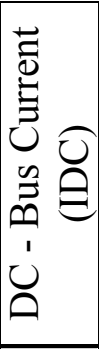 & 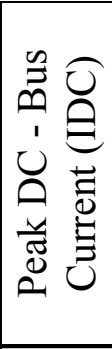 & 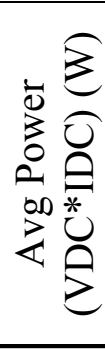 & $\begin{array}{l}\mathcal{Z} \\
\dot{0} \\
0 \\
0 \\
\dot{0} \\
\dot{0} \\
\dot{0}\end{array}$ & 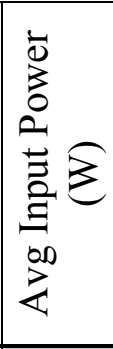 & 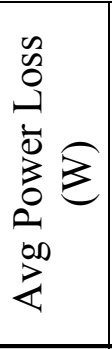 & 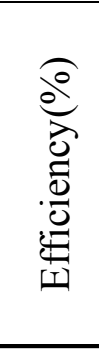 \\
\hline 1750 & 0 & 0.00 & 214.47 & 3.765 & 400 & 297.9 & -0.01 & 11 & -3.17 & 310 & 0.00 & 3.17 & 0.0 \\
\hline 1750 & 10 & 1.66 & 214.27 & 3.657 & 386.4 & 296.1 & 0.45 & 5.08 & 14.0 & 310 & 16.60 & 2.60 & 84.3 \\
\hline 1750 & 20 & 3.64 & 215.24 & 3.3 & 337.8 & 297.6 & 0.24 & 13.10 & 67.0 & 310 & 72.80 & 5.80 & 92.03 \\
\hline 1750 & 30 & 5.92 & 215.45 & 2.556 & 245.9 & 299.1 & 0.56 & 24.73 & 160.0 & 310 & 177.6 & 17.60 & 90.09 \\
\hline 1750 & 40 & 8.63 & 215.94 & 1.143 & 97.9 & 300.6 & 1.05 & 36.83 & 312.0 & 310 & 345.2 & 33.20 & 90.38 \\
\hline 1750 & 50 & 9.11 & 215.8 & 0.078 & 0.135 & 309.1 & 1.33 & 43.22 & 407.0 & 310 & 455.5 & 48.50 & 89.35 \\
\hline 1750 & 60 & 7.45 & 215.93 & 0.078 & 0.146 & 309.0 & 1.33 & 42.57 & 407.0 & 310 & 447.0 & 40.00 & 91.05 \\
\hline
\end{tabular}




\begin{tabular}{|c|c|c|c|c|c|c|c|c|c|c|c|c|c|}
\hline 1750 & 70 & 6.32 & 215.99 & 0.078 & 0.159 & 308.8 & 1.32 & 41.92 & 408.0 & 310 & 442.4 & 34.40 & 92.22 \\
\hline 1750 & 80 & 5.49 & 215.83 & 0.078 & 0.145 & 308.8 & 1.30 & 41.25 & 400.0 & 310 & 439.2 & 39.20 & 91.07 \\
\hline 1750 & 85 & 5.14 & 215.46 & 0.078 & 0.126 & 308.9 & 1.31 & 40.53 & 402.0 & 310 & 436.9 & 34.90 & 92.01 \\
\hline 1750 & 90 & 4.83 & 215.41 & 0.078 & 0.153 & 308.5 & 1.32 & 40.24 & 401.0 & 310 & 434.7 & 33.70 & 92.25 \\
\hline 1750 & 95 & 4.55 & 215.52 & 0.078 & 0.15 & 310.5 & 1.30 & 39.69 & 401.0 & 310 & 432.3 & 31.25 & 92.77 \\
\hline 1750 & 100 & 4.31 & 213.37 & 0.085 & 0.16 & 309.3 & 1.30 & 39.17 & 403.0 & 310 & 431.0 & 28.00 & 93.50 \\
\hline
\end{tabular}

Table D - 21 Electrical performance test data for DC-DC module prototype v4.1 with PI Controller, $f_{s}=4.649 \mathrm{kHz}$, and $1750 \mathrm{RPM}$ constant motor speed

\begin{tabular}{|c|c|c|c|c|c|c|c|c|c|c|c|c|c|}
\hline $\begin{array}{c}\text { Inductor } \\
\text { Temperature (F) }\end{array}$ & 74 & 77 & 78 & 79 & 85 & 94 & 95 & 97 & 97 & 98 & 97 & 96 & 96 \\
\hline $\begin{array}{c}\text { Trace ( } \\
\text { Temperature (F) }\end{array}$ & 75 & 81 & 85 & 88 & 104 & 110 & 108 & 108 & 108 & 106 & 106 & 106 & 104 \\
\hline $\begin{array}{c}\text { IGBT } \\
\text { Temperature (F) }\end{array}$ & 75 & 85 & 91 & 95 & 114 & 126 & 130 & 133 & 128 & 126 & 125 & 123 & 124 \\
\hline
\end{tabular}

Table D - 22 Thermal performance test data for DC-DC module prototype v4.1 with PI controller, $f_{s}=4.649 \mathrm{kHz}$, and $1750 \mathrm{RPM}$ constant motor speed

\begin{tabular}{|c|c|c|c|c|c|c|c|c|c|c|c|c|c|}
\hline 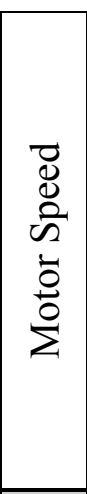 & 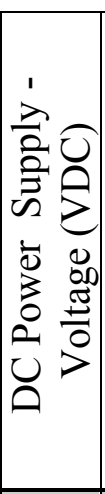 & 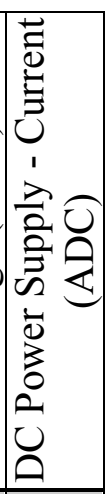 & 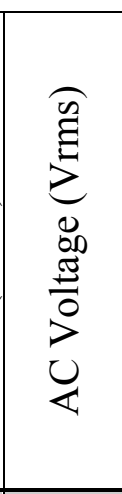 & 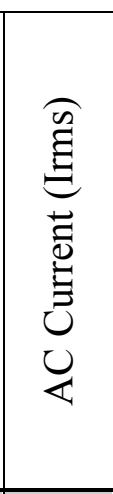 & 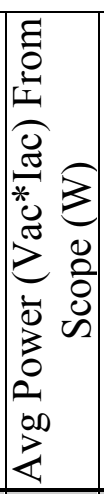 & 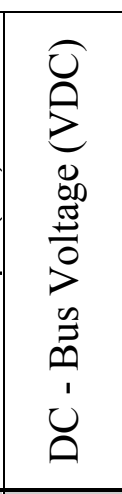 & 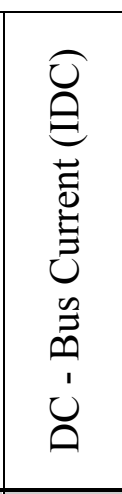 & 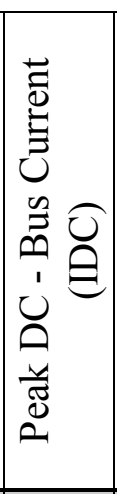 & 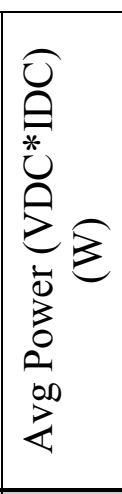 & 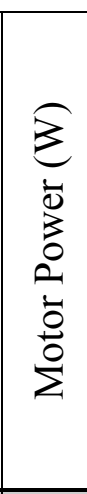 & 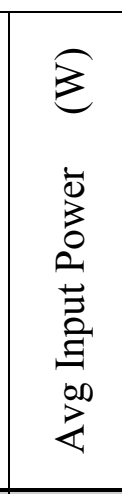 & $\begin{array}{l}3 \\
0 \\
0 \\
0 \\
0 \\
\overline{0} \\
0 \\
0 \\
0 \\
00 \\
3\end{array}$ & 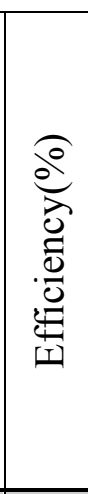 \\
\hline 250 & 0 & 0.0 & 214.52 & 6.609 & 75 & 293.82 & 0.0132 & $\mathrm{n} / \mathrm{a}$ & -3.75 & 595 & 0 & 3.75 & 0.00 \\
\hline 250 & 10 & 1.3 & 214.32 & 6.587 & 754 & 293.95 & 0.0229 & 4.61 & 9.10 & 595 & 12.7 & 3.600 & 71. \\
\hline 2250 & 20 & 2.8 & 214.41 & 6.359 & 716 & 294.75 & 0.107 & 11.34 & 25.50 & 595 & 55.2 & 29.7 & 46.2 \\
\hline 2250 & 30 & 4.5 & 214.06 & 5.773 & \begin{tabular}{|l|}
627 \\
\end{tabular} & 295.7 & 0.396 & $\mid 19.99$ & 124.00 & 595 & 133.95 & 9.950 & 92.6 \\
\hline 2250 & 40 & 6.4 & 214.42 & 4.891 & 518 & 296.8 & 0.773 & 33.03 & 242.40 & 595 & 257 & 14.6 & 94.3 \\
\hline 2250 & 50 & 8.70 & 217.19 & 3.497 & 357 & 298.6 & 1.262 & 46.91 & 398.00 & 595 & 434.7 & 6.750 & 91.6 \\
\hline
\end{tabular}

Table D - 23 Electrical performance test Data for DC-DC module prototype 44.2 with PI Controller, $f_{s}=5.029 \mathrm{kHz}$, and $2250 \mathrm{RPM}$ constant motor speed

\begin{tabular}{|l|l|l|l|l|l|l|}
\hline Trace Temperature (F) & 76 & 85 & 90 & 98 & 106 & 140 \\
\hline
\end{tabular}




\begin{tabular}{|c|c|c|c|c|c|c|}
\hline IGBT Temperature (F) & 76 & 84 & 90 & 101 & 111 & 147 \\
\hline Case Temperature (F) & 76 & 84 & 89 & 97 & 106 & 128 \\
\hline
\end{tabular}

Table D - 24 Thermal performance test data for DC-DC module prototype v4.2 with PI Controller, $f s=5.029 \mathrm{kHz}$, and 2250 RPM constant motor speed 